GEORGE A. AKERLOF

University of California, Berkeley

ANDREW K. ROSE

University of California, Berkeley

JANET L. YELLEN

University of California, Berkeley

\title{
Job Switching and Job Satisfaction in the U.S. Labor Market
}

SUCCESSFUL MACROECONOMIC THEORIES must explain important empirical regularities. One indisputable regularity is the highly procyclic nature of quits: many more people voluntarily leave their jobs when unemployment is low than when it is high. In this paper, we demonstrate that theories based on the assumption that unemployment is involuntary can easily explain procyclic quits. ${ }^{1}$ We construct and empirically validate a simple model of labor turnover; the model is Keynesian in that the labor

We are indebted to Nara Ardeni, Pier Ardeni, Emilia Ghelfi, James Ratliff, and Jorge Streb for able research assistance and to Irma Adelman, Alessandra Casella, John Cochrane, Bill Dickens, Barry Eichengreen, Jeff Frankel, Michael Katz, Jonathan Leonard, David Levine, Charles O'Reilly, Jamie Robinson, Christopher Ruhm, Paul Ruud, Bernard Saffran, George Shanthikumar, Robert Shiller, Carol Utter, Fran Van Loo, Nancy Wallace, James Wilcox, and members of the Brookings Panel for valuable discussion and comments. We are grateful to the National Science Foundation under grant SES 8807807, the Sloan Foundation, the Institute for Business and Economic Research, and the Institute for Industrial Relations at Berkeley for financial assistance.

1. The importance of the cyclical nature of quits as a symptom of non-market-clearing has also been emphasized by James Tobin, "Inflation and Unemployment," American Economic Review, vol. 62 (March 1972), pp. 1-18; and Arthur M. Okun, "RationalExpectations-with-Misperceptions as a Theory of the Business Cycle," Journal of Money, Credit and Banking, vol. 12 (November 1980, part 2), pp. 817-25. 
market is nonclearing: jobs are rationed. Market-clearing theories such as search theory and real business cycle theory cannot account for the procyclic behavior of quits.

Despite its simplicity, our model has a rich set of implications consistent with the U.S. labor market: a large proportion of quits are due to job switches that involve no spell of unemployment; quits are procyclic despite the fact that wages are acyclic; quits are concentrated in low-wage jobs; quit rates decline as tenure increases; there is an inverse relationship between vacancies and unemployment; many quits involve low or negative wage changes. The consistency of our model with observed features of the U.S. labor market demonstrates the soundness of models with nonclearing labor markets.

Models with job rationing exhibit a significant market failure: a characteristic of equilibrium in models with rigid wages is that some individuals covet jobs held by others who are no better qualified. When wages are sticky, people cannot obtain jobs they desire by offering to work for lower pay. As a result, the autonomous departure of an individual from a job creates a sequence of opportunities that we call a vacancy chain. ${ }^{2}$ The vacancy chain concept provides the key to understanding why quits are procyclic.

Suppose, for example, that an employee (A) autonomously withdraws from the labor force, creating a job vacancy. This vacancy provides an opportunity for workers who covet A's job. Suppose that B takes A's old position. If B is employed, B's quit creates a further vacancy. Now suppose that $\mathrm{C}$ takes $\mathrm{B}$ 's old position; if $\mathrm{C}$ is employed, the vacancy chain continues. However, if $\mathrm{C}$ is unemployed or out of the labor force, the chain of vacancies, which began with A's departure from his or her job, ends. The length of a vacancy chain can be defined as the number of job switches that occur, on average, per autonomous vacancy. The vacancy chain consists of a succession of "employment-toemployment" job switches ("E-to-E" quits) that involve no intervening spell of unemployment.

2. Bruno Contini and Riccardo Revelli have independently employed the concept of vacancy chains in modeling the relation between net and gross flows in the labor market. See "Job Creation and Labour Mobility: The Vacancy Chain Model and Some Empirical Findings" (Universita di Torino, March 1988). The implications of vacancy chains for mobility in organizations are explored in Harrison White, Chains of Opportunity (Harvard University Press, 1970). 
Vacancy chains are triggered by the creation of autonomous vacancies. The latter occur because of new job creation, withdrawal of workers from the labor force, and voluntary quits into unemployment. Vacancy chains end only when a vacancy is filled by an individual who is either unemployed or out of the labor force.

In our model, quits are procyclic because vacancy chains are longer when unemployment is low. The expected length of a vacancy chain in a simple model of turnover varies inversely with the unemployment rate. Vacancy chains are short when unemployment is high because the number of jobseekers who are unemployed or out of the labor force is large relative to the number of employed jobseekers. In this case, the probability of recruiting an unemployed individual to any given vacancy, thus ending the chain, is high. In a high-pressure, low-unemployment economy, there are fewer unemployed or out-of-the-labor-force jobseekers relative to employed jobseekers; thus vacancy chains are longer. The logic of the vacancy chain explains why total quits (and especially E-to-E quits) are procyclic. Quits increase as opportunities expand; the opportunities for job switching are significantly greater when unemployment is low than when it is high. ${ }^{3}$

Models with clearing labor markets, in contrast, generate predictions concerning quits that are inconsistent with observed empirical regularities. Search theory, for example, predicts-wrongly-a positive correlation between quits and unemployment. According to this theory, workers who (incorrectly) perceive their current wages to be low quit to search for new jobs, causing unemployment to rise. Real business cycle models predict-also wrongly - a negative correlation between aggregate employment and the quit rate, at least in the short run. Negative productivity shocks lower the reward to work. Quits should rise as individuals withdraw from the labor force. Since such shocks are unlikely to be neutral, quits should also rise as workers voluntarily reallocate themselves across sectors.

In addition to generating positive predictions consistent with observed patterns of labor turnover, models with involuntary unemployment have interesting normative implications. We show that a reduction in unemployment raises welfare by more than the output gain captured

3. For an alternative non-market-clearing model, see Robert E. Hall and Edward P. Lazear, "The Excess Sensitivity of Layoffs and Quits to Demand," Journal of Labor Economics, vol. 2 (April 1984), pp. 233-57. 
in Okun's Law, since improved matching between workers and jobs creates an additional welfare benefit.

The logic of the vacancy chain relies on the idea that some employed workers are ready to switch jobs when openings become available. Workers are ready to switch jobs, in our model, for either higher wages or higher nonpecuniary rewards. We assume that the nonpecuniary reward realized by a worker on any particular job is match-dependent and varies over time. Workers who grow to dislike the nonpecuniary aspects of their jobs become anxious to switch. When unemployment is high, workers who dislike their jobs are likely to be stuck. When it is low, and therefore vacancy chains are long, unhappy workers find opportunities to move to jobs with preferred nonpecuniary characteristics more quickly. At low unemployment rates, high turnover enables workers unhappy with the nonpecuniary aspects of their jobs to trade places more easily, resulting in higher average job satisfaction, even if quitters do not, on average, experience wage gains. The low-unemployment economy is an economy of opportunity, in which workers who are dissatisfied with their jobs have a high degree of mobility. Heretofore, economists have tended to emphasize the costs of turnover. We emphasize the gains. The costs of mobility are already taken into account by Okun's Law, since they are reflected in the level of output. But the increase in nonpecuniary rewards resulting from increased "liquidity" of the economy at lower rates of unemployment is outside the bounds of Okun's Law, which focuses on changes in real GNP. Logically, such nonpecuniary rewards should be included in a comprehensive measure of total economic welfare, such as the "measure of economic welfare" computed by William Nordhaus and James Tobin. ${ }^{4}$

Our assumptions concerning nonpecuniary rewards are not only normatively interesting, but empirically reasonable. Indeed, any realistic portrait of labor turnover must include a role for nonpecuniary rewards (although such rewards are inessential to a theoretical explanation of the procyclic nature of E-E quits). Our empirical work shows that nonpecuniary rewards are significant relative to wages and that these

4. See William Nordhaus and James Tobin, "Is Growth Obsolete?" in National Bureau of Economic Research, Fiftieth Anniversary Colloquium (Columbia University Press, 1972). 
rewards fluctuate over time for a given worker in a given job. In fact, nonpecuniary considerations motivate most "job-related" quits. That such rewards exist and vary over time explains why many job changers realize insignificant or negative wage changes, and yet achieve significant gains in overall job satisfaction. In addition, fluctuations in these rewards help explain why total quits are so large, averaging 24 percent of the manufacturing work force annually in the United States since World War II. ${ }^{5}$ Nonpecuniary rewards are thus essential to an understanding of turnover in the American labor market.

In what follows, we first present a simple model of turnover in a rationed labor market. Simulations demonstrate the close correspondence between the predictions of this model and the features of labor turnover in the U.S. economy. In addition, the simulations indicate that the welfare gains associated with lower unemployment may be 10-20 percent in excess of the output gains summarized in Okun's Law. We also compare our vacancy chain model with alternative real business cycle theories.

Next, we assess the empirical validity of key assumptions and implications of the model. First, we present evidence about turnover patterns in the U.S. economy. We demonstrate that employment-toemployment quits account for at least 30 percent of all quits, while quits from employment to unemployment are less than 18 percent of all quits. We also present rough estimates of the cyclic behavior of E-E and E-U (employment-to-unemployment) quits. We then examine the time series properties of aggregate quits, layoffs, and unemployment. A permanent decline in the unemployment rate is associated with a permanent rise in the quit rate (the elasticity is roughly one); the short-run response is even more pronounced. In contrast, we find a strong transitory correlation between layoffs and unemployment, but no permanent relationship.

After a brief review of empirical evidence in support of the assumption that jobs are rationed, we establish empirically the importance of nonpecuniary rewards in quit decisions. The National Longitudinal Survey (NLS) provides a monetary measure of specific nonpecuniary rewards. These rewards are typically large, averaging over a third of the

5. The annual quit rate in manufacturing averaged 23.8 percent from January 1948 through December 1981, as reported in Employment and Earnings. 
wage rate, although they vary substantially both across individuals and over time. Econometric tests confirm the hypotheses that proportionate changes in pecuniary and nonpecuniary rewards are of equal importance in affecting both the level of worker satisfaction and workers' propensities to quit. However, because nonpecuniary rewards are so variable, most job-related quits are motivated by nonpecuniary rewards. These results imply that the NLS measure is a suitable proxy for the nonpecuniary rewards in our theoretical model. The analysis also establishes that a significant fraction of quitters suffer wage cuts but achieve gains in overall satisfaction, consistent with the theoretical model.

\section{A Matching Model with Job Rationing}

In this section, we construct a model of labor turnover based on the assumption of job rationing. The model illustrates the interactions among different types of labor turnover through the vacancy chain, as well as the cyclic features of labor turnover in a rationed labor market.

\section{ASSUMPTIONS OF THE MODEL}

The key assumptions of the model follow.

Fixed Labor Force and Number of Jobs. There is an exogenously determined number of jobs, $\bar{N}$, and a fixed labor force, $\bar{L}$, although workers may enter and leave the labor force. $\bar{N}$ is less than $\bar{L}$, so the unemployment rate is $u=(\bar{L}-\bar{N}) / \bar{L}$. The unemployment rate is treated as a parameter in this model, since it is assumed to be exogenously determined by aggregate demand.

Workers do not leave the labor force as a direct consequence of unemployment; that is, there is no "discouraged worker" effect in this model. Furthermore, on entering the labor force, workers search for jobs and therefore must have at least a minimal spell of unemployment.

Rents. Jobs pay rents. The rudimentary model we initially construct has just one type of job. It pays a wage $w$, which is in excess of $b$, the reward from the worker's alternative, which is unemployment. We subsequently modify the model to consider the more realistic case in which there exists a variety of jobs, each in fixed supply, paying differing wage premiums. This accords with the finding of others that different 
industries pay varying wage premiums to workers with seemingly identical personal characteristics. ${ }^{6}$

The Unemployment Benefit. Individuals who are unemployed earn benefits, $b$, that include transfer payments plus any value that the unemployed attach to leisure. The benefit replacement ratio, $b / w$, is defined as the ratio of the unemployment benefit (including the value of leisure) to the after-tax wage; we assume that $b / w$ is significantly less than one. For simplicity, we assume that the unemployment benefit received by a worker is independent of his wage on his previous job, which implies that lower-paid jobs have higher benefit replacement ratios. In benchmark simulations we assume that the benefit replacement ratio for the average worker is $0.6 .^{7}$

Nonpecuniary Rewards and Job Satisfaction. The total reward to working, which determines the overall level of satisfaction achieved by a worker in any given job, consists of two components: the wage, or pecuniary reward, and a nonpecuniary reward. Our empirical work later demonstrates the importance of nonpecuniary elements in determining the total reward from work, or stated differently, in explaining the level of a worker's job satisfaction.

Nonpecuniary rewards can be divided into two parts-the reward to work "in general" and any additional reward to working for a specific firm. Time-varying specific rewards are important in explaining job switching and are the focus of our model. General rewards to work are initially ignored in our simulations. The consequences of this simplification are discussed below. The specific nonpecuniary reward, denoted $x$, accruing to a worker can be defined as the increase in wages that an individual would require to be willing to switch from his or her current job to a similar job, with a different firm, in the same local area (thereby abstracting from relocation costs). Specific rewards exist when, for

6. See Alan B. Krueger and Lawrence H. Summers, "Efficiency Wages and the InterIndustry Wage Structure,' Econometrica, vol. 56 (March 1988), pp. 259-93; and William T. Dickens and Lawrence F. Katz, "Industry Wage Patterns and Theories of Wage Determination" (University of California, Berkeley, 1986).

7. Martin Feldstein estimates the average (monetary) benefit replacement ratio for the U.S. population aged 25 to 55 , excluding government employees, agricultural workers, and the self-employed, to be 0.55 . The benefit replacement ratio is the proportion of lost net-of-tax earnings that would be replaced by unemployment insurance benefits. See Martin Feldstein, "The Effect of Unemployment Insurance on Temporary Layoff Unemployment," American Economic Review, vol. 68 (December 1978), pp. 834-46. 
example, workers especially like (or dislike) their coworkers, supervisors, or company policy.

We assume in the model that a worker's total reward is the sum of the wage received, $w$, and a specific nonpecuniary reward, $x$. For simplicity, $x$ is assumed to have an initial value of zero for all new job incumbents. ${ }^{8}$ Over time, the worker's nonpecuniary reward, $x$, is assumed to follow a random walk. Some workers become happier as a consequence of this diffusion process, while other workers become less happy. In benchmark simulations we assume that the annual standard deviation of the change in $x$ relative to the mean wage is 0.1 . Empirical evidence presented later indicates that this is a conservative choice.

General nonpecuniary rewards from work exist if (abstracting from any specific reward) the typical jobholder derives utility from working in excess of the utility from wage income. This occurs if, for example, people find working intrinsically "interesting," "challenging," or "socially worthwhile." General nonpecuniary rewards from work are independent of the particular characteristics of the current job. The existence of such general rewards has little impact on the characteristics of turnover in simulations of the model; ${ }^{9}$ by ignoring general rewards,

8. The assumption that $x$ is initially equal to zero for all individuals is restrictive. It implies that individuals regard the nonpecuniary rewards on all alternative jobs as initially identical, both ex ante and ex post.

The model could be generalized, at the expense of additional computational complexity, by assuming that the nonpecuniary reward earned by a worker on a job has a "permanent" component-the initial value of $x$ achieved by a given worker in a new job-and also a stochastic component, which follows an assumed random process. Our simulations take the permanent component of $x$ to be equal to zero for all individuals, and assume that the stochastic component follows a random walk.

One could, alternatively, assume that the permanent component of $x$ is observable ex ante by workers and, for any given job, differs across individuals. In this case, individuals would be observed quitting jobs with positive specific rewards when they receive offers of jobs with higher expected nonpecuniary rewards at comparable or lower wages. This phenomenon is clearly of empirical relevance, as discussed later.

One could also assume that the permanent component of $x$ differs across individuals for a given job, is not observable ex ante, but is observable ex post through experience. Such an addition would result in a more steeply declining tenure-quit relation than in the simulations reported. Additional turnover at low tenure would be generated as individuals rapidly discover that they dislike new jobs and apply for other jobs for which they are better matched. This aspect of matching is undoubtedly of relevance in explaining the high incidence of quitting among young people.

9. With a positive general reward to work, $g$, the benefit replacement ratio should be defined as $b /(w+g)$. Inclusion of general rewards in the model is accomplished, other 
we do, however, underestimate the cyclic sensitivity of nonpecuniary income and the relevant adjustment to Okun's Law. Later we present evidence that general rewards are an important component of the total reward to work.

Job-Related E-to-U Quits. One source of the autonomous vacancies that trigger vacancy chains is the flow of job-related quits into unemployment by unhappy employed individuals. Workers quit to become unemployed for job-related reasons if anticipated lifetime rewards, should they stay in their current jobs, fall to equality with anticipated lifetime rewards should they quit to become unemployed. The number of such job-related quits per period is denoted $Q_{E U}^{j}$. Anticipated lifetime income is the expected present value of the worker's stream of rewards: workers receive $w+x$ in periods of employment and $b$ in periods of unemployment. Workers are fully rational in our model and have complete information about the structure of the economy.

In a model in which $x$ is a continuous variable, the marginal total reward at which a rational worker quits into unemployment is less than the unemployment benefit. Since $x$ may rise, $w+x-b$ may become positive before the worker is offered a better job; therefore a job has a positive "option value" (relative to unemployment). Below some threshold, $w+x-b$ is sufficiently negative that the current losses that must be suffered from remaining employed rather than becoming unemployed outweigh the option value of the job. When $w+x-b$ reaches this threshold, the worker quits into unemployment. This assumes that the worker's chances of receiving a desirable job are unaffected by his employment status, so that there is no gain in search effectiveness from becoming unemployed.

As noted, the optimality of choosing a threshold for quitting from $\mathrm{E}$ to $\mathrm{U}$ with a negative value of $w+x-b$ relies on the assumption that employed and unemployed workers are equally effective in searching for job offers. We relax this assumption in several simulations.

Job Creation and Exogenous Quits. According to the logic of the vacancy chain, employed individuals receive opportunities to move that are proportional to the number of autonomous vacancies in the labor market. We shall assume that the number of autonomous vacancies that

things being equal, by lowering the value of the benefit replacement ratio chosen for simulations. 
appear each period is large, even in a steady state with a constant number of jobs. Job-related quits into unemployment constitute one source of autonomous vacancies. However, the bulk of autonomous vacancies stems from the creation of new jobs and employee quits for non-jobrelated reasons into unemployment or out of the labor force; the flow of such vacancies is assumed to be a fraction $\beta$ of total employment.

One of the most important sources of autonomous vacancy creation is the ongoing process of economic change, which results in the destruction of some jobs (causing the permanent involuntary layoff of their incumbents), coupled with the simultaneous creation of new jobs. When Jonathan Leonard studied annual files compiled from the March Unemployment Compensation Contribution reports in the state of Wisconsin during 1977-82, he found that, on average, 11 percent of all jobs in Wisconsin were destroyed each year, while a comparable number of jobs were created. ${ }^{10}$

Another important source of autonomous vacancy creation is the departure of individuals from the labor force (E-to-O quits), because, for example, of poor health or retirement. In a steady state, with a constant labor force, such exits from the labor force are matched by new entry and reentry. Finally, vacancies are created when workers quit from employment to unemployment for non-job-related, or "exogenous," reasons. For example, an individual whose mate has geographically relocated may be forced to quit his job in spite of the expectation that the move will result in a loss in total labor reward.

E-to-E Quits. In our rudimentary model with only one type of job, which pays a wage $w$, any dissatisfied worker earning a negative nonpecuniary reward (but insufficiently unhappy to quit into unemployment) can apply for other jobs. Jobs offer an initial nonpecuniary return of zero, and wage $w$. If an unhappy worker receives a job offer, the worker will quit ( $\mathrm{E}$ to $\mathrm{E}$ ), thus continuing a vacancy chain initiated by an autonomous vacancy. ${ }^{11}$ The number of such quits per period is denoted $Q_{E E}$.

10. See Jonathan S. Leonard, "In the Wrong Place at the Wrong Time: The Extent of Frictional and Structural Unemployment,"' in Kevin Lang and Jonathan S. Leonard, eds., Unemployment and the Structure of Labor Markets (Basil Blackwell, 1987), pp. 141-63.

11. Under the assumptions of our model of costless search and the random walk character of $x$, it is optimal for a worker who is employed and receives a job offer with higher total return to accept it. This holds as well in the multiple-job model. Similarly, it is also optimal for the unemployed to accept the first job offer received. 
When the model is expanded to include multiple job types paying different wages, the same general principle applies: workers will constantly be on the lookout for job offers paying higher total rewards (pecuniary plus nonpecuniary) than their current jobs; E-to-E quits occur whenever a worker receives a better job offer. In the expanded model, with multiple jobs, a job offer can be better either because it offers a higher wage or because it affords a higher nonpecuniary reward. Thus some E-to-E quits will be motivated by wage gains, and a fraction of these will involve nonpecuniary losses, while other E-to-E quits will be motivated primarily by the desire of the quitter to raise his or her nonpecuniary reward. Such quits may, but will not always, entail wage cuts.

Flows from $U$ to $E$. Any unemployed jobseeker will accept any job offer received, as is consistent with our assumption that jobs pay rents relative to unemployment and are ex ante identical.

\section{SUMMARY OF ASSUMPTIONS}

To summarize, the rudimentary model with one job is characterized by eleven assumptions.

- Labor force. There is a fixed labor force $\bar{L}$. Workers do not leave the labor force as a consequence of unemployment. On entering the labor force workers initially experience some spell of unemployment. All workers are identical.

- Jobs. There is a fixed number of jobs $\bar{N}$, with $\bar{N}<\bar{L}$.

-Wages. Jobs pay a wage $w$. The unemployment benefit is $b$ and the replacement ratio, $b / w$, is less than one.

-Nonpecuniary returns on new jobs. Nonpecuniary returns are denoted $x$. When jobs are new, $x=0$ for all individuals.

-Movements of nonpecuniary returns. The nonpecuniary return $x$ subsequently follows a random walk; the standard deviation of the change of $x$ is a constant per unit of time.

-Creation of autonomous vacancies due to job-related quits from $E$ to $U$. A worker whose expected discounted lifetime income if he remains employed is less than his expected discounted lifetime income if he becomes unemployed, will quit to become unemployed. This behavior is the source of job-related E-to-U (employment-to-unemployment) quits.

-Creation of autonomous vacancies due to job creation and destruc- 
tion, E-to-O quits, and exogenous $E$-to- $U$ quits. A fraction $\beta$ of jobs are randomly terminated in each period, because of job destruction, departure of the incumbents from the labor force, and exogenously motivated quits into unemployment. A comparable number of vacancies is created.

-Nature of E-to-E quits. Search is costless; therefore workers with $x<0$ apply for jobs. If a job offer is received, the worker quits and takes the new job. Such quits are the source of E-to-E (employment-toemployment) quits.

-Nature of U-to-E flows. Unemployed workers apply for jobs. If an unemployed worker receives a job offer, the offer is accepted.

-Equal search efficiency of unemployed and employed jobseekers. Unemployed and employed applicants have equal probabilities of receiving any job offer.

- Constancy of total employment and the size of the labor force over time. The number of jobs destroyed each period equals the number of jobs created. Vacancies are filled immediately. Departures from the labor force equal entries, so that the total number of jobs, $\bar{N}$, and the size of the labor force, $\bar{L}$, remain unchanged over time.

\section{PROPERTIES OF THE MODEL}

The preceding assumptions yield a model of turnover that offers both simplicity and many interactions of interest. To understand the operation of the rudimentary one-job model and the simulation results to be described, it is useful to derive an explicit formula for the steady-state level of quits from $E$ to $E$.

To obtain this expression, it is necessary to make use of two conditions that hold in a steady state with constant labor force, employment, and unemployment: first, the flow of individuals into unemployment equals the flow of individuals out of unemployment; and, second, the flow of individuals into the labor force equals the flow of individuals out of the labor force.

The flow of individuals into unemployment is the sum of the flow from $\mathrm{E}$ to $\mathrm{U}\left(F_{E U}\right)$ plus the flow from "out of the labor force" $(\mathrm{O})$ to $\mathrm{U}\left(F_{O U}\right)$. The flow of individuals out of unemployment is equal to the flow from $\mathrm{U}$ to $\mathrm{E}\left(F_{U E}\right)$ plus any flow from $\mathrm{U}$ to $\mathrm{O}\left(F_{U O}\right)$. Thus, $F_{U E}+F_{U O}=F_{E U}+F_{O U}$ in a steady state.

The flow of individuals into and out of the labor force is also equal in 
a steady state. The flow of persons into the labor force consists of the flow from $\mathrm{O}$ to $\mathrm{U}\left(F_{O U}\right)$ and any flow from $\mathrm{O}$ to $\mathrm{E}\left(F_{O E}\right)$. Because we assume that all new entrants and reentrants to the labor force must initially pass through unemployment, $F_{O E}$ is zero. The flow of persons out of the labor force consists of flows from $\mathrm{E}$ to $\mathrm{O}\left(F_{E O}\right)$ plus any flow from $\mathrm{U}$ to $\mathrm{O}\left(F_{U O}\right)$. Under these assumptions, $F_{O U}=F_{E O}+F_{U O}$. This, in turn, implies that $F_{U E}=F_{E U}+F_{E O}$.

In our model, flows from $\mathrm{E}$ to $\mathrm{U}$ and $\mathrm{E}$ to $\mathrm{O}$ occur as a consequence of job-related quits into unemployment, layoffs, E-to-O quits, and exogenous $\mathrm{E}-$ to- $\mathrm{U}$ quits. The sum of these flows from $\mathrm{E}$ to $\mathrm{U}$ and $\mathrm{E}$ to $\mathrm{O}$ equals $Q_{E U}^{j}+\beta N .{ }^{12}$ Thus,

$$
F_{U E}=Q_{E U}^{j}+\beta N .
$$

From the assumption that unhappy employed jobseekers and unemployed jobseekers have equal probabilities of receiving job offers, it follows that the number of E-to-E moves relative to the number of U-to-E moves will be equal to the relative numbers of employed and unemployed job seekers. Thus,

$$
\frac{Q_{E E}}{F_{U E}}=\frac{\alpha N}{L-N},
$$

where $Q_{E E}$ denotes the total flow of E-to-E quits, $\alpha$ denotes the fraction of employed workers with $x<0$-namely, the proportion of employed jobseekers-and $L-N$ is the number of unemployed individuals. Combining equations 1 and 2 yields

$$
Q_{E E}=\frac{\alpha N}{L-N}\left(Q_{E U}^{j}+\beta N\right) .
$$

Letting $u=(L-N) / L$ denote the unemployment rate and substituting, one obtains

$$
Q_{E E}=\alpha \frac{1-u}{u}\left(Q_{E U}^{j}+\beta N\right) .
$$

The flow of quits from $\mathrm{E}$ to $\mathrm{E}$ is a multiple of the number of autonomous

12. From our assumption that people do not leave the labor force just because they become unemployed, it follows that layoffs do not generate flows from $\mathrm{E}$ to $\mathrm{O}$ and that all flows from $\mathrm{E}$ to $\mathrm{O}$ are quits. 
vacancies. This mobility multiplier is simply the length of the vacancy chain, defined as the ratio of E-to-E moves per autonomous vacancy created $\left(Q_{E E} / F_{U E}\right)$. From equations 2 and 4 we obtain

$$
\text { Length of vacancy chain }=\alpha \frac{1-u}{u} .
$$

For example, with $\alpha=0.2$ and $u=0.1$ the length of the vacancy chain is 1.8 ; if the unemployment rate declines to $u=0.05$, the length of the vacancy chain would increase to 3:8, in the absence of any change in $\alpha$.

Consideration of each of the terms in equation 4 explains why E-to-E quits are so highly procyclic. The denominator plays the key role in the formula. A decrease in $u$ means that proportionately more employed persons are randomly offered jobs before an unemployed person is randomly found to fill an autonomous vacancy. The fraction of workers who will accept an E-to-E offer varies somewhat with $u$, as our simulations will reveal, but not by as much. Indeed, the only reason why the fraction of employed jobseekers falls at all during expansions is precisely that the flow of persons from $\mathrm{E}$ to $\mathrm{E}$ is larger, resulting in a smaller fraction of dissatisfied employees in equilibrium.

A third factor affecting the cyclic behavior of E-to-E quits is the behavior of job-related quits from $E$ to $U$. The two reasons why such quits could change cyclically operate in opposite directions. In bad times, when there are few job openings, unhappy workers are less likely to find other jobs before they become so unhappy that they will quit to become unemployed. This suggests that job-related E-to-U quits may actually rise when the unemployment rate increases. On the other hand, as unemployment rises, unemployment durations rise, and so the cost of becoming unemployed increases. The net result is that quits from $\mathrm{E}$ to $U$ vary ambiguously with the unemployment rate from a theoretical standpoint. As we show when we discuss turnover in the labor market, it appears that in U.S. data, quits from employment into unemployment actually fall as the unemployment rate rises.

\section{SIMULATIONS}

To obtain solutions for the steady-state levels of labor market flows and the equilibrium distribution of rents (including nonpecuniary returns) through simulations, relatively few parameters need be chosen. These 
parameters include the unemployment rate, the replacement ratio, the standard deviation of the shock to the nonpecuniary reward, the interest rate, and the rate at which jobs terminate, $\beta$. (The interest rate is relevant to workers in evaluating the potential gains from quitting into unemployment for job-related reasons, since in making this decision, workers must calculate the present value of the "stay" strategy of keeping their jobs, relative to the present value of the "quit" strategy of becoming unemployed.)

With few difficulties the continuous model described above translates into a model where both time and $x$ are discrete, which is amenable to simulation. The only technical detail worth noting is the method used to approximate a chosen value of the standard deviation of movement in $x$. In the discrete model, we assume that the nonpecuniary reward, $x$, remains unchanged with probability $s$, that it rises one step with probability $(1-s) / 2$, and that it declines by one step with probability $(1-s) / 2$. Given the step size, appropriate selection of $s$ yields the chosen standard deviation of $x$.

The One-Job Model. Table 1 reports the results of simulations of the one-job model. Total E-to-E quits at a 10 percent unemployment rate amount to 3.5 percent of the work force a quarter, which is a sensible order of magnitude relative to U.S. data. Unemployment duration at this high unemployment rate averages 10 months and job tenure is 44 months. Again, these numbers seem reasonable, given the complexities-intrinsic matching, worker heterogeneity, asymmetric information, imperfect labor markets-that are left out of the model.

A decrease in the fraction of the labor force unemployed from 10 percent to 5 percent has two noteworthy effects. First, a sizable (19.3 percent) increase occurs in the number of E-to-E quits. Second, the 5 percentage point decrease in the unemployment rate has a significant effect on job satisfaction, shown by a uniform increase in the cumulative frequency distribution of rents.

The underlying causes of the change in the E-to-E quit rate can be decomposed using equation 4 . From equation 4 , E-to-E quits should be roughly proportional to $\alpha$, the fraction of the population with a negative nonpecuniary return. As $u$ goes from 10 percent to 5 percent, the first term in equation $4, \alpha$, falls 48.7 percent (taking the arc elasticity). The fall in $\alpha$ is itself the consequence of the higher degree of job mobility in the 5 percent unemployment economy. The equilibrium of the economy 
Table 1. Turnover and Nonpecuniary Rewards in a One-Job Model ${ }^{a}$

\begin{tabular}{lcc}
\hline \multicolumn{1}{c}{ Item } & \multicolumn{2}{c}{ Unemployment rate } \\
\cline { 2 - 3 } & $u=0.05$ & $u=0.10$ \\
\hline Quits & & \\
$\mathrm{E}^{\mathrm{n}}$ to $^{\mathrm{b}}$ & 0.041 & 0.035 \\
$\mathrm{E}$ to U $^{\mathrm{b}}$ & 0.000 & 0.000 \\
Nonpecuniary reward $^{\mathrm{c}}$ & 0.143 & 0.128 \\
Fraction of unhappy employees & 0.066 & 0.108 \\
Mean unemployment duration & 1.67 & 3.33 \\
(in quarters) & & \\
Mean job tenure (in quarters) & 13.87 & 14.56 \\
\hline
\end{tabular}

Source: Authors' calculations.

a. Simulations assume the following parameters: benefit replacement ratio $=0.6$; annual standard deviation of movement in $x$ relative to the mean wage $=0.1 ; s=0.75 ; \beta=12$ percent a year; interest rate $=18$ percent a year.

b. Quarterly quits per employee.

c. Average value of the nonpecuniary return $(x)$, relative to the mean wage.

has relatively fewer dissatisfied workers (that is, workers with negative $x$ ) on average; the second term, $(1-u) / u$ (again, taking the arc elasticity), has risen 71.4 percent because of the decline in $u$; and the third term $\left(Q_{E U}^{j}+\beta N\right)$ remains virtually unchanged, because $Q_{E U}^{j}$ is small and layoffs are constant. Note that the actual change in $\mathrm{E}$ to $\mathrm{E}$ of 19.3 percent is approximately the sum of the changes in the three terms (the discrepancy of 3.4 percent is due to the discrete nature of the change).

The information reported in table 1 can be used to assess the welfare effects of a reduction in the aggregate unemployment rate. According to table 1, the decrease in the unemployment rate from 10 percent to 5 percent raises the specific nonpecuniary reward earned by the typical employed person by an amount equivalent to 1.5 percent of the average wage. In addition, a significant fraction of the labor force obtains jobs that pay an average specific nonpecuniary reward of 13.5 percent of the wage rate.

These two figures can be combined to calculate the amount that additional nonpecuniary income would add to the cyclic output gains captured in Okun's Law. George Perry and Arthur Okun have calculated that a 1 percentage point change in the unemployment rate leads to a 2.1 percent change in labor hours. ${ }^{13}$ A 5 percentage point decrease in

13. See George L. Perry, "Labor Force Structure, Potential Output, and Productivity," BPEA, 3:1971, pp. 533-65; and Arthur M. Okun, "Upward Mobility in a Highpressure Economy,'' BPEA, 1:1973, p. 211. 
unemployment thus implies a 10.5 percent increase in labor hours. On average, each extra hour worked yields the typical worker specific nonpecuniary income amounting to $0.135 w$ an hour. The addition to total specific nonpecuniary rewards due to the expansion in hours worked thus amounts to 1.4 percent ( 13.5 percent times 10.5 percent) of the aggregate wage bill. Adding to this figure the gain in average specific nonpecuniary income of employed workers-equal to 1.5 percent of wages-yields a total increase in aggregate nonpecuniary income due to the 5 percentage point drop in the unemployment rate of 2.9 percent of total wages. This amounts to 0.58 percent of the wage bill for each percentage point of unemployment. If the wage bill constitutes two-thirds of output, then a 1 percentage point reduction in unemployment raises welfare by 0.37 percent of GNP because of increases in specific nonpecuniary income. Inclusion of such nonpecuniary gains would thus add 0.37 percent per 1 percentage point reduction in the unemployment rate to Okun's Law.

The preceding calculation ignores any extra general nonpecuniary rewards to work, as well as any disutility from reduced leisure as unemployment falls. Later we present evidence suggesting that general rewards exceed the value of leisure. Simulations of the model generate a mean nonpecuniary reward of 13.5 percent of the wage rate; the addition to Okun's Law is sensitive to this value. As we will show, the 13.5 percent figure is considerably less than our estimate of the actual mean nonpecuniary rewards. For both of these reasons, the above calculation is likely to understate the appropriate adjustment to Okun's Law.

The Multiple-Job Model. The preceding simulation has the virtue of demonstrating the principles whereby decreases in unemployment increase total quits, especially E-to-E quits. However, the model has several unrealistic features and counterfactual implications. First, as we document later, a significant fraction of E-to-E quits, although by no means the majority, involve wage increases. In the rudimentary model, with only one type of job, such wage increases cannot occur. Second, the number of E-to-U quits is quite small. In contrast, we estimate that E-to-U quits are approximately 20 percent of all quits in the United States. Finally, as others have documented, the rewards to otherwise identical individuals across industries and occupations differ substan- 
Table 2. Turnover and Nonpecuniary Rewards in a Multiple-Job Model with Benchmark Parameters ${ }^{\text {a }}$

Labor market flows and nonpecuniary rewards

\begin{tabular}{|c|c|c|}
\hline \multirow[b]{2}{*}{ Item } & \multicolumn{2}{|c|}{ Unemployment rate } \\
\hline & $u=0.05$ & $u=0.10$ \\
\hline \multicolumn{3}{|l|}{ Quits } \\
\hline $\mathrm{E}$ to $\mathrm{E}^{\mathrm{b}}$ & 0.0507 & 0.0423 \\
\hline $\mathrm{E}$ to $\mathrm{U}^{\mathrm{b}}$ & 0.0012 & 0.0005 \\
\hline Nonpecuniary reward ${ }^{\mathfrak{c}}$ & 0.0821 & 0.0756 \\
\hline $\begin{array}{l}\text { Mean unemployment duration } \\
\text { (in quarters) }\end{array}$ & 2.15 & 3.80 \\
\hline Mean job tenure (in quarters) & 12.2 & 13.7 \\
\hline
\end{tabular}

Quits per quarter per employee by job type: $\mathbf{u}=\mathbf{0 . 0 5}$

\begin{tabular}{cccccccc} 
& \multicolumn{7}{c}{ Wage in job i relative to mean wage of all jobs } \\
\cline { 2 - 5 } Quits & 0.7 & 0.8 & 0.9 & 1.0 & 1.1 & 1.2 & 1.3 \\
\hline${\text { E to } \mathrm{E}^{\text {d }}}$ & 0.161 & 0.085 & 0.047 & 0.029 & 0.017 & 0.010 & 0.005 \\
E to $\mathrm{U}^{\text {d }}$ & 0.006 & 0.002 & 0.000 & 0.000 & 0.000 & 0.000 & 0.000
\end{tabular}

E-E quits per quarter per employee from job type $\mathbf{i}$ to job type $\mathbf{j}: \mathbf{d} u=0.05$

\begin{tabular}{cccccccc} 
Relative wage & \multicolumn{7}{c}{ Relative wage of job type $j$} \\
\cline { 2 - 8 } of job type $i$ & 0.7 & 0.8 & 0.9 & 1.0 & 1.1 & 1.2 & 1.3 \\
\hline 0.7 & 0.031 & 0.056 & 0.029 & 0.018 & 0.011 & 0.009 & 0.006 \\
0.8 & 0.007 & 0.015 & 0.022 & 0.016 & 0.011 & 0.008 & 0.006 \\
0.9 & 0.002 & 0.004 & 0.007 & 0.011 & 0.009 & 0.007 & 0.006 \\
1.0 & 0.001 & 0.002 & 0.003 & 0.004 & 0.007 & 0.006 & 0.006 \\
1.1 & 0.000 & 0.001 & 0.001 & 0.002 & 0.004 & 0.004 & 0.005 \\
1.2 & 0.000 & 0.000 & 0.001 & 0.001 & 0.002 & 0.003 & 0.004 \\
1.3 & 0.000 & 0.000 & 0.000 & 0.001 & 0.001 & 0.001 & 0.002 \\
\hline
\end{tabular}

tially and cannot be explained by appeal to compensating differentials. ${ }^{14}$ These problems are jointly remediable by the introduction of multiple job types into the simulations.

Accordingly, we have performed simulations of a model identical to that described above, except that it assumes a uniform distribution of jobs differing in their wages. We assume that the various job types are available in identical numbers, and that the differential in reward between "adjacent" job types is a constant—with the rewards to job $i$ defined as

14. See Krueger and Summers, "Efficiency Wages and the Inter-Industry Wage Structure"; and Dickens and Katz, "Industry Wage Patterns." 
Table 2 (continued)

Quits per quarter per employee by nonpecuniary reward: $u=0.05$

\begin{tabular}{cccccccccc} 
& \multicolumn{10}{c}{ Nonpecuniary reward } \\
\cline { 2 - 9 } Quits & -0.4 & -0.3 & -0.2 & -0.1 & 0.0 & 0.1 & 0.2 & 0.3 & 0.4 \\
\hline${\text { E to } \mathrm{E}^{\mathrm{b}}}^{\mathrm{b}}$ & 0.0006 & 0.0015 & 0.0041 & 0.0141 & 0.0225 & 0.0054 & 0.0015 & 0.0004 & 0.0001 \\
${\text { E to } \mathrm{U}^{\mathrm{b}}}^{0.0001}$ & 0.0002 & 0.0009 & 0.0000 & 0.0000 & 0.0000 & 0.0000 & 0.0000 & 0.0000
\end{tabular}

Mean continued tenure projected by current tenure

\begin{tabular}{cc}
$\begin{array}{c}\text { Current tenure }(t) \\
\text { (years) }\end{array}$ & $\begin{array}{c}\text { Continued tenure } \\
\text { (years) }\end{array}$ \\
\hline $0 \leq t<1$ & 3.3 \\
$1 \leq t<2$ & 3.9 \\
$2 \leq t<3$ & 4.5 \\
$3 \leq t<4$ & 4.8 \\
$4 \leq t<5$ & 5.3 \\
$5 \leq t<7$ & 6.3 \\
$10 \leq t<20$ & 6.4 \\
$t>20$ & 7.0 \\
\hline
\end{tabular}

Source: Authors' calculations.

a. Simulations assume the following parameters: seven job types available in equal numbers; wage differential between job types equals 10 percent of the mean wage; mean wage ( $=$ wage of job type 4$)=1$; benefit replacement ratio $=0.6$; annual standard deviation of movement in $x$ relative to the mean wage $=0.1 ; s=0.75 ; \beta=12$ percent per year; interest rate $=18$ percent per year; probability of receiving application from employed and unemployed persons $=1.0$.

b. Quarterly quits per employee.

c. Average value of the nonpecuniary return, $x$, relative to the mean wage.

d. Quarterly quits per employee in job type i.

the ratio of job $i$ 's wage to the mean wage in the economy. Simulations of the many-job model yield interesting and realistic results.

Table 2 reports the results of simulations of a model with seven different jobs, offering pecuniary rewards ranging from $0.7 \bar{w}$ to $1.3 \bar{w}$ (that is, the worst job, job 1, pays 70 percent of the economywide average and the best job, job 7, pays 130 percent of the mean wage). We assume that the unemployment benefit ratio is 0.6 of the average wage for all workers. This implies that the benefit replacement ratio is higher for lower-paid jobs. Finally we assume that there are equal proportions of each job type, independent of the unemployment rate. As Arthur Okun has shown, a more realistic assumption is that "good jobs" increase proportionately more than bad ones during expansions, leading to additional upward mobility in the transition between steady states. ${ }^{15}$

15. Okun, "Upward Mobility in a High-pressure Economy.", 
In the benchmark simulation of the multiple-job model described in table 2, the average nonpecuniary reward with an unemployment rate of 10 percent is 7.56 percent of wages; when the unemployment rate falls to 5 percent, the nonpecuniary reward rises to 8.21 percent of wages. In this simulation, as in simulations with other parameter values, the introduction of many job types reduces the average nonpecuniary reward by approximately 50 percent when compared with the one-job model. A calculation identical to that described earlier indicates that the change in welfare due to higher nonpecuniary rewards at lower unemployment rates would add 0.195 percent to Okun's Law. That is, a 1 percentage point change in the unemployment rate in this benchmark simulation raises nonpecuniary rewards by 0.30 percent of the wage bill or 0.195 percent of GNP.

As the top panel of table 2 reports, the rate of job switching is somewhat higher in the multiple-job model than in the single-job model, but still of a reasonable order of magnitude. E-to-E quits remain highly procyclic, increasing by 23.4 percent (taking the arc elasticity) as a consequence of a 5 percentage point cut in the unemployment rate. However, the number of E-to-U quits, although higher, remains negligible-an outcome that, upon reflection, is not unrealistic given the assumptions of the model. When all jobs pay rents, as in the simulation model, it is rash to quit into unemployment. The more sensible strategy for unhappy agents is to wait until a better job offer appears.

Quits into unemployment are low because unemployment confers no advantage in terms of searching for alternative jobs in our simulation. In contrast, if unemployment makes it easier to search, so that the "job application rate" of employed jobseekers is lower than that of the unemployed, then there $i s$ an advantage to quitting into unemployment. Simulations assuming alternative application rates are reported in table 3. With a 50 percent application rate, for example, quits into unemployment are higher in all phases of the business cycle. As the unemployment rate falls from 10 percent to 5 percent in this case, E-to-U quits rise dramatically, from 0.3 percent to 1.3 percent a quarter. The latter figure constitutes roughly 36 percent of the E-to-E quits. ${ }^{16}$

16. A special supplement to the Current Population Survey (CPS) in May 1976 investigated the job search activities of employed workers. See Carl Rosenfeld, "The Extent of Job Search by Employed Workers," Department of Labor, Special Labor Force 
Given the simplicity of the model generating turnover, the simulated economy has a surprisingly close correspondence to actual labor markets. For example, as the second and third panels of table 2 reveal, most quits occur among the poor jobs for which the benefit replacement ratios are high. Quits into both unemployment and other jobs are disproportionately high for individuals in low-wage jobs. Moreover, quitters out of low-wage jobs move in disproportionate numbers to other jobs at the low-wage end of the quality spectrum, creating a disproportionate number of vacancies in such low-wage jobs. These findings correspond to the usual description of turnover in dual labor markets, although, in a well-defined sense, our model is not a dual labor market, since there is a uniform distribution of jobs over a significant range and all jobs are rationed. The probability that an applicant will receive a job offer of a given type ranges from a 42 percent chance that an applicant will receive a job that pays 30 percent below the average wage in a given quarter, to a 0.65 percent probability that the applicant will be offered a job that pays 30 percent above the average wage. The easy availability of lowwage jobs in the real world, as in our model, could create the erroneous impression that labor markets are clearing.

Although nonpecuniary and pecuniary considerations are of equal importance in motivating turnover in this model, only a small fraction of E-to-E moves involve wage cuts. In the simulations reported in table 2, 8.5 percent of E-to-E moves entail wage cuts; 18.7 percent involve no change, and 72.8 percent involve wage increases. Nevertheless, it is important to note that in the model, as in reality, aggregate wages are acyclic. As the fourth panel of table 2 shows, the great majority of E-to-E quitters also achieve gains in nonpecuniary rewards; only a few E-to-E movers-14.6 percent-accept a nonpecuniary loss to achieve a pecuniary gain. (Under the assumption that the nonpecuniary reward

Report 202 (GPO, 1977). In this month, 3.3 million employed workers searched for a job, compared with 6.3 million unemployed persons (all of whom by definition looked for work). The ratio of employed to unemployed job applicants was therefore 0.52 . In our theoretical model with an unemployment rate of 7 percent (the closest integer unemployment rate to the May 1976 unemployment rate of 7.4 percent), with half the unhappy employees applying for jobs, the ratio of applications received from the employed to those received from the unemployed, was 0.63 . The two ratios describe a similar, but not exactly identical, concept. That they are of the same order of magnitude and are at least roughly equal suggests that the employed do in fact search less intensively than the unemployed. 
Table 3. Sensitivity of Quits and Average Nonpecuniary Rewards to Changes in Individual Parameters ${ }^{\mathrm{a}}$

\begin{tabular}{|c|c|c|c|c|c|c|}
\hline \multicolumn{7}{|c|}{ Probability that applications are made by unhappy employees } \\
\hline \multirow[b]{2}{*}{ Item } & \multicolumn{2}{|c|}{1.0} & \multicolumn{2}{|c|}{0.75} & \multicolumn{2}{|c|}{0.50} \\
\hline & $u=0.05$ & $u=0.10$ & $u=0.05$ & $u=0.10$ & $u=0.05$ & $u=0.10$ \\
\hline \multicolumn{7}{|l|}{ Quits } \\
\hline $\mathrm{E}$ to $\mathrm{E}^{\mathrm{b}}$ & 0.0506 & 0.0423 & 0.0463 & 0.0367 & 0.0362 & 0.0298 \\
\hline$E$ to $U^{b}$ & 0.0012 & 0.0005 & 0.0017 & 0.0027 & 0.0132 & 0.0032 \\
\hline $\begin{array}{l}\text { Ratio of nonpecuniary } \\
\text { reward to wage }\end{array}$ & 0.0821 & 0.0756 & 0.0807 & 0.0723 & 0.0832 & 0.0723 \\
\hline
\end{tabular}

Variance in year-to-year change in nonpecuniary reward relative to mean wage

\begin{tabular}{|c|c|c|c|c|c|c|}
\hline \multirow[b]{2}{*}{ Item } & \multicolumn{2}{|c|}{0.02} & \multicolumn{2}{|c|}{0.01} & \multicolumn{2}{|c|}{0.005} \\
\hline & $u=0.05$ & $u=0.10$ & $u=0.05$ & $u=0.10$ & $u=0.05$ & $u=0.10$ \\
\hline Quits & & & & & & \\
\hline $\mathrm{E}$ to $\mathrm{E}^{\mathrm{b}}$ & 0.0573 & 0.0450 & 0.0506 & 0.0423 & 0.0471 & 0.0392 \\
\hline $\mathrm{E}$ to $\mathrm{U}^{\mathrm{b}}$ & 0.0035 & 0.0016 & 0.0012 & 0.0005 & 0.0004 & 0.0009 \\
\hline $\begin{array}{l}\text { Ratio of nonpecuniary } \\
\text { reward to wage }\end{array}$ & 0.1406 & 0.1252 & 0.0821 & 0.0756 & 0.0412 & 0.0369 \\
\hline
\end{tabular}

Probability of job loss per quarter

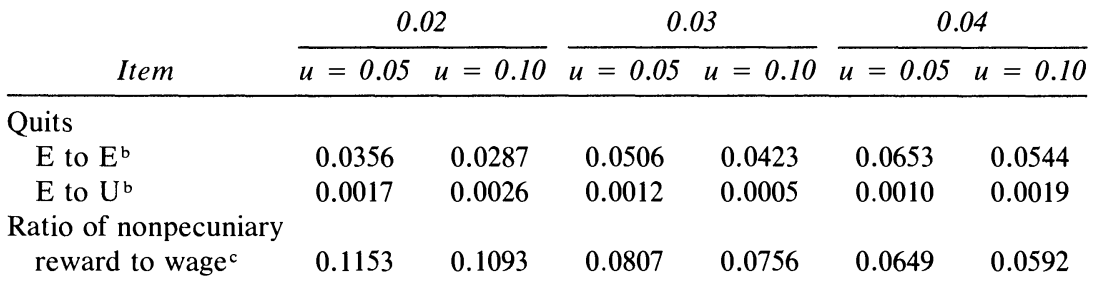

Average unemployment benefits relative to wage

\begin{tabular}{|c|c|c|c|c|c|c|}
\hline \multirow[b]{2}{*}{ Item } & \multicolumn{2}{|c|}{$0.6^{\mathrm{a}}$} & \multicolumn{2}{|c|}{$0.7^{\mathrm{d}}$} & \multicolumn{2}{|c|}{$0.8^{\mathrm{e}}$} \\
\hline & $u=0.05$ & $u=0.10$ & $u=0.05$ & $u=0.10$ & $u=0.05$ & $u=0.10$ \\
\hline \multicolumn{7}{|l|}{ Quits } \\
\hline $\mathrm{E}$ to $\mathrm{E}^{\mathrm{b}}$ & 0.0507 & 0.0423 & 0.0489 & 0.0398 & 0.0657 & 0.0509 \\
\hline$E$ to $U^{b}$ & 0.0012 & 0.0005 & 0.0016 & 0.0027 & 0.0026 & 0.0009 \\
\hline $\begin{array}{l}\text { Ratio of nonpecuniary } \\
\text { reward to wage }\end{array}$ & 0.0821 & 0.0756 & 0.0994 & 0.0914 & 0.1131 & 0.0973 \\
\hline
\end{tabular}

Source: Authors' calculations.

a. Benchmark parameter values: seven job types available in equal numbers; wage differential between job types equals 10 percent of the mean wage; mean wage $(=$ wage of job type 4$)=1$; benefit replacement ratio $=0.6$; annual variance of movement in $x=0.01 ; s=0.75 ; \beta=12$ percent per year; interest rate $=18$ percent per year; probability of receiving application from employed and unemployed persons $=1.0$.

b. Quarterly quits per employee.

c. Average value of the nonpecuniary return, $x$, relative to the mean wage.

d. Calculations assume five jobs available in equal numbers; wage differential between job types equals 10 percent of the mean wage; mean wage (= wage of job type 3$)=1$.

e. Calculations assume seven jobs, equally spaced, with mean wage $=1.0 ; s=0$; wage differential between jobs equals 5 percent of the mean wage. 
in the new job is zero, all workers with an initial positive nonpecuniary reward will suffer a loss.)

Another realistic feature of our model is declining hazard functions for job tenure: the longer a worker has been employed, the longer the worker is expected to remain at the same job. ${ }^{17}$ On average, high-tenure workers have high nonpecuniary rewards and are therefore less likely to quit. The bottom panel of table 2 shows the actuarially expected continued job tenure by length of stay in jobs.

Finally, it is interesting to note that our model generates a slightly negative correlation across individuals between wages and nonpecuniary rewards-a pattern that could be mistaken for compensating differentials-without any competitive behavior on the part of firms. In our model vacancies arise infrequently in high-wage jobs, and thus individuals find it hard to move to comparable wage positions should their nonpecuniary rewards decline. In contrast, individuals in low-wage jobs can move with relative ease to other low-wage jobs if they suffer a decline in nonpecuniary rewards. The result is that high-wage workers, on average, earn slightly lower nonpecuniary rewards.

Table 3 presents the results of alternative simulations designed to test the robustness of the findings reported above. These simulations reveal the sensitivity of the results to individual parameter variations. As in table 2 , we run a benchmark simulation and then examine the consequences of varying the parameters one at a time. As a rule of thumb, the average nonpecuniary reward is roughly proportional to the variance of the movement in $x$. Changes in the rate of interest have literally no effect on any variable since the interest rate affects only the lower bound on the total reward at which workers optimally quit from E to U. In our simulations, the step size was too large for this lower bound to be affected by changes in the rate of interest over the range from 6 percent to 18 percent a year. As noted above, going from one job to evenly distributed jobs significantly increases E-to-U flows; it decreases the average nonpecuniary reward by roughly one-half. Reduction of the benefit replacement ratio slightly lowers the average nonpecuniary return (although the results in the bottom panel of table 3 should be interpreted carefully because changes in the benefit replacement ratio necessitate

17. Additional explanations for this correlation include the accumulation of firmspecific human capital and intrinsic matching, as discussed in footnote 8 . 
changes in the assumed distribution of jobs). A decrease in $\beta$, which lowers the autonomous vacancy creation rate, increases the value of the nonpecuniary reward.

So far we have discussed only the steady-state behavior of labor market flows and nonpecuniary rewards with different values of the unemployment rate; we have not attempted to characterize the behavior of these variables during transitions between different unemployment rates. However, we have also performed simulations that provide insight into the dynamic behavior of the model. For example, we track the effects of a 2 percentage point cut in the unemployment rate over time. Initially there is a 10 percent unemployment rate and then, in a given quarter, 2 percent more jobs are created, lowering the unemployment rate from 10 percent to 8 percent. This causes a monotonic change in the average nonpecuniary reward between the two steady states. The E-to-E quit rate rises dramatically in the quarter of the change, overshooting the new steady state temporarily before declining to its new, higher longrun level. This result mirrors the actual dynamic behavior of quits and unemployment.

\section{THE BEVERIDGE CURVE}

The Beveridge curve summarizes the relationship between aggregate unemployment and vacancies. It is frequently approximated by a rectangular hyperbola so that

$$
v=k / u,
$$

where $v$ is the stock of vacancies per employee, $u$ is the unemployment rate, and $k$ is a constant that determines the position of the Beveridge curve. The parameter $k$ is commonly viewed as a measure of the extent of mismatch or structural unemployment in the labor market. According to the usual logic, a larger $k$ implies that at a given unemployment rate, $u$, there are fewer in the unemployment pool who are willing to accept jobs, or else fewer of the unemployed are eligible for the available jobs. ${ }^{18}$

In the preceding model, all vacancies are filled instantaneously. As a result, the stock (but not the flow) of vacancies is zero, precluding any

18. See James L. Medoff, "U.S. Labor Markets: Imbalance, Wage Growth, and Productivity in the 1970s," BPEA, 1:1983, pp. 87-120. 
relationship between the stock of vacancies and unemployment. Furthermore, since vacancies are filled instantaneously, there is no distinction between total job slots and the number of filled jobs.

The model can be amended to assume, realistically, that the time to fill vacancies is not zero but a positive constant, $\overline{d_{v}}$. In the model, qualified labor is readily available; therefore it is natural to assume that $\overline{d_{v}}$ is a constant determined by the nature of institutional procedures, independent of short-term features of the labor market. The introduction of a fixed time to fill vacancies into the model results in no change whatsoever in labor market flows or nonpecuniary returns for a fixed number of filled jobs.

This slight generalization of our model affords an alternative interpretation of the Beveridge curve.${ }^{19} \mathrm{~A}$ Beveridge-like relation arises in spite of the absence of any mismatch between workers and jobs. With time to fill vacancies, shifts in the Beveridge curve may occur because of changes in the average level or distribution of rents paid by jobs, a change in the number of exogenous quits to unemployment or out of the labor force, or a change in the permanent layoff rate.

In a single-job model, the steady-state flow of new vacancies per period is the sum of E-to-E quits $\left(Q_{E E}\right)$ plus autonomous vacancies: $Q_{E U}^{j}+\beta N$, where $N$ is the number of filled jobs. Using equation 4 for E-to-E quits, the flow of new vacancies, $V$, is accordingly

$$
V=\alpha \frac{1-u}{u}\left(Q_{E U}^{j}+\beta N\right)+\left(Q_{E U}^{j}+\beta N\right) .
$$

Since the stock of vacancies equals the flow of vacancies times the average duration of a vacancy,

$$
v=V \overline{d_{v}} / N .
$$

Combining equations 7 and 8 , the stock of vacancies, $v$, is

$$
v=\bar{d}_{v} \frac{[\alpha(1-u)+u]}{u}\left(\frac{Q_{E U}^{j}}{N}+\beta\right) .
$$

Both the old and new interpretations of shifts in the Beveridge curve are present in equation 9. Consistent with the usual interpretation, a shift in the Beveridge curve can occur because of greater balkanization of the

19. We are grateful to Jonathan Leonard for bringing this point to our attention. 
labor market; this will affect $\alpha$, the proportion of employed workers willing to accept a given job. In the longer run it will affect $\overline{d_{v}}$, because thin markets usually have rather time-consuming methods for filling vacancies (compare, for example, the methods involved in filling skilled and unskilled jobs). According to the new interpretation, changes in the $\left[\left(Q_{E U}^{j} / N\right)+\beta\right]$ term will also shift the Beveridge curve. Markets that have more exogenous job destruction and re-creation, or more gross outflow from the labor force and more gross inflow into it, will have higher quit rates per employee and therefore higher vacancy rates. Both the demographic mix of the labor force and the industrial structure of the economy affect $\left[\left(Q_{E U}^{j} / N\right)+\beta\right]$. Shifts in either will affect the stability of the quit-unemployment relationship over time as well as the Beveridge curve. These considerations are also germane to the quit-unemployment relationship in cross sections (for example, across cities). Estimation of quit-unemployment relationships that fail to control for variations in gross flows may find a weak or incorrectly signed relationship. ${ }^{20}$

\section{COMPARISON WITH EARLIER MATCHING MODELS}

The model that we have presented is a matching model: two types of agents, workers and employers with available jobs, are being paired. ${ }^{21}$ One important difference between our model and other matching models in the literature is that our model has only negative externalities from increased unemployment, whereas others have positive externalities. The canonical matching market is the marriage market, with two types of agents, male and female. Unemployment corresponds to being single; an E-to-E quit is analogous to divorce with subsequent remarriage; an

20. This point potentially explains the instability of the quit-unemployment relationship noted by Martin Baily, the significance of the demographic terms noted by James Medoff, and the weak cross-sectional results on quits and unemployment found by Martin David using the Panel Study of Income Dynamics and by Henry Farber using National Longitudinal Survey data. See Martin Neil Baily, "Labor Market Performance, Competition, and Inflation," in Baily, ed., Workers, Jobs, and Inflation (Brookings, 1982); Medoff, "U.S. Labor Markets"; Martin David, "The Dynamics of Family Labor Supply Decisions: Quitting and Relocating as Family Unit Decisions," in James N. Morgan, ed., Five Thousand American Families: Patterns of Economic Progress, vol. 2 (Ann Arbor: Institute for Social Research, 1974); and Henry S. Farber, "Unionism, Labor Turnover, and Wages of Young Men," in Research in Labor Economics, vol. 3 (JAI Press, 1980), pp. 33-53.

21. A very clear synthesis of work on matching models including a review of his own work is given by Dale T. Mortensen, "Matching: Finding a Partner for Life or Otherwise," American Journal of Sociology, vol. 94 (Supplement 1988), pp. S215-S240. 
E-to-U quit is analogous to divorce without remarriage. The analogy with marriage makes it clear why unemployment is so bad for workers. For workers, high unemployment corresponds to a large number of single persons of the same sex. For an unhappily married person ambitious to do better, the existence of many single people of the same sex almost surely hurts his or her own prospects.

Peter Diamond has found that the level of unemployment is typically not optimal in search models. The reason is that each worker who accepts a job ignores the impact of his or her withdrawal from the unemployment pool on the ability of others to match. Whether the equilibrium unemployment rate is too high or too low depends on the details of the matching process. In some of these models, workers match with each other, so that the incentive to withdraw from unemployment is too great and the equilibrium unemployment rate is consequently too low. ${ }^{22}$ Why does our model unambiguously yield only positive benefits from decreased unemployment? In our model, all matches are intrinsically identical; thus there are no gains in terms of better matches between workers and firms if there are more unemployed workers. However, unemployed workers do make it more difficult for other workers to get jobs. The externalities from reduced unemployment are only positive.

The detailed mechanics of matching in our model differ in several respects from those of other matching models. However, these differences are inessential since the cyclic properties of our model would obtain under more general assumptions. For example, matching models like those of Boyan Jovanovic assume that some matches between workers and firms are intrinsically good while others are intrinsically bad; for simplicity, we have assumed that all matches are equally good at the outset. ${ }^{23}$ As footnote 8 explains, we have assumed that the permanent component of match quality, defined as the value of $x$ at the

22. See Peter A. Diamond, "Mobility Costs, Frictional Unemployment and Efficiency," Journal of Political Economy, vol. 89 (August 1981), pp. 789-812; Diamond and Eric Maskin," An Equilibrium Analysis of Search and Breach of Contract, I: Steady States," Bell Journal of Economics, vol. 10 (Spring 1979), pp. 282-316; Diamond, "Wage Determination and Efficiency in Search Equilibrium," Review of Economic Studies, vol. 49 (April 1982), pp. 217-27; and Diamond, "Aggregate Demand Management in Search Equilibrium," Journal of Political Economy, vol. 90 (October 1982), pp. 881-94. In the latter study, employed workers (those who have found coconuts) provide trade externalities to other employed workers. As a result, equilibrium employment is usually too low.

23. See Boyan Jovanovic, "Job Matching and the Theory of Turnover," Journal of Political Economy, vol. 87 (October 1979), pp. 972-90. Also, see Jovanovic, “Firm- 
outset of a job, is the same for all matches. The more realistic assumption made by Jovanovic would complicate our simulations without changing their cyclic character or welfare implications. In addition, good and bad matches are typically defined to differ in terms of measured output and associated wages; similarly, in our model good matches raise welfare, although the additional returns are nonpecuniary. Incorporating Jovanovic's assumptions about the matching process in our model with rationing would also yield more E-to-E quits in a high-pressure economy, although the social benefit of these quits would take the form of higher physical output. In our model, the benefits from better matches are nonpecuniary and thus not included in Okun's Law. Finally, in Jovanovic's model, the true quality of a match is recognized by the partners only after some period of time; in our model, the true quality of the match is perceived immediately but evolves stochastically over time. In both cases, separations are endogenous, and matches that have worked out better tend to last longer. Thus our model exhibits the same bias toward good matches as the intrinsic matching models, with the advantage of greater simplicity.

\section{MARKET-CLEARING THEORIES AND QUITS}

While job-rationing, vacancy-chain theory easily explains the cyclical behavior of quits, neither of the two major market-clearing theoriesreal business cycle theory and new classical theory based on search and imperfect information-successfully accounts for this covariation. ${ }^{24}$

Search theory predicts, wrongly, that individuals quit into unemployment to search for better jobs more frequently at high unemployment

specific Capital and Turnover,' Journal of Political Economy, vol. 87 (December 1979), pp. 1247-60; and Jovanovic, "Matching, Turnover, and Unemployment," Journal of Political Economy, vol. 92 (February 1984), pp. 108-22.

24. For a description of real business cycle theory, see Finn Kydland and Edward Prescott, "Time to Build and Aggregate Fluctuations," Econometrica, vol. 50 (November 1982), pp. 1345-70; and John B. Long and Charles I. Plosser, "Real Business Cycles," Journal of Political Economy, vol. 91 (February 1983), pp. 39-69. On new classical theory, see Milton Friedman, "The Role of Monetary Policy," American Economic Review, vol. 58 (March 1968), pp. 1-17; Edmund S. Phelps, "Introduction: The New Microeconomics in Employment and Inflation Theory," in Edmund S. Phelps and others, Microeconomic Foundations of Employment and Inflation Theory (Norton, 1970); and Robert E. Lucas, "Some International Evidence on Output-Inflation Tradeoffs," American Economic Review, vol. 63 (June 1973), pp. 326-34. 
rates. According to search theory, unexpected deflation causes high unemployment because unemployed workers become less willing to accept job offers. In addition, employed workers quit their jobs to become unemployed more frequently because they are dissatisfied with their current wages relative to their (incorrect) perceptions of the available alternatives. Thus E-to-U quits should be positively correlated with unemployment, a prediction not supported by the data. There is no particular reason for cyclic behavior of E-to-E quits in the search model.

There is some ambiguity as to the exact predictions of real business cycle models concerning turnover; nevertheless, it seems difficult to explain the cyclic behavior of turnover with real business cycle theory.

According to real business cycle theory, individuals choose whether or not to work and, should they decide to work, the sector in which to be employed. The driving force of the business cycle is productivity shocks. Positive productivity shocks raise the average reward to work relative to nonwork, thus causing a boom as employment expands. Negative productivity shocks lower the average reward to work and induce departures from the labor force. Because productivity shocks are only coincidentally sectorally neutral, such shocks typically alter the relative rewards to working among sectors, thus inducing some sectoral reallocation of employment.

The short-run and steady-state impacts of productivity shocks on quits can be derived only in the context of a well-specified model. Appendix A presents an explicit analysis of the relationship between labor market flows and productivity shocks in a simple two-sector real business cycle model. The results of this analysis can be easily summarized. Under plausible assumptions, negative productivity shocks raise quits dramatically in the short run. This occurs for two reasons: first, individuals quit to withdraw from the labor force; second, some employed workers quit to switch sectors in response to changing relative sectoral rewards. As Appendix A explains, negative productivity shocks are likely to have a positive or ambiguous effect on quits once a new steady-state allocation of labor is achieved. Both the short-run and longrun predictions of this theory are counterfactual. In reality, an increase in the aggregate unemployment rate (or, more appropriately, a reduction in the aggregate employment rate) reduces quits in both the short run and the long run. The short-run response of quits to changes in either unemployment or employment exceeds the long-run effect. 
Many economists have argued that no meaningful economic distinction exists between quits and layoffs. If this argument is correct, any test of the predictions of real business cycle theory should make use of data not on quits but rather on total separations including layoffs. As we note in the following section, however, the time series behavior of total separations is similar to that of quits alone. Following an increase in the unemployment rate (or a decline in the employment rate), total separations decline significantly almost immediately. An increase in the unemployment rate also lowers steady-state separations but by a smaller amount.

Simple versions of real business cycle theory incorporate no meaningful function for unemployment. However, David Lilien and Steven Davis have argued that unemployment should be viewed as an investment that workers make in order to switch employment activities. ${ }^{25}$ According to this view, a spell of unemployment is necessary for search and "retooling" to occur. An unemployment spell is simply the cost of labor mobility. This hypothesis leads to further empirical predictions. As Davis notes, labor reallocation should be higher when unemployment is high than when unemployment is low. On the basis of careful empirical work, Davis concludes that this is what actually occurs. He finds that increases in unemployment are associated with increased flows into and out of unemployment. Since temporary layoff unemployment is not large, Davis concludes that labor reallocation is greater at higher unemployment rates.

While appreciating the ingenuity of the preceding argument, we disagree with the conclusion for two reasons. First, as noted above, total steady-state separations (due to layoffs and quits) decline as unemployment rises, indicating that labor reallocation declines as unemployment rises. Davis's focus on labor reallocation following unemployment is potentially misleading, since it ignores the many separations and accessions that involve no unemployment (for example E-E job

25. See David M. Lilien, "Sectoral Shifts and Cyclical Unemployment," Journal of Political Economy, vol. 90 (August 1982), pp. 777-93; and Steven J. Davis, "Fluctuations in the Pace of Labor Reallocation," Carnegie-Rochester Conference Series on Public Policy, vol. 27 (1987), pp. 335-402; and Davis, "Allocative Disturbances and Specific Capital in Real Business Cycle Theories," American Economic Review, vol. 77 (May 1987, Papers and Proceedings, 1986), pp. 326-31. Also of relevance is James D. Hamilton, "A Neoclassical Model of Unemployment and the Business Cycle," Journal of Political Economy, vol. 96 (June 1988), pp. 593-617. 
switches). Second, as will be discussed in the next section, Kevin Murphy and Robert Topel find that the two-digit intersectoral annual mobility rate of prime age men was strongly procyclic from 1970 to 1985 , indicating that reallocation of labor varies positively, not negatively, with aggregate activity. ${ }^{26}$

\section{THE MODEL AND THE LABOR MARKET}

The picture of the labor market presented by our model is not an exact copy of reality but a distortion, aimed at revealing some essential features. How close is the correspondence between the key features of the model and those of the U.S. economy?

The model predicts that quits, and especially E-E quits, are large and cyclic. The model is premised on the assumption that jobs pay wages in excess of market-clearing. It also assumes that nonpecuniary rewards are an important element of total labor income, and that the level of nonpecuniary rewards, along with wages, influences quit behavior. Do these predictions and premises correspond to data from the U.S. economy? To answer these questions, the next four sections will discuss respectively: the evidence concerning turnover patterns in the U.S. economy; the extent of job rationing; the importance of nonpecuniary rewards in labor income; and the role of wages and nonpecuniary rewards in quit decisions.

\section{Turnover in the Labor Market}

In this section we will examine the size and cyclic behavior of labor market flows. First, we will establish the magnitude of layoffs and quits, and of the three components of quits: E-E, E-U, and E-O. Then we will

26. See Kevin M. Murphy and Robert H. Topel, "The Evolution of Unemployment in the United States," in Stanley Fischer, ed., NBER Macroeconomics Annual, 1987 (MIT Press, 1987), pp. 11-58, especially pp. 48-49. Murphy and Topel's results coincide with our own calculations using data from two special surveys of job changing, one conducted in 1955 and the other in 1961. These reveal that the rate of job switching between one-digit industries as a fraction of total employment was 22.7 percent in 1955 , a year with 4.4 percent unemployment, in comparison with 18 percent in 1961, a year with 6.7 percent unemployment. See Gertrude Bancroft and Stuart Garfinkle, "Job Mobility in 1961, " U.S. Department of Labor, Special Labor Force Report 35 (GPO, August 1963); and Bureau of the Census, Current Population Reports, Series P-50, no. 70, "Job Mobility of Workers in 1955" (GPO, February 1957). 
examine the cyclic behavior of the aggregates and of the E-E and E-U components, respectively.

\section{SIZE OF TURNOVER AND THE COMPONENTS OF QUITS}

The data most commonly used to examine labor turnover in the United States are the series compiled by the Bureau of Labor Statistics (BLS). In the language of the form filled out monthly by business establishments, quits are "terminations of employment initiated by the employee," while layoffs are separations "initiated by the employer without prejudice to the worker,' so long as the termination is greater than one week; layoffs also include terminations of temporary or seasonal work. Discharges are terminations "initiated by the employer" for cause. Reasons for "other separations" include military duty, retirement, health, and transfer to another establishment of the same firm.

The BLS data have serious limitations: only manufacturing is covered; not all states participated in the survey at all times; there are no data on the demographic characteristics of the employees, nor on the characteristics of the jobs in question; the voluntary nature of the response imparts a bias towards larger, older firms with low turnover. These limitations notwithstanding, the BLS data are useful, especially because the series is continuous from 1919 through 1982, when it was discontinued. ${ }^{27}$ BLS data show that both quits and layoffs are large. From January 1948 through December 1981, total quits averaged 1.98 per 100 employees a month. Over the same period, layoffs averaged 1.63 per 100 employees a month.

Unfortunately, there is no published time series corresponding either to $Q_{E E}$ or to $Q_{E U}$ for the United States. Nevertheless, using information from a special BLS report on job changers for 1961, it is possible to place a lower bound of 29.6 percent on E-E changes as a fraction of all quits in that year. ${ }^{28}$ We have also estimated that, for $1969-81$, E-U quits were approximately 17.8 percent of all quits.

$E$ - $E$ Quits. In this section we combine cross-section data from the 1961 BLS survey of job changers with the standard BLS establishment-

27. See Robert E. Hall and David M. Lilien, "The Measurement and Significance of Labor Turnover," Background Paper 27 (National Commission on Employment and Unemployment Statistics, 1979), for a discussion of the characteristics and limitations of the BLS series.

28. See Bancroft and Garfinkle, "Job Mobility in 1961." 
based data on quits for the same year to provide a lower-bound estimate of $\mathrm{E}-\mathrm{E}$ quits as a fraction of total quits.

In February 1962 special questions were asked of job changers as an addition to the annual Income Supplement of the Current Population Survey. According to the survey, over the calendar year 1961 there were 4.3 million job changes whose primary motive was "improvement of (job) status." All of these changes were voluntary and therefore quits, but not all were E-E; some were followed by spells of unemployment. Since these job shifts were motivated by improvement of job status, however, it would be illogical to classify any of these as E-O shifts. By subtracting the number of shifts involving unemployment we obtain the number of E-E job shifts to improve status. For 1961, data are available on the fraction of individuals experiencing unemployment who changed jobs exactly once; 21.4 percent of single job changers who switched "to improve status" experienced unemployment. It is necessary to estimate the fraction of shifts by multiple job changers into unemployment. A reasonable assumption is that the incidence of unemployment for multiple and single job changers was identical. ${ }^{29}$ Accordingly, we estimate 3.4 million E-E shifts for job improvement (78.6 percent of 4.3 million).

What is the ratio of the status-improving E-E quits to all quits? The special study on job changers fails to report all job separations; it tabulates separations only for individuals with subsequent employment during the survey year. Therefore another source must be used to calculate total job quits.

We use the standard BLS establishment series on turnover, which reports a quit rate of 1.2 percent a month for manufacturing employees in 1961, and adjust this figure upward to offset the manufacturing bias. No quit rate more comprehensive than all manufacturing is available; since quits are lower in manufacturing than in the rest of the economy, an adjustment must be made. For job changers, from the 1961 BLS survey, quits per employee are 22.5 percent higher in the economy as a whole than in manufacturing. ${ }^{30}$ Applying this fraction to the BLS

29. For all job changes, the fraction of multiple shifters with no unemployment is roughly the square of the fraction of single shifters with no unemployment, as would be expected if both groups had the same probability of moving from $E$ to $U$ on any switch; Bancroft and Garfinkle, "Job Mobility in 1961," table B, p. A-6.

30. In contrast, however, John Baldwin, "Labor Force Turnover from Separations Data" (Queens University, 1988), using Canadian data on quit rates by industry, finds the quit rate in Canadian manufacturing to be 3.5 percent higher than the economywide quit rate. 
manufacturing quit rate in 1961 yields an estimated economywide annual quit rate for 1961 of 17.6 percent. With an average work force in 1961 of 65.5 million, quits totaled some 11.5 million. E-E status-improving quits were thus 29.6 percent ( 3.4 million/11.5 million) of all quits. ${ }^{31}$

This estimate is a lower bound. For two reasons, the numerator is undoubtedly an underestimate of total quits from $\mathrm{E}$ to E. First, only quits "to improve status" were included in our estimate. In the BLS report on job changers, shifts for "other reasons" amounted to 55 percent of shifts for improvement of job status. "Other reasons", exclude job loss and termination of temporary jobs, as well as status improvement: While some other reasons, such as discharge and retirement, are clearly not part of E-E quits, many other-reason shifts should be so classified. In our own compilation of data on mature men from the National Longitudinal Survey, 79 percent of all exogenous or otherreason quits, excluding those for health and retirement, were E-E in 1969-71 (see table 4); exogenous quits were 30 percent of all mature male quits (again excluding those for health and retirement).

Second, in labor market surveys, transitions recalled one year later are often forgotten by the respondent. ${ }^{32}$ In the Current Population Survey, a single household member gives not only his or her own labor market experience, but also that of all other household members. Retrospectively recalled job changes can be expected to record a much smaller number of quits than the BLS establishment data, which rely on contemporaneous records of employers.

E-U Quits. For E-U quits, it is possible to construct a data series for 1968-82. Since 1968, the BLS has divided the unemployed by cause.

31. This finding on the importance of E-E shifts is also documented by J. Peter Mattila, "Job Quitting and Frictional Unemployment," American Economic Review, vol. 64 (March 1974), pp. 235-39, on the basis of his examination of the BLS Survey of Job Changers in 1955 and 1961 and earlier cross-section studies. Mattila assumed that multiple and single job changers to improve status would have different probabilities of making an E-U transition; however, the data on the incidence of unemployment spells for single and multiple job changers suggest a common constant probability of losing time between jobs for all shifts.

32. See, for example, Richard D. Morgenstern and Nancy S. Barrett, "The Retrospective Bias in Unemployment Reporting by Sex, Race and Age,' Journal of the American Statistical Association, vol. 69 (June 1974), pp. 355-57; George A. Akerlof and Janet L. Yellen, "Unemployment through the Filter of Memory," Quarterly Journal of Economics, vol. 100 (August 1985), pp. 748-73; and Lawrence H. Summers, "Why Is the Unemployment Rate So Very High near Full Employment?” BPEA, 2:1986, pp. 339-96, especially pp. 358-59. 
Table 4. Distribution of E-E, E-U, and E-O Moves by Reason for Separation in National Longitudinal Survey of Mature Men, 1969-1971 ${ }^{\text {a }}$

\begin{tabular}{|c|c|c|c|c|}
\hline \multirow[b]{2}{*}{ Item } & \multirow{2}{*}{$\begin{array}{c}\text { Annual moves per } \\
100 \text { employees }\end{array}$} & \multicolumn{3}{|c|}{ Fractions of moves that are } \\
\hline & & $\overline{E-E^{\mathrm{b}}}$ & $E-U^{\mathrm{c}}$ & $\overline{E-O^{\mathrm{d}}}$ \\
\hline All separations & 9.4 & 0.47 & 0.39 & 0.14 \\
\hline Total quits & 3.5 & 0.77 & 0.15 & 0.07 \\
\hline Quit-wages ${ }^{e}$ & 0.7 & 0.80 & 0.13 & 0.07 \\
\hline Quit-nonpecuniary $f^{f}$ & 1.7 & 0.76 & 0.21 & 0.03 \\
\hline Quit-exogenous ${ }^{\mathrm{g}}$ & 1.0 & 0.79 & 0.07 & 0.14 \\
\hline Total job losses & 5.9 & 0.29 & 0.53 & 0.18 \\
\hline
\end{tabular}

Source: Authors' calculations using data from the National Longitudinal Survey of Mature Men.

a. Separations include all reported job terminations for any reason excluding within-firm (same-employer) job switches, terminations of simultaneous jobs, and quits due to health and retirement. The latter two categories are excluded from the BLS aggregate quit statistics. In contrast to earlier surveys, the 1971 NLS survey obtained a complete work history of an individual's moves since the 1969 survey.

b. A move is classified as E-E if the respondent either had a new job lined up before departure from the old job or reported no weeks not working prior to the subsequent job.

c. A move is classified as E-U if the respondent did not have a job lined up before departure from the old job and reports an unemployment spell subsequent to departure from the old job.

d. A move is classified as E-O if the respondent left last job and is out of the labor force in 1971 or if the respondent had no unemployment and a period of nonwork between jobs. This classification method is biased in favor of overreporting of E-U relative to E-O spells because it treats any transition between jobs involving a $U$ spell as an E-U transition, whereas in fact some spells could be E-O-U-E sequences.

e. A quit is categorized as Quit-wages if dissatisfaction with wages is reported as the major reason for leaving the job.

f. A quit is categorized as Quit-nonpecuniary if the reported reason for leaving the job was: interpersonal reasons, disliked hours or conditions, or found better job.

g. A quit is categorized as Quit-exogenous if the reported reason for leaving the job was: family reasons, location, moved, transferred or promoted (with new employer), and other.

Those who were laid off are said to have "lost last job." Those who made O-U transitions are classified as "new entrants" and "reentrants" to the labor force. Those who made E-U quits are classified as "left last job." The flow into this pool of unemployed "job leavers" is the flow of E-U quits. In a steady state, division of the stock of unemployed job leavers by their average spell of unemployment gives the flow of $E$ to $U$ quits. Hal Sider has calculated the average unemployment spell length from 1968 to 1982 for the whole population. The assumption that these spell lengths apply to job leavers as well as to the whole population yields an estimate of E-U flows. ${ }^{33}$ For this period, the average of the annual estimated ratios of E-U quits to the economywide quits is 17.8 percent.

33. See Hal Sider, "Unemployment Duration and Incidence: 1968-82," American Economic Review, vol. 75 (June 1985), pp. 461-72. Results obtained by Stephen T. Marston in "Employment Instability and High Unemployment Rates," BPEA, 1:1976, pp. 169203, justify this assumption. Marston (p. 191) found that the duration of spells of unemployment of job leavers was slightly longer than that of job losers in March 1973 by comparing the ratio of the flows of leavers to losers to the ratio of the stocks of leavers to losers. 
To obtain economywide quits, an upward adjustment of 22.5 percent was made to the BLS quit rates, to compensate for the nonrepresentative nature of quits in manufacturing.

So far it has been seen that E-E quits are a significant fraction of all quits, being very conservatively estimated at 29.6 percent of all quits for 1961. E-U quits account for a significant, but by no means dominant share of all quits, being estimated at 17.8 percent for the period 1968-82. Corroborative evidence on the distributions of these E-E and E-U quits comes from data we have compiled for mature men in the National Longitudinal Survey for the period 1969-71, a period for which a virtually complete work history is available. For this period, 77 percent of all quits were E-E; 15 percent, E-U; and only 7 percent, E-O. These figures exclude quits related to retirements and health, to conform to the BLS definition of quits. This group is special, of course, particularly in its high attachment to the labor force, so E-O quits would be expected to be unusually small. It is useful to see that this expectation is realized and also that the E-U quits are small relative to E-E.

\section{CYCLIC BEHAVIOR OF AGGREGATE QUITS AND LAYOFFS}

We now turn to the cyclic behavior of aggregate quits and layoffs.

Quits. Figure 1 illustrates the procyclicality of quits. The simple correlation between the log of the quit rate and the log of the civilian unemployment rate from January 1948 through December 1981 is -0.74 . The simple correlation between the growth of quits and the percentage change in the unemployment rate over the same period is -0.34 (the standard error of both statistics is approximately 0.05 ). These statistics are robust with respect to choice of sample period. ${ }^{34}$

Our theoretical model implies the existence of a steady-state relationship between the quit rate and the unemployment rate; if the unemployment rate declines permanently, the quit rate will rise. Consider a time series on the natural log of the quit rate, $q_{t}$, and the log of the unemployment rate, $u_{t}$. Suppose that

34. We have checked the robustness of this cyclic behavior in many ways-for instance, allowing for time trends, lags of the quit rate, different lags in unemployment, changes in sample period and different functional form (in terms of growth rates rather than levels)and have used other variables besides unemployment as indicators of cyclic activity. We have also confirmed that quits are cyclic with nonparametric "sign" tests. There seems to be no doubt that quits are extremely cyclic. The procyclic behavior of quits has been corroborated in every previous time series investigation of which we are aware. 
Figure 1. Quits and Unemployment, 1948-81

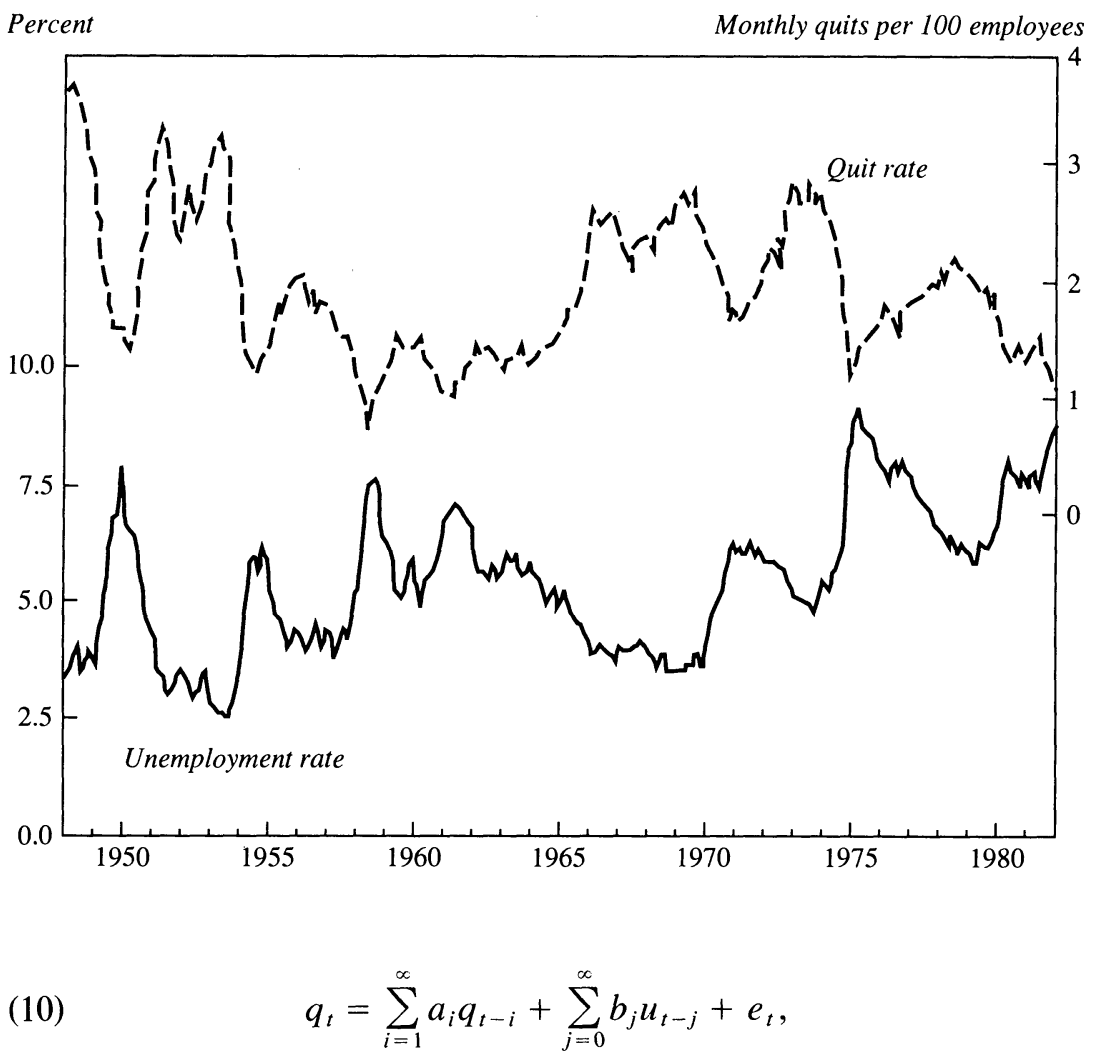

where $e_{t}$ is a white-noise error term. A test of the hypothesis of a steadystate relation between $q$ and $u$ is that the sum of the $b_{j}$ coefficients, which will be denoted $B$, is not zero while the sum of the $a_{i}$ coefficients, which will be denoted $A$, is strictly less than 1 . The steady-state change in $q$ associated with a unit change in $u$ is then $B /(1-A)$.

Before attempting to estimate the magnitude of $B /(1-A)$ it is important to check that there does exist some stable long-run relationship between $q$ and its key determinants, including $u$. Technically, one cannot reject the hypothesis that both the log of the quit rate and the log of the unemployment rate have unit roots at the 5 percent level $;{ }^{35}$ loosely

35. See Wayne A. Fuller, Introduction to Statistical Time Series (John Wiley, 1976), for a description of the tests and critical values. Our Dickey-Fuller tests include a constant and are "augmented" by 12 lags of the growth rate. These results are robust with respect to the choice of sample. 
speaking, they individually move like random walks with additional dynamics. Although each of the variables may have a unit root, there may still be a stable relation between them. If a linear combination of two variables, each of which has a unit root, is stationary, the two variables are said to be cointegrated. A steady-state change in the level of one variable is then associated with a steady-state change in the other.

We applied the Engle-Granger test for cointegration to quits and unemployment. We included three demographic factors frequently used in calculations of weighted unemployment rates: the fractions of teens, women, and the elderly in the labor force ${ }^{36}$ These variables are appropriate in our model, because they potentially affect the rate of autonomous vacancy creation. We find that the $\log$ of quits and the $\log$ of unemployment are cointegrated from 1948 to 1982. The cointegrating or steady-state equation linking $q$ and $u$ is

$$
\begin{aligned}
q= & 6.70-1.26 u-20.25 \frac{\text { Employed men aged over } 55}{\text { Labor force }} \\
& -9.34 \frac{\text { Women in labor force }}{\text { Labor force }}+13.89 \frac{\text { Teens in labor force }}{\text { Labor force }},
\end{aligned}
$$

Number of observations: 372; sample period: January 1951-December 1981;

Engle-Yoo ADF statistic: 4.83 (significant at the 5 percent level). ${ }^{37}$

The coefficients of the cointegrating equation indicate that the long-run elasticity of the quit rate with respect to the unemployment rate is -1.26 . Thus, a permanent increase in the unemployment rate from 5 percent to 6 percent would lead to a permanent decline in the quit rate from, for example, 1.9 quits a month to 1.46 quits a month. Further, when the quit rate is modeled in an error correction model, the dynamic responses also seem sensible. In particular, the quit rate rises quickly in the short run in response to a decrease in the unemployment rate, before settling down to its new higher steady state. ${ }^{38}$ This corresponds to the dynamic behavior of the simulation model.

As discussed above, real business cycle models imply a negative

36. See George L. Perry, "Changing Labor Markets and Inflation," BPEA, 3:1970, pp. 411-41.

37. See Robert F. Engle and Byung Sam Yoo, "Forecasting and Testing in CoIntegrated Systems," Journal of Econometrics, vol. 35 (May 1987), pp. 143-59.

38. The error correction model relates the change in the log of the quit rate to the cointegrating vector estimated in equation 11 above, the current value and lags in the 
short-run relationship between the quit rate and employment rather than between the quit rate and unemployment. In actual fact quits are positively correlated (and cointegrated) with the employment rate. The $\log$ of the employment rate is cointegrated with the log of the quit rate; the relationship is positive. When the relationship between the employment rate and the quit rate is modeled in an error correction framework, the results are qualitatively identical to those described above. An increase in the employment rate leads to a short-run surge in quits that temporarily overshoots the higher steady-state rate.

Quits in Cities. Further evidence on the cyclic behavior of quits and unemployment comes from an examination of the relationships between quits and unemployment rates by Standard Metropolitan Statistical Area. When we estimate the relationship between the log of the quit rate and the log of unemployment over time, we find overwhelming evidence of a statistically significant relationship for each of the 16 cities for which data are available from 1958 through 1980 (this relationship is estimated using Zellner's SURE technique). As we noted above, our model does not predict any simple cross-section correlation between quits and unemployment across cities due to the possibility of variations in demographic and industrial mix factors that would affect the layoff and exogenous quit rates. Cross-section regressions for each year in our sample reveal a negative and significant relation between $q$ and $u$ across cities for only 6 out of 23 years. In 14 years, the relation was negative and insignificant; in 3, positive and significant.

Quits in War and Depression. The extremes of war and depression dramatize the correlation between quits and economic activity. Quits in the 1920 s averaged 3.7 percent monthly and fell to 1.0 percent monthly during the depressed decade of the 1930s. At the height of World War II (in 1943 and 1944) quits averaged more than 6.2 percent monthly.

Layoffs. As figure 2 shows, layoffs display kurtosis: they rise to large spikes at, or shortly after, the beginning of recessions. ${ }^{39}$ In contrast to

change in the log of the unemployment rate, and lags in the dependent variable (the change in q). See James E. H. Davidson, David F. Hendry, Frank Srba, and Steven Yeo, "Econometric Modelling of the Aggregate Time-Series Relationship Between Consumers' Expenditure and Income in the United Kingdom," Economic Journal, vol. 88 (December 1978), pp. 661-92.

39. The Jarque-Bera test for kurtosis of the residuals of a regression of the log of the layoff rate on the log of the unemployment rate is 4.62 , which is significant at the 5 percent level. This statistic is distributed as chi-square with 1 degree of freedom under the null hypothesis of normality. 
Figure 2. Layoffs and Unemployment, 1948-81

Percent

Monthly layoffs per 100 employees

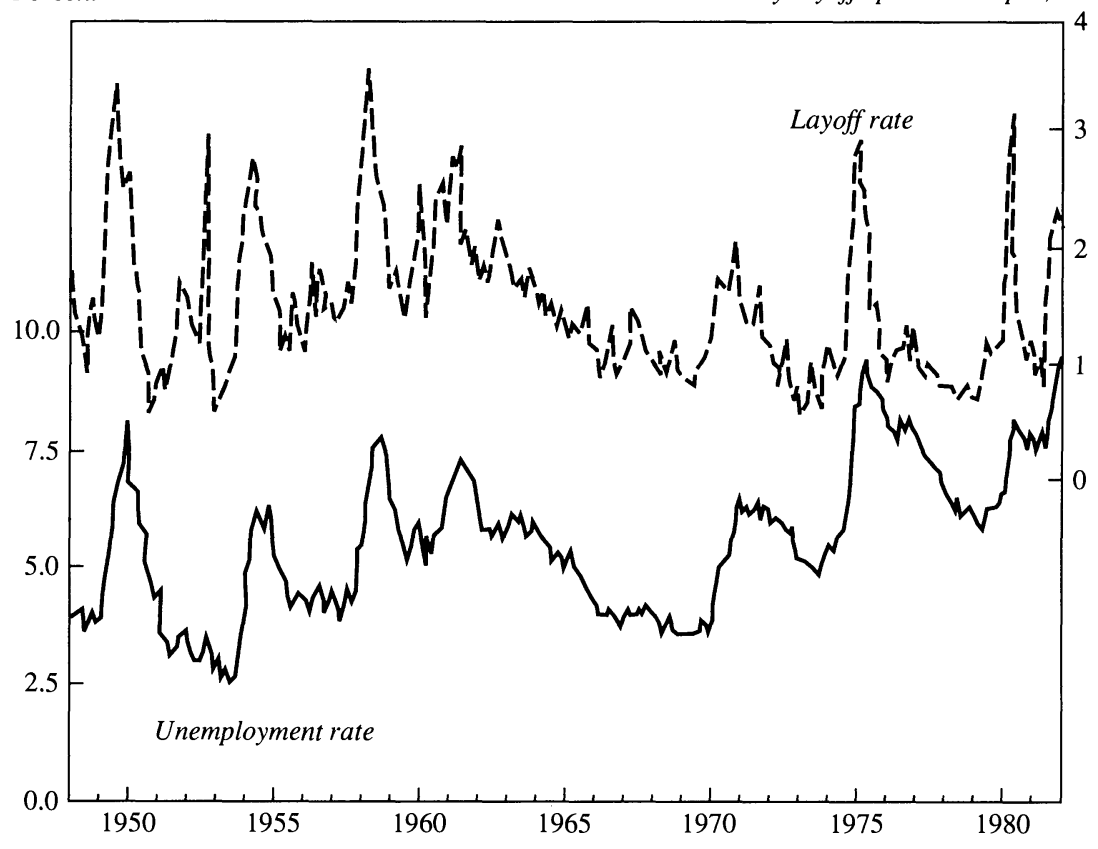

quits, layoffs do not seem to have any strong steady-state relationship to unemployment. The countercyclic behavior of layoffs appears to be short-run rather than steady-state. ${ }^{40}$

Total Separations. Our model implies that, in response to a permanent reduction in the unemployment rate, the separation rate rises dramatically, temporarily overshooting its new, higher steady-state value. It is especially important to test this prediction because some economists deny the existence of any meaningful economic distinction

40. For the sample period from January 1949 through December 1981 the hypothesis that layoffs have a unit root can be rejected at the 1 percent significance level with DickeyFuller tests. This precludes the possibility of a cointegrating relationship between the unemployment rate and the layoff rate since the former appears to have a unit root. Alternatively, a simple $F$-test cannot reject the hypothesis that the coefficients on the lags of the $\log$ of the unemployment rate (in a regression of the log of the layoff rate on the current and lagged values of the log of the unemployment rate and lags of the dependent variable) sum to zero. Nevertheless, there is a strong positive relation between innovations in the unemployment rate and innovations in the layoff rate. 
between quits and layoffs. Despite the fact that layoffs are countercyclic, the sum of quits and layoffs (almost total separations, except for "other" separations and discharges) is still procyclic. For instance, a regression of the growth rate of the sum of quits plus layoffs on the current and lagged values of the growth rate of the unemployment rate yields a negative and significant relationship, with a steady-state elasticity of around -0.26 . This result stands up to a variety of changes in the specification of the model. ${ }^{41}$

\section{CYCLIC NATURE OF E-E AND E-U QUITS}

Support for the cyclic nature of E-E quits comes from a comparison of data from the BLS special report on job changes for 1961 and an earlier, less complete, survey for $1955 .{ }^{42}$ Unemployment was significantly greater in 1961 than in 1955-4.3 percent as compared with 6.7 percent-and the number of job shifts to improve status per employee was significantly greater in 1955 than in 1961. In 1955 this ratio was 8.1 per hundred employees for the whole year, whereas in 1961 the same ratio was 6.5 per hundred employees. This number does not exactly correspond to $Q_{E E} / E$ in our theoretical model, but instead corresponds to the sum $\left(Q_{E U}^{j}+Q_{E E}\right) / E$. It represents the number of changes to improve status irrespective of whether the quit was into unemployment or directly into a new job. Ideally, we would like to know $Q_{E E} / E$, but the composite number is perhaps more interesting empirically than the $Q_{E E}$ component. The basis for our model is the hypothesis of more job mobility at low unemployment. At lower unemployment rates, more opportunities for improved job status occur because jobs are rationed and vacancy chains are longer. The change in $\left(Q_{E U}^{j}+Q_{E E}\right) / E$ between these two years, which is the change in status-improving moves per employee, does suggest that at high unemployment, such mobility is lower. ${ }^{43}$

41. Modeling the separation rate and the unemployment rate in an error correction model allows one to trace out the dynamic relationship between the two variables. An increase in the unemployment rate raises total separations contemporaneously (due to the spiky nature of layoffs); this effect is quickly offset and total separations decline within a quarter, remaining lower in steady state.

42. See "Job Mobility of Workers in 1955."

43. It is interesting to note that the rate of job shifting to improve status fell within every individual demographic subgroup between 1955 and 1961 with the exception of men 
A further indication that opportunities, and therefore mobility, dry up when unemployment rises has been given by Murphy and Topel. Using CPS reports for adult males linked between adjacent years, they computed the fraction of workers who report a different employer for the longest job "last year," and a different two-digit industry between the two jobs. Murphy and Topel note that the periods of sharpest decline in this measure of mobility are coincident with the recessions of 1975 and 1983, which represent the peaks of cyclic unemployment in the postwar period. ${ }^{44}$ For 1973, when the unemployment rate was 4.9 percent, intersectoral mobility was 10.1 percent of the adult males. For 1983 , with 9.6 percent unemployment, mobility was 6.8 percent. This procyclic mobility occurred despite the fact that at higher unemployment rates there are more unemployed workers seeking job opportunities. It might be expected that many of these workers would find jobs in industries different from their last. Murphy and Topel interpret their findings as rejecting an explanation of rising unemployment due to structural changes.

The E-U series described above reveals the procyclic nature of quits into unemployment quite clearly. For 1970 , with a 4.8 percent unemployment rate, the annual rate of E-to-U quits was 4.6 percent. For 1982 (when the unemployment rate was 9.5 percent), the annual E-to-U quit rate had declined to 3.4 percent. Regression analysis shows significant negative correlation between unemployment and E-to-U quits; the correlation between the annual demeaned growth rates of $Q_{E U}$ and $u$ has a $t$-statistic of 5.7 for the period 1969-82. In our theoretical model the impact of changing unemployment on the E-U quit rate is ambiguous: on the one hand, as unemployment rises, there is decreased incentive to quit, because spells of unemployment last longer; on the other hand, persons who quit because of job dissatisfaction or exogenous causes will

and women over 65 . For example, for men aged 45-64, the rate of quitting to improve status fell from 4.1 percent in 1955 to 2.1 percent in 1961 . This suggests that changes in demographic composition of employment are not wholly responsible for the cyclic behavior of aggregate quits, although quit rates vary substantially across demographic groups and employment shares of demographic subgroups vary cyclically. A simple calculation shows that the contribution of demographic shifts to the change in total quits between 1955 and 1961 was quite minor: between 1955 and 1961 the status-improving quit rate fell from 6.7 percent to 5.3 percent. If the composition of the labor force had remained unchanged, the fall would have instead been from 6.7 percent to 5.5 percent.

44. See Murphy and Topel, "The Evolution of Unemployment," pp. 48-49. 
be less likely to find alternative jobs when unemployment rates are higher. It is apparent empirically, however, that the disincentive effect dominates the E-to-U quitting decision. ${ }^{45}$

\section{Rents in Wage Payments}

Our model of turnover depends crucially on the assumptions that jobs are rationed and workers receive rents. The assumption that jobs pay rents has a long and venerable history in economics. Exploring its consequences, which is the purpose of this paper, is part of a long tradition.

Twenty years ago, most macroeconomists assumed rationing in labor markets. Since that time, alternative models with rational expectations and market clearing have been proposed; curiously, they retain their popularity, despite the numerous empirical rejections of such models. Such rejections, of course, constitute only weak evidence in favor of job rationing. Still, they offer no reason for abandoning job rationing models, whose basis was not sophisticated statistical tests but rather a collection of empirical evidence concerning the operation of labor markets.

The current controversy between Keynesian and new classical economists marks the continuation of a debate in labor economics between the "institutionalists," who believed that a variety of institutions were important in creating wage dispersion in labor markets, and the "theorists," who believed that labor markets cleared. ${ }^{46}$ Persistent wage

45. The size of turnover, as revealed by the BLS establishment series, is so very large as to suggest that the data could be seriously in error, although there is also evidence indicating that these data underestimate total quits. (See State of California Employment Development Department, Employment Service Potential, September 1977.) Surprisingly, a conservative compilation of data from the 1961 Work Experience Survey and from the 1961 survey on job changes yields a lower bound for employment separations only 20 percent lower than the separation rate reported in the standard BLS series after adjustment for exclusion of nonmanufacturing in the establishment series. This calculation is available from the authors upon request.

46. We interpret the term Keynesian broadly to include such new Keynesian approaches as those surveyed by Bruce C. Greenwald and Joseph E. Stiglitz, "Examining Alternative Macroeconomic Theories," BPEA, 1:1988, pp. 207-60. See Lloyd Ulman, "Labor Mobility and the Industrial Wage Structure in the Postwar United States," Quarterly Journal of Economics, vol. 79 (February 1965), pp. 73-97, and references . therein, for a summary of the debate between the institutionalists and the theorists. 
dispersion in excess of compensating differentials for workers of identical characteristics is clearly inconsistent with any market-clearing theory, in which only the highest-paying firms could succeed in hiring.

The institutionalists used as an important bit of evidence in favor of their non-market-clearing view the negative correlation between wages and quits. According to their argument, if higher wages result in lower quit rates, high-wage jobs must be more desirable. This same argument has been made by Krueger and Summers, who find significant interindustry and occupational wage differentials for workers with similar characteristics. ${ }^{47}$ According to Krueger and Summers, the impact of industry affiliation on wages ranges from a high of 38 percent above the mean for the petroleum industry, to 37 percent below the mean for private household services. They also show that when individual workers shift industries, their change in wage accords with the differences in industry wage differentials. Furthermore, quits fall as the industry wage premiums rise. Dickens and Katz have found a high correlation between the pay of different occupations across industries. ${ }^{48}$ For example, in industries where the engineers secure high wages, so also do the secretaries. Finally, the considerable wage dispersion uncovered in national samples has also been found in numerous studies of local labor markets. ${ }^{49}$

Our model assumes that even the worst jobs pay wages in excess of market clearing and thus unemployed workers are quick to accept job offers. This assumption is consistent with several bits of empirical evidence. For example, in a study of metalworking plants in New Haven, Lloyd Reynolds found that the lowest-paying plants had no trouble getting labor, even in 1948, when the labor market was very tight, with

47. See Krueger and Summers, "Efficiency Wages and the Inter-Industry Wage Structure." We could view our multiple-job model as having seven different industries, each of which pays a different wage. A large number of earlier studies, using cross-section industry data, found negative correlations between industry quit rates and wage levels. For a survey, see Donald O. Parsons, "Models of Labor Market Turnover: A Theoretical and Empirical Survey," in Research in Labor Economics, vol. 1 (JAI Press, 1978), pp. 185-223.

48. See Dickens and Katz, "Industry Wage Patterns."

49. For dramatic examples see, John T. Dunlop, "The Task of Contemporary Wage Theory," in Dunlop, ed., The Theory of Wage Determination (St. Martin's Press, 1957), pp. 3-27; and Lloyd Reynolds, The Structure of Labor Markets: Wages and Labor Mobility in Theory and Practice (Harper and Brothers, 1951). 
a 3 percent local unemployment rate, and starting wages ranged from a low of 69 cents an hour to a high of $\$ 1.19$ an hour on average. The lowwage plants seemed to have as many applicants as the high-wage plants but fewer acceptances. Reynolds concludes that although the low-wage firms got lower-quality labor, they were "getting a 'better buy' i.e., labor was costing less per efficiency unit than it was costing the high-wage firms." ${ }_{50}$

Another study documents the ready availability of labor in a local labor market. In 1978 a Fortune reporter tracked down all the helpwanted ads in Middletown, New York, the commercial center for a county 65 miles north of New York City with 273,000 people. Of the 228 ads that appeared in the main county paper for the week in question, only 42 offered full-time nonskilled positions. The employers offering these jobs were "swamped by a tidal wave of applicants." The unemployment rate at the time in Orange County was 7.4 percent, which was high but not very high. ${ }^{51}$

This evidence on the labor market from Middletown accords with a revealing statistic for the U.S. labor market as a whole. According to the May 1976 special study of job search methods, only about 8.5 percent of those workers unemployed at the time of the interview reported having received and rejected a job offer..$^{52}$ On the steady-state assumption that workers are interviewed with uniform probability throughout their spell of unemployment, this means that by the end of their spell, 17 percent will have rejected a job offer. Eighty-three percent of all unemployed workers accept the first job offer received.

The interesting and important question of how firms decide what wages to pay is now the subject of a substantial theoretical literature. "Efficiency wage" theory attempts to explain why firms might pay wages in excess of market clearing: with low wages, equity norms may induce workers to have low morale, resulting in various subtle and not

50. Reynolds, Structure of Labor Markets, pp. 10, 190, 218-19.

51. See Herbert E. Meyer, "Jobs and Want Ads: A Look Behind the Words," Fortune, vol. 98 (November 20, 1978), pp. 88-96.

52. See Carl Rosenfeld, "Job Search of the Unemployed, May 1976," Department of Labor, Bureau of Labor Statistics, Special Labor Force Report 210 (GPO, 1978), p. 41. This same statistic was also quoted by Kim B. Clark and Lawrence H. Summers, "Labor Market Dynamics and Unemployment: A Reconsideration," BPEA, 1:1979, p. 55, in a similar context. 
so subtle forms of sabotage; quit rates are apt to be high; workers are apt to shirk; the quality of available labor will be low; and the threat of unionization will be high. All these motives for above-market-clearing wages have been studied in some detail. Our model assumes that wage differentials are exogenously rather than optimally determined, an assumption that accords with the conclusions of Krueger and Summers and Dickens and Katz, who find no patterns in wage differentials that could be easily explained by optimizing theories. ${ }^{53}$ The most natural explanation for such differentials is that they are chosen to accord with customary views of equity both between owners and employees of the firm and across occupational groups within the firm. ${ }^{54}$

\section{The Importance of Nonpecuniary Rewards in Total Labor Income}

Our model assumes that nonpecuniary rewards constitute a significant portion of total labor income, and change stochastically over time, thus motivating a significant fraction of quits. Here, we verify these assumptions.

THE IMPORTANCE OF NONPECUNIARY REWARDS IN

MOTIVATING WORK

Psychologists and sociologists have long been interested in the motivations of workers and the underlying causes of job satisfaction. The preponderance of evidence suggests the importance of nonpecuniary factors as a component of total rewards. Robert Quinn, Graham Staines, and Margaret McCullough, for example, describing the results of the Quality of Employment Survey (a national panel), concluded that having

53. See Alan B. Krueger and Lawrence H. Summers, "Reflections on the Interindustry Wage Structure," in Lang and Leonard, eds., Unemployment and the Structure of Labor Markets, pp. 17-47; William T. Dickens and Lawrence F. Katz, "Interindustry Wage Differences and Industry Characteristics," in Lang and Leonard, eds., Unemployment and the Structure of Labor Markets, pp. 48-89.

54. See Ulman, "Labor Mobility and the Industrial Wage Structure"; and George A. Akerlof and Janet L. Yellen, "Fairness and Unemployment," American Economic Review, vol. 78 (May 1988, Papers and Proceedings, 1987), pp. 44-49; and "The Fair Wage/Effort Hypothesis and Unemployment" (University of California, Berkeley, July 1987). 
the resources to do one's work, good financial rewards, challenging work, and good relations with coworkers are each of approximately equal importance to workers..$^{55}$

The National Longitudinal Survey of mature men provides a rich data set for studying the motivations of American workers. This panel consists of 5,020 men aged between 45 and 59 in 1966. The men were surveyed 12 times between 1966 and 1983. Of the four original cohorts of the NLS, we have chosen the mature men because this group had the greatest commitment to the labor force, thus simplifying the analysis by minimizing the complications involved in entry and reentry into, and exit from, the labor force. In comparison with the other (younger) cohorts of the NLS, turnover due to "intrinisic" matching is likely to be small.

For various subperiods, we classify respondents by mover status. Our analysis distinguishes five subgroups: "stayers" - those who stayed in the same job throughout the period; "wage-quitters"- -those who quit their base-year job and cited wages as the primary reason; " nonpecuniary quitters" - those who quit their base-year job for reasons related to the job other than wages; "exogenous quitters"- -those who quit for reasons unrelated to the job, such as health or family; and "job losers," who were laid off or discharged. ${ }^{56}$

Table 5 presents a variety of indicators of the importance of nonpecuniary factors to the typical mature American male, classified by mover status in 1966-67. In 1966, the NLS asked respondents the question, "What would you say is more important about any job; good wages or liking the work?" Seventy-three percent of the population responded that "liking the work" was more important. This view was shared by the majority of every mover group. The NLS also asked respondents in 1966, "If by some chance you were to get enough money to live comfortably without working, do you think that you would work anyway?" On average, 77 percent of the men said that they would work

55. See Frank J. Landy and Don A. Trumbo, Psychology of Work Behavior, rev. ed. (Dorsey Press, 1980), for a survey of the evidence of the importance of nonpecuniary rewards. See also Robert P. Quinn, Graham L. Staines, and Margaret R. McCullough, Job Satisfaction: Is There a Trend? Department of Labor, Manpower Research Monograph 30 (GPO, 1974).

56. To the maximum extent possible, we have taken account of multiple transitions between jobs, and included multiple movers in the analysis only when the motive underlying each move was identical. 
Table 5. Attitudes toward Work in 1966 by 1966-1967 Mover Group

\begin{tabular}{|c|c|c|c|c|c|c|}
\hline \multirow[b]{2}{*}{ Item } & \multirow[b]{2}{*}{$\begin{array}{c}\text { All } \\
\text { workers }\end{array}$} & \multirow[b]{2}{*}{$\begin{array}{c}\text { Job } \\
\text { stayers }^{\mathrm{a}}\end{array}$} & \multicolumn{3}{|c|}{ Job quitters by reason ${ }^{b}$} & \multirow[b]{2}{*}{$\begin{array}{c}\text { Job } \\
\text { losers }^{b}\end{array}$} \\
\hline & & & Wages $^{\mathrm{c}}$ & $\begin{array}{c}\text { Non- } \\
\text { pecuniary }\end{array}$ & Exogenous & \\
\hline $\begin{array}{l}\text { Fraction reporting that } \\
\text { "liking work is more } \\
\text { important than wages", }\end{array}$ & 0.73 & 0.74 & 0.85 & 0.66 & 0.67 & 0.56 \\
\hline $\begin{array}{l}\text { Fraction "strongly } \\
\text { committed" to work }\end{array}$ & 0.77 & 0.76 & 0.88 & 0.87 & 0.78 & 0.81 \\
\hline $\begin{array}{l}\text { Fraction who like their } \\
\text { job "very much", } \\
\text { Fraction who dislike } \\
\text { their job "somewhat", } \\
\text { or "very much", }\end{array}$ & 0.56 & 0.58 & 0.40 & 0.43 & 0.41 & 0.48 \\
\hline $\begin{array}{l}\text { Source: Authors' calculations u } \\
\text { a. An individual is classified as } \\
\text { year surveys and never reports le } \\
\text { b. An individual is classified as } \\
\text { the base-year and terminal-year s } \\
\text { reported departures from interven } \\
\text { c. A quit is categorized as Quit } \\
\text { job; Quit-nonpecuniary if the repc } \\
\text { hours or conditions, or found bet } \\
\text { personal reasons, location, move } \\
\text { d. An individual is classified as }\end{array}$ & $\begin{array}{l}\text { Ising data fro } \\
\text { a stayer ove } \\
\text { caving his ori } \\
\text { s a wage-, no } \\
\text { urveys; he re } \\
\text { ing jobs are } \\
\text {-wages if dis } \\
\text { orted reason } \\
\text { tter job; Quit } \\
\text { d, health, ret } \\
\text { s strongly co }\end{array}$ & $\begin{array}{l}\text { m the Natior } \\
\text { er a given su } \\
\text { ginal employ } \\
\text { onpecuniary- } \\
\text { eports leavin } \\
\text { also for the } \\
\text { satisfaction } \\
\text { for leaving t } \\
\text { t-exogenous } \\
\text { irement, and }\end{array}$ & $\begin{array}{l}\text { nal Longitud } \\
\text { bperiod if he } \\
\text { er in any su } \\
\text {, exogenous } \\
g \text { the base-y } \\
\text { correspondin } \\
\text { vith wages is } \\
\text { he job was: } \\
\text { if the report } \\
\text { other. } \\
\text { work if he a }\end{array}$ & $\begin{array}{l}\text { linal Survey of } \\
\text { is employed in } \\
\text { rvey. } \\
\text {-quitter or a job } \\
\text { ear job for the co } \\
\text { ig reason. } \\
\text { reported as the } \\
\text { type of work, int } \\
\text { ed reason for lea } \\
\text { nswers that he }\end{array}$ & $\begin{array}{l}\text { Iature Men. } \\
\text { both the base- anc } \\
\text { loser if he was en } \\
\text { orresponding reaso } \\
\text { major reason for l } \\
\text { terpersonal reason } \\
\text { aving the job was: } \\
\text { vould work even i }\end{array}$ & $\begin{array}{l}\text { terminal- } \\
\text { ployed in } \\
\text { and any } \\
\text { aving the } \\
\text {, disliked } \\
\text { family or } \\
\text { by some }\end{array}$ \\
\hline
\end{tabular}

even if they didn't need the money ${ }^{57}$ When asked why, 15.1 percent of men indicated that they enjoyed working, liked the specific kind of work they were currently doing, were "able" to work or enjoyed the companionship; another 57.4 percent said they would be bored, suggesting a positive distaste for leisure in large amounts. ${ }^{58}$

57. Comparable results were obtained from the Quality of Employment Survey. In 1977, for example, 71.5 percent of 2,273 respondents stated that they would continue to work if they were to get enough money to live as comfortably as they would like for the rest of their lives; 76.3 percent disagreed with the statement, "I'd be happier if I didn't have to work at all." See Robert P. Quinn and Graham L. Staines, The 1977 Quality of Employment Survey (Ann Arbor: Institute for Social Research, 1979), pp. 240-41.

58. This preference for work over leisure may explain why benefit replacement ratios can be very high for a large fraction of the labor force, yet institutional forms have not developed whereby workers collect substantial amounts of unemployment insurance while enjoying leisure. In 1971, 30.4 percent of the population had benefit replacement ratios in excess of 70 percent (see Feldstein, "The Effect of Unemployment Insurance on Temporary Layoff Unemployment," p. 840), while unemployment insurance programs paid less than 1 percent of total wages and salaries (Economic Report of the President, 1975, pp. $266,281)$. For the same reason, nonpecuniary rewards are likely to be relevant to an individual's labor force participation decision, and could be incorporated in equations that estimate the hours of labor that individuals choose to supply. 
The NLS also attempted to gauge the level of total job satisfaction of employed respondents in most years, as well as the reasons for job satisfaction. The following sequence of questions was used: "How do you feel about the job you have now? Do you like it very much? fairly well? dislike it somewhat? or dislike it very much?" "What are the things you like best about your job? What are the things about your job that you don't like?'' In addition, the survey asked respondents to assess how their attitude toward their jobs had changed since the previous survey, with the questions "Would you say you like your present job more, less, or about the same as (the job you held) last year?" "What would you say is the main reason that you like your present job (more, less)?"

Table 5 reports the fractions of each mover group who were "very satisfied" and "somewhat or very dissatisfied" with their work. The primary factors that account for the respondents' level of satisfaction and dissatisfaction are reported, for the population as a whole, in table 6 , which classifies all of the factors mentioned by respondents into two categories: pecuniary and nonpecuniary. Pecuniary reasons include earnings, job security, steady work, and good fringe benefits. Nonpecuniary factors include, for example, kind of work; ability or capacity to do the work; feeling that work is important, satisfying, or challenging; interesting work; being one's own boss, having responsibility; not having too much pressure or responsibility; congenial coworkers; hours; working conditions; supervision; company policy; good union; meeting interesting people. Table 5 reveals that the majority of the population report themselves to be "very satisfied." Nevertheless, a substantial number of individuals describe themselves as dissatisfied. The fraction of unhappy workers ranges from 5.9 percent of those who do not switch jobs, to 21.8 percent for those who later did switch jobs for nonpecuniary reasons. As is abundantly apparent from table 6, nonpecuniary factors are mentioned as the most important features of jobs, both positive and negative, across the entire range of the satisfaction spectrum. Over 80 percent of those who like their jobs cite a nonpecuniary reason as the primary cause of their satisfaction. Among those who dislike their jobs, in over 80 percent of the cases, the culprit is nonpecuniary. ${ }^{59}$

59. These results are exactly consistent with the findings of Lloyd Reynolds and Joseph Shister in their study of 800 manual workers in New Haven in 1947. Lloyd R. Reynolds and Joseph Shister, Job Horizons: A Study of Job Satisfaction and Labor Mobility (Harper and Row, 1949); see especially table 1, p. 7. 
Table 6. Fractions of Population Reporting Pecuniary and Nonpecuniary Factors in Job Satisfaction, 1966

\begin{tabular}{lccccc}
\hline & & \multicolumn{4}{c}{ Workers by level of job satisfaction } \\
\cline { 3 - 6 } \multicolumn{1}{c}{ Item } & $\begin{array}{c}\text { All } \\
\text { workers }\end{array}$ & $\begin{array}{c}\text { Dislike } \\
\text { very much }\end{array}$ & $\begin{array}{c}\text { Dislike } \\
\text { somewhat }\end{array}$ & $\begin{array}{c}\text { Like } \\
\text { fairly well }\end{array}$ & $\begin{array}{c}\text { Like } \\
\text { very much }\end{array}$ \\
\hline $\begin{array}{l}\text { Factor liked most } \\
\quad \text { Nonpecuniary }\end{array}$ & 0.84 & 0.66 & 0.68 & 0.79 & 0.88 \\
$\quad \begin{array}{l}\text { Pecuniary } \\
\text { Pactor liked least }\end{array}$ & 0.16 & 0.34 & 0.32 & 0.21 & 0.12 \\
$\quad$ Nonpecuniary & 0.54 & 0.82 & 0.80 & 0.61 & 0.47 \\
Pecuniary & 0.15 & 0.17 & 0.18 & 0.19 & 0.11 \\
'Nothing'c & 0.31 & 0.01 & 0.02 & 0.20 & 0.42 \\
\hline
\end{tabular}

Source: Authors' calculations from the National Longitudinal Survey of Mature Men.

a. The following categories of response to the factor liked best were defined as nonpecuniary: like kind of work; have ability or capacity to do work; work is important, satisfying, challenging; type of work is interesting; own boss, independent; not much pressure or responsibility; work involves responsibility; seniority; hours; working conditions; supervision; company policy; congenial coworkers; good union; keeps me busy; meet interesting people; chance for advancement. The analogous categories were used in classifying responses to the factor liked least.

b. Pecuniary reasons include earnings, job security, steady work, fringe benefits.

c. Respondent could not name anything disliked.

According to our model, the overall level of job satisfaction changes over time; nonpecuniary factors contribute in an important way to shifts in worker satisfaction. The descriptive statistics reported in table 7 verify that these assumptions are reasonable. A significant fraction of the population, approximately 19 percent, experienced a change in attitude toward their job substantial enough for them to respond that they liked their jobs either better or worse in 1967 than in 1966. As would be expected, the great majority of job changers experienced a change in attitude; many stayers also experienced some change in satisfaction, including a significant number whose level of satisfaction declined.

In the multiple-job model described earlier, two factors determine the level of overall labor reward: wages and nonpecuniary rewards. Movements in both of these factors potentially contribute to variations in job satisfaction over time. Table 7 provides insight into the relative importance of pecuniary and nonpecuniary factors as causes of changes in job satisfaction. For the population as a whole, 75.6 percent of all individuals who experienced a change in attitude reported that the major reason for the change was nonpecuniary. Of those reporting a more favorable attitude in 1967, 73.7 percent indicated a nonpecuniary cause, while 82.6 percent of workers with lower job satisfaction cited a nonpecuniary reason. Even among individuals who quit to obtain wage increases, 
Table 7. Change in Attitude between 1966 and 1967 and Reasons for Change in Attitude by Mover Group

\begin{tabular}{|c|c|c|c|c|c|c|c|c|c|c|}
\hline \multirow[b]{3}{*}{ Item } & \multirow{2}{*}{\multicolumn{2}{|c|}{ Job stayers }} & \multicolumn{6}{|c|}{ Job quitters by reason } & & \\
\hline & & & \multicolumn{2}{|c|}{ Wages } & \multicolumn{2}{|c|}{$\begin{array}{c}\text { Non- } \\
\text { pecuniary }\end{array}$} & \multicolumn{2}{|c|}{ Exogenous } & \multicolumn{2}{|c|}{ Job losers } \\
\hline & $\begin{array}{l}\text { Like } \\
\text { more }\end{array}$ & $\begin{array}{l}\text { Like } \\
\text { less }\end{array}$ & $\begin{array}{l}\text { Like } \\
\text { more }\end{array}$ & $\begin{array}{l}\text { Like } \\
\text { less }\end{array}$ & $\begin{array}{l}\text { Like } \\
\text { more }\end{array}$ & $\begin{array}{l}\text { Like } \\
\text { less }\end{array}$ & $\begin{array}{l}\text { Like } \\
\text { more }\end{array}$ & $\begin{array}{l}\text { Like } \\
\text { less }\end{array}$ & $\begin{array}{l}\text { Like } \\
\text { more }\end{array}$ & $\begin{array}{l}\text { Like } \\
\text { less }\end{array}$ \\
\hline $\begin{array}{l}\text { Fraction of worker } \\
\text { with change in } \\
\text { attitude }\end{array}$ & 0.11 & 0.06 & 0.81 & 0.00 & 0.66 & 0.09 & 0.47 & 0.16 & 0.36 & 0.18 \\
\hline $\begin{array}{l}\text { Reason for change } \\
\text { in attitude }\end{array}$ & & & & & & & & & & \\
\hline Nonpecuniary & 0.76 & 0.87 & 0.24 & n.a. & 0.65 & 0.50 & 0.77 & 0.75 & 0.83 & 0.64 \\
\hline Pecuniary & 0.23 & 0.13 & 0.76 & n.a. & 0.35 & 0.50 & 0.23 & 0.25 & 0.17 & 0.36 \\
\hline
\end{tabular}

24 percent believe that the major reason they like their new job more is nonpecuniary. Clearly, nonpecuniary factors explain much of the variance in job satisfaction for individual workers over time.

The attitudinal patterns that characterize mature American males are not atypical for the population as a whole. Herbert Parnes reports comparable findings for young men. ${ }^{60}$ For example, 76.2 percent of young men aged 16-24 state that liking the work is more important than good wages, and a mere 12.9 (13.1) percent of young men cite pecuniary factors as the thing they like best (least) about their jobs. The young men are slightly less satisfied with their jobs overall than the mature men: 48.7 percent indicate that they like their current job very much, while 9.7 percent report that they dislike their jobs somewhat or very much.

\section{THE SIZE AND VARIABILITY OF SPECIFIC NONPECUNIARY REWARDS}

The previous section established the general importance of nonpecuniary rewards as a determinant of job satisfaction. However, our

60. See Herbert S. Parnes, Robert C. Miljus, Ruth S. Spitz, and Associates, Career Thresholds, vol. 1, Department of Labor, Manpower Administration, Manpower Research Monograph 16 (GPO, 1970). 
argument - that job switches enhance welfare, and that movements in nonpecuniary rewards generate turnover-is premised on the assumption that there is an important specific component to nonpecuniary rewards. More precisely, our variable $x$ measures the difference in nonpecuniary rewards between the current job and other jobs for which the worker is qualified. Nonpecuniary rewards to work could be large, but the job-specific component of these rewards small, if, for example, the typical worker receives pleasure from working because it makes him or her feel socially useful, but all jobs for which a worker is qualified would provide this same psychic reward. We thus need to establish that there is an important specific nonpecuniary reward to work-that the typical worker perceives qualitative differences, either positive or negative, between his current job and others for which he is qualified. There are many possible reasons why a current job might not be regarded as identical to a similar alternative at another firm: feelings of appreciation or underappreciation by colleagues or supervisors, especially good or poor management, personnel policies perceived as especially fair or unfair, and coworkers or bosses regarded as especially amiable or disagreeable.

An ideal measure of the specific nonpecuniary reward realized by a worker would be the amount that the worker would be willing to pay to avoid a shift to another job of the same generic type at a new firm. A worker who is willing to pay to avoid switching firms is clearly capturing surplus on his current job. It turns out this ideal measure of specific nonpecuniary rewards is available in the National Longitudinal Survey. In 1966 and 1971, all employed respondents in the NLS were asked the following question: "Suppose someone IN THIS AREA offered you a job in the same line of work you're in now. What would the wage or salary have to be for you to be willing to take it?' If one subtracts the current wage from the respondent's answer, and then divides by the current wage (if multiplied by 100), the resulting number gives the percentage increase in pay that the respondent would require to shift employment to another firm in the same area in the same line of work. This can be used as a measure of the individual's specific nonpecuniary reward, denoted $N P R$. The question is specifically worded to avoid considerations of geographical mobility or occupational switches. ${ }^{61}$

61. For a detailed discussion of this measure, see Herbert S. Parnes and others, The Pre-Retirement Years (Ohio State University, Center for Human Resource Research, 
The Cross-Sectional Distribution of Nonpecuniary Rewards. How large are the specific nonpecuniary rewards earned by mature male workers? Of the 4,012 mature men answering the question in 1966, 1,854 gave a precise numerical response. For these individuals, the mean value of $N P R$ was 36 percent, while the median value was 25 percent. Ten percent of these respondents have negative values of $N P R$, indicating their willingness to take pay cuts in order to switch jobs. Another 10 percent of this group required a wage increase in excess of 75 percent to switch to a new firm. An additional 2,158 men were unable or unwilling to specify a precise figure. Their responses were grouped into the following categories: 1,717 individuals (42.8 percent of total respondents) said that they "would not take a job at any pay"; 181 respondents (4.5 percent) said that they "would take a steady job at the same or less pay"; 47 respondents (1.2 percent) said that they "would accept a job offer"; and 213 responses were classified as "other" or "don't know."

Given the large group of individuals expressing the sentiment that they "would not move at any pay" and the smaller but still significant percentage indicating a willingness to move at the same or less pay, it is clear that the characteristics of the distribution of NPR in the population would be distorted if one were to ignore respondents not giving a numerical answer to the question.

One way of characterizing the distribution of $N P R$ in the population as a whole is to use an arbitrary but sensible method to convert the qualitative responses given by so many respondents into quantitative ones. We have done this in several ways. One simple scheme is as follows: treat individuals who "would not move at any pay" as requiring a 100 percent pay hike to move; treat individuals who "would accept a steady job at the same or less pay" and also those who "would accept" as being willing to accept a 10 percent pay cut; and treat other responses as having zero $N P R$ on average. This simple, but arbitrary, aggregation scheme produces a distribution of $N P R$ in the population with the following characteristics: the mean value of $N P R$ is 54 percent; the median value of $N P R$ is 42.9 percent; 10 percent of the population is

1968), pp. 147-68; and Herbert S. Parnes and Ruth S. Spitz, "A Conceptual Framework for Studying Labor Mobility," Monthly Labor Review, vol. 92 (November 1969), pp. 5558. Parnes refers to this measure as an index of "attachment" and uses it to explain mobility patterns. A follow-up question asks the respondent what the wage or salary would have to be for him to be willing to take a job in the same line of work in a different geographical area. 
willing to accept a pay cut; and 1 percent would require a pay increase in excess of 150 percent to switch jobs. A more conservative aggregation scheme, for example assigning a lower $N P R$ value to those "unwilling to move at any wage," results in a reduction in the mean of NPR. It is noteworthy that the mean value of $N P R$ exceeds the mean nonpecuniary return generated by the simulation model, thus suggesting that the addition to Okun's Law is understated in the presentation of our model. ${ }^{62}$

The aggregation scheme described above is convenient but arbitrary. Accordingly, in the statistical analysis discussed below, we have also used a dummy variable approach, in which qualitative and quantitative answers are treated separately. It turns out, however, that all of the analysis is robust to the method used to measure NPR; one cannot statistically reject the appropriateness of the arbitrary aggregation scheme that we have chosen.

Other studies provide further support for the finding that a significant fraction of workers earn large positive specific nonpecuniary rewards, but that a nonnegligible number of individuals earn negative nonpecuniary rewards. For example, Herbert Parnes and others found that the distribution of nonpecuniary rewards for young men aged 16-24 in the NLS of 1966 was similar to that of mature men but with a lower mean, as would be expected ${ }^{63}$ In a recent survey by the consulting firm Towers, Perrin, Forster, and Crosby, 29 percent of 10,000 employees sampled in 10 companies said that they would consider taking a job elsewhere at the same pay. ${ }^{64}$ A survey of middle managers compiled by the National Institute for Business Management found that approximately 35 percent felt they " would be happier elsewhere," and over three quarters of these

62. The addition to Okun's Law is further underestimated in the section of our paper where we present our model if there is a general, as well as a specific, nonpecuniary reward to work.

63. Of young men not in school, 22.4 percent said they "would accept at the same or a lower wage"; 8.7 percent indicated a willingness to move for a wage increase less than 10 percent; 43 percent would accept for a wage increase of $10-50$ percent; 9.9 percent indicated a willingness to move for a wage increase of more than 50 percent; and 16 percent said they would not accept at any conceivable wage; see Parnes, Miljus, Spitz, and Associates, Career Thresholds, vol. 1, p. 151.

64. See Towers, Perrin, Forster, and Crosby, Inc., "The National Employee Attitude Survey: What Employees Think About Their Jobs . . . Their Supervisors . . . And Their Employers"' (October 1987), p. 7. 
gave a nonpecuniary reason for their dissatisfaction. ${ }^{65}$ Twenty percent said they would be willing to take a cut in pay to move. ${ }^{66}$

The Variance of Nonpecuniary Rewards over Time. An important assumption of our model is that specific nonpecuniary rewards vary over time for an individual in a given job. Our benchmark simulations assume that the standard deviation of the change in the nonpecuniary reward $(x)$ relative to the mean wage is 0.1 . Is this assumption realistic?

In fact, statistics from the NLS show this assumption to be conservative. As mentioned above, data on NPR are available for employed individuals for 1966 and 1971. For individuals providing a numerical answer to the question in both years, the sample standard deviation of the change in $N P R$ over the five-year period is 0.81 . This implies an annual standard deviation of $N P R$ of $0.36(0.81 / \sqrt{5})$. For individuals who stayed in the same job over the five-year period, the annual standard deviation of the change in NPR is 0.42 . These figures become substantially larger if one uses the aggregation scheme for converting qualitative responses described above and somewhat smaller accounting for the possibility of white-noise measurement error. ${ }^{67}$

65. National Institute for Business Management, "Personal Report for the Executive: Responses to Survey On Middle Managers," August 1, 1987, p. 6.

66. One question that arises in our use of $N P R$ as a measure of nonpecuniary rewards is the possibility that positive values of $N P R$ merely indicate the avoidance of a one-time moving cost, rather than a flow of nonpecuniary returns in the current job. First and foremost, the wording of the question was specifically designed to avoid such considerations. Further, a number of empirical features of $N P R$ militate against this interpretation. First, the variance of $N P R$ over time would be zero if $N P R$ reflected a moving cost; we show below that the variance of $N P R$ over time is large. Second, NPR would not be correlated with satisfaction in this event; in fact, as we show, NPR and wages are of comparable importance in explaining satisfaction. Third, one would not expect to observe negative values of NPR; in fact, the fraction of individuals with negative $N P R$ is in agreement with our simulated model. Fourth, one would not expect to see individuals switch jobs for nonpecuniary reasons, realizing low or negative wage changes, if $N P R$ merely represents an "exit fee"; in fact, there are many such individuals. Finally, and most important, it is difficult to rationalize the enormous size of job switching by focusing solely on pecuniary factors; the existence of "exit fees" would explain why people do not switch jobs and not why people do switch jobs so frequently.

67. The calculation of the annual standard deviation is based on our theoretical assumption that increments to NPR are independent. In fact, computation of the correlation between the change in NPR and its level in 1966 yields a statistically significant negative correlation of 0.3 . This implies that our calculation overestimates the standard deviation of NPR. The negative correlation between NPR and the change in NPR could be due either to measurement error in NPR or to a tendency for $N P R$ to behave in a slightly 


\section{The Causes and Consequences of Quits}

Why do quits occur? Do quitters end up better off? What are the consequences of quitting for wages and nonpecuniary rewards? Our model offers predictions concerning all of these questions. The empirical analysis described in this section establishes the validity of these predictions.

Before turning to this analysis, we begin with a review of the antecedent literature. The next subsection provides an overview of our findings concerning the causes and consequences of quits for mature men in the National Longitudinal Survey. The final subsection presents our econometric analysis of quits and subsequent rewards. Appendix B analyzes the robustness of these results.

\section{THE PREVIOUS LITERATURE}

The empirical work that follows uses data from the National Longitudinal Survey concerning workers' job satisfaction. The very existence of the NLS is a consequence of the work of a generation of labor market scholars whose studies of mobility were based on interviews primarily with workers and, less commonly, with management and union leaders. ${ }^{68}$

autoregressive fashion. Assuming that the negative correlation is due solely to white-noise measurement error implies that the standard deviation of the change in NPR for stayers is 0.29 instead of 0.42 a year.

68. See, among others, Sumner H. Slichter, The Turnover of Factory Labor (D. Appleton and Company, 1919); Clark Kerr, "Migration to the Seattle Labor Market Area, 1940-1942," University of Washington Publications in the Social Sciences (August 1942); Gladys Louise Palmer, Labor Mobility in Six Cities: A Report on the Survey of Patterns and Factors in Labor Mobility (Social Science Research Council, 1954); Reynolds and Shister, Job Horizons; Margaret Gordon, "The Mobility of San Francisco Workers, 1940-1949" (University of California Institute of Industrial Relations, Berkeley, November 1951); Charles A. Myers and George P. Schultz, The Dynamics of a Labor Market (Prentice-Hall, 1951); Charles A. Myers and W. Rupert Maclaurin, The Movement of Factory Workers: A Study of a New England Industrial Community, 1937-39 and 1942 (Wiley \& Sons, Inc., 1943); Herbert S. Parnes, Research on Labor Mobility: An Appraisal of Research Findings in the United States (Social Science Research Council, 1954); Reynolds, The Structure of Labor Markets; E. Wight Bakke and others, Labor Mobility and Economic Opportunity (Technology Press and John Wiley \& Sons, 1954); and W. S. Woytinsky, Three Aspects of Labor Dynamics (Social Science Research Council, 1942). 
There were two schools of thought concerning the causes of mobility: one was that workers pursue only pecuniary goals; the other, that workers' decisions were motivated by nonpecuniary concerns. This work conclusively showed that a good fraction of labor mobility, both voluntary and involuntary, resulted in wage losses.

In his careful review of the literature, including five studies that specifically involved voluntary shifts, Parnes lists the fraction of workers taking wage cuts. ${ }^{69}$ In a study of New Haven manual workers, 52 percent of workers quitting their jobs from 1945 to 1948 took a cut in their gross weekly take-home pay..$^{70}$ In a study of Fitchburg workers voluntarily shifting between manufacturing and utilities from 1937 to 1939,30 percent took a cut in hourly earnings. ${ }^{71}$ In a study of Minneapolis workers mobile between 1947 and 1948, 32 percent took a cut in hourly wages; from 1943 to 1948,11 percent took a cut in hourly wages. ${ }^{72}$ In a survey of workers in six different cities, 19 percent of voluntary shifts for "better wages or advancement" resulted in wage cuts. ${ }^{73}$

The common occurrence of wage loss in voluntary movements suggests that much voluntary movement is for nonpecuniary reasons, a conclusion supported also by Parnes's review of the literature. He tabulates results from nine samples. Of these, the maximum fraction of workers reporting voluntary separation for wages or other economic reasons was 42 percent; the minimum was 11 percent. Of the nine samples, the maximum fraction reporting voluntary separation for "intrinsic nature of job" or "human relations factors" was 61 percent and the minimum was 9 percent. (In the last sample 47 percent reported leaving for reasons that could not be classified by Parnes as either wage or "nonpecuniary.") Thus a significant number of extant studies have found that a sizable fraction of voluntary separations involves wage cuts and is motivated by nonpecuniary reasons. It is also important to note that the questions we analyze from the National Longitudinal Survey are not isolated curiosities but are rather the culmination of 30 years of work by scholars who were, in two senses, in the field.

69. See Parnes, Research on Labor Mobility, p. 176.

70. Reynolds, The Structure of Labor Markets.

71. Myers and Maclaurin, Movement of Factory Workers.

72. Herbert G. Heneman, Jr., Harland Fox, and Dale Yoder, "Patterns of Manpower Mobility: Minneapolis, 1948," University of Minnesota Industrial Relations Center Bulletin No. 10, pp. 1-28.

73. See Myers and Shultz, Dynamics of a Labor Market. 
The role of nonpecuniary factors in explaining labor mobility has been emphasized in more recent work using cross-sectional data sets. Ann Bartel and George Borjas, using NLS data, have modeled the probability that an individual will quit his or her job and have demonstrated the significance of job satisfaction variables. ${ }^{74}$ Peter Gottschalk and Tim Maloney, Gregory Duncan, and Martin David have provided econometric evidence of the role of nonpecuniary factors in quit decisions using data from the Panel Study on Income Dynamics. ${ }^{75}$ Richard Freeman has estimated quit equations in a variety of cross sections and shown that the addition of job satisfaction measures raises explanatory power. ${ }^{76}$ Finally, Bartel and Borjas and Gottschalk and Maloney have shown that quits lead to significantly greater improvements in job satisfaction than involuntary separations do, and Bartel and Borjas provide evidence that many of these gains are nonpecuniary. ${ }^{77}$ Our work is complementary to that of these authors, although our econometric methodology differs from theirs.

\section{SUMMARY OF FINDINGS FROM THE NLS MATURE MALE SAMPLE}

Table 8 presents descriptive statistics from the mature male sample of the NLS concerning the characteristics of movers and stayers, as well as the gains they achieved in wages and total satisfaction for various subperiods between 1966 and 1971. In certain contexts, simple descrip-

74. See Ann P. Bartel, "Wages, Nonwage Job Characteristics, and Labor Mobility," Industrial and Labor Relations Review, vol. 35 (July 1982), pp. 578-89; Ann Bartel and George J. Borjas, "Wage Growth and Job Turnover: An Empirical Analysis," in Sherwin Rosen, ed., Studies in Labor Markets (University of Chicago Press, 1981), pp. 65-90; and Ann P. Bartel and George J. Borjas, "Middle-Age Job Mobility: Its Determinants and Consequences," in Seymour Wolfbein, ed., Men in the Pre-Retirement Years (Temple University Press, 1977), pp. 39-97.

75. See Peter Gottschalk and Tim Maloney, "Involuntary Terminations, Unemployment, and Job Matching: A Test of Job Search Theory," Journal of Labor Economics, vol. 3 (April 1985), pp. 109-22; Gregory Duncan, "Nonpecuniary Work Rewards," in Morgan, ed., Five Thousand American Families: Patterns of Economic Progress, vol. 2; David, "The Dynamics of Family Labor Supply Decisions: Quitting and Relocating as Family Unit Decisions.",

76. See Richard Freeman, "Job Satisfaction as an Economic Variable," American Economic Review, vol. 68 (May 1978, Papers and Proceedings, 1977), pp. 135-42.

77. See Bartel and Borjas, "Middle-Age Job Mobility"; and Gottschalk and Maloney, "Involuntary Terminations, Unemployment, and Job Matching." 
tive statistics may be misleading. However, the econometric analysis of the next section shows that the picture of reality conveyed by these statistics is warranted. In fact, the information in table 8 provides an excellent summary of our findings.

Who Quits and Why? As table 8 shows, 57 percent of all quitters in our sample reported job-related motives for quitting. Approximately 75 percent of this group were primarily motivated by nonpecuniary reasons; the remaining 25 percent were primarily concerned with wages. Individuals with low base-year rewards, either pecuniary or nonpecuniary, have high propensities to quit. In the econometric model of the next section the probability of a job-related quit is seen to depend on the sum of the individual's wage (in excess of the mean of his alternatives) and his nonpecuniary reward. It is apparent in table 8 that quitters for nonpecuniary reasons between 1966 and 1967 and between 1966 and 1969 had significantly lower nonpecuniary income in 1966 than a control group of stayers. ${ }^{78}$ Similarly, wage-quitters had significantly lower base-period wages than stayers in every subperiod. In several of the subperiods, wage-quitters had below-average nonpecuniary rewards, while nonpecuniary quitters also had below-average wages. Indeed, as a group, the job-related quitters had below-average wage and nonpecuniary rewards, as is consistent with our model.

An individual's expressed satisfaction is a summary statement of his overall feelings about his job, and in principle the level of satisfaction provides a measure of an individual's total reward from work. Indeed, according to the econometric results of the next section, quit behavior depends on the sum of wage and nonpecuniary income; and satisfaction is a monotonic, discrete function of this sum. In every year for which data are available, both subgroups of job-related quitters (and the group as a whole) described themselves as more dissatisfied with their jobs, on average, than the control group of stayers. This correlation is not significant, however, for every subgroup in every subperiod.

Do Quitters Gain? According to table 8, job-related quits result in gains in overall labor income. Two measures of changes in overall well-

78. It is worthwhile noting that while the mean $N P R$ of nonpecuniary job quitters was significantly below that of stayers, it is significantly positive. This fact suggests that this group of quitters most likely had ex ante information that the nonpecuniary rewards in their new jobs would be higher. In contrast, our model assumed that the ex ante expectation of the nonpecuniary reward on a new job was zero for jobseekers. 


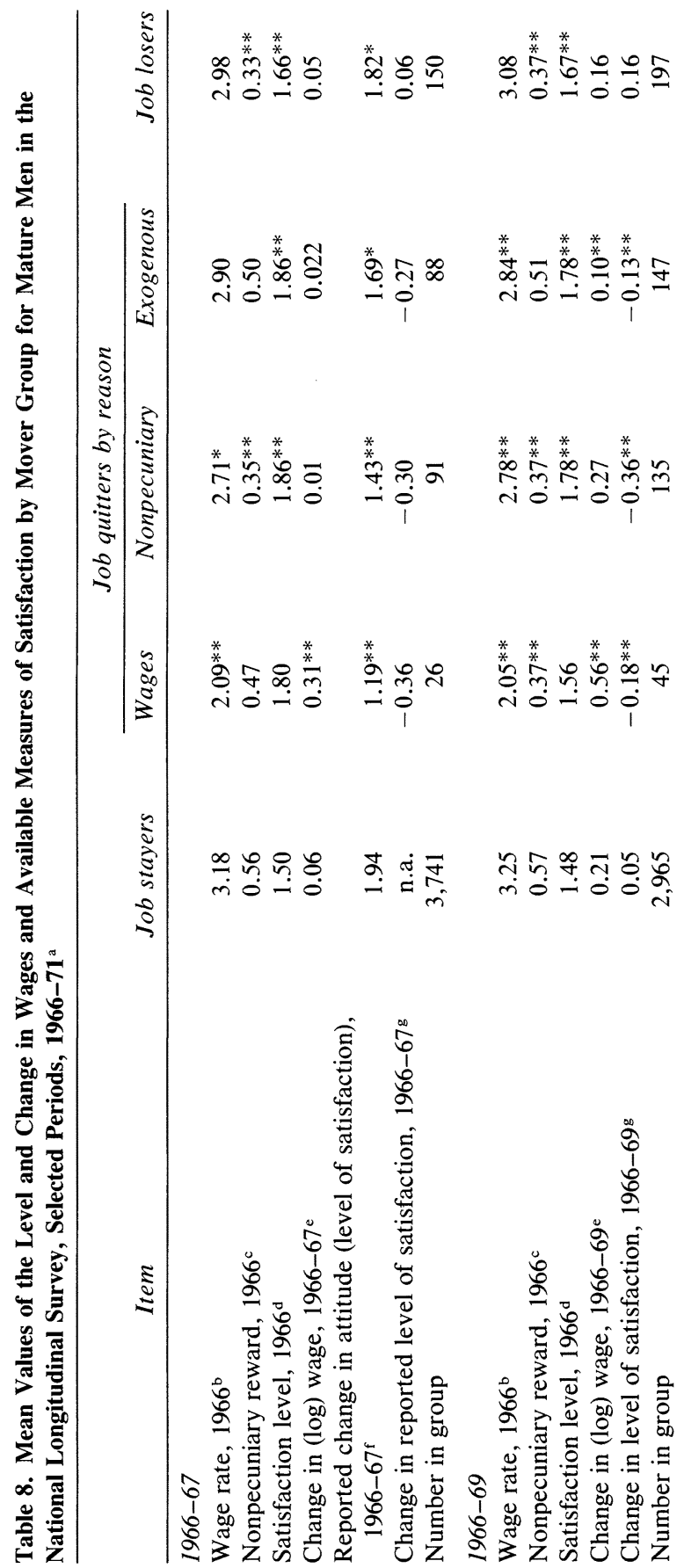




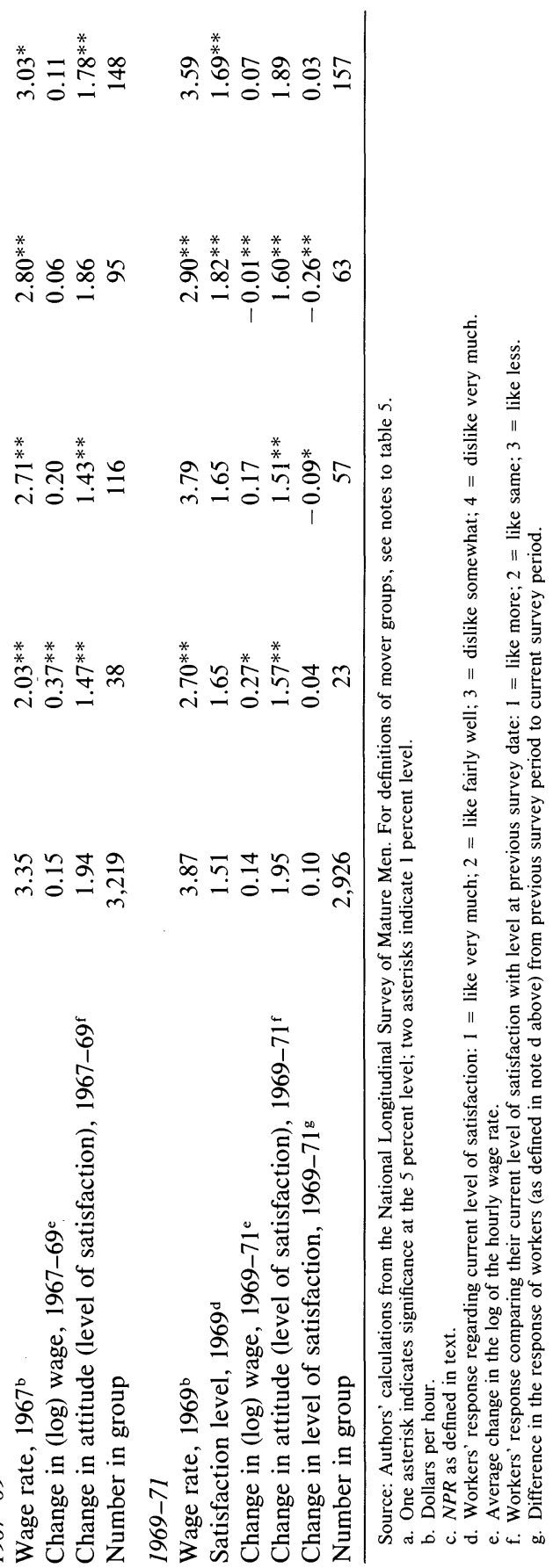


being can be calculated from data in the NLS; in most subperiods only one of these measures is available, the 1969-71 period being the only exception. The first measure is the respondent's answer in the terminal year to a question asking whether he likes his current job the same, more, or less than his job on the previous survey date. The second measure is the difference between the respondent's satisfaction level in his terminal-year interview and the level of satisfaction expressed earlier, in the base-year interview. The two measures are not equally useful in assessing the gains from quitting: the first measure is conceptually superior to the second.

In answering the question that is the basis of the first measure (a question asked in the terminal year about the respondent's comparative well-being in his current and previous job), a mover is likely to compare his current feelings with those he had immediately prior to his departure from his previous job. In contrast, the second measure of gain takes as its base the mover's feelings about the base-year job, not at the time of departure, but at the time of the base-period interview, which may have occurred well before departure. In our model, opportunities take time to appear; therefore on every survey date some respondents will already be dissatisfied with their jobs. These individuals will be waiting for a chance to move. The dissatisfaction of these respondents would accordingly be registered in their base-year answer to the satisfaction question. But if nonpecuniary rewards are stochastic, as we assume, other respondents will become dissatisfied with their jobs subsequent to the base-year survey; a fraction of this latter group will succeed in moving prior to the terminal-year survey. During the period between interviews, the first group quit jobs considered unsatisfactory at the time of their base-year interview. In contrast, the second group left jobs with which they became unhappy only after the base-period interview took place. In terms of our model, the first group already had a low $x$ at the time of their base-year interview, and this second measure of the change in satisfaction should show an improvement; however, the second group experienced negative shocks to $x$ after their base-year interview, and thus they are likely to appear less satisfied according to this same measure even if their job switch actually raised their nonpecuniary reward.

The second measure of the change in satisfaction of quitters, which 
records changes in satisfaction between interview dates, is ambiguously signed; at a minimum, it gives an underestimate of the gains from quits. This underestimate increases with the length of the period between interviews. Indeed, for the long period, 1966-71, there is no significant difference in the 1966 level of NPR between job-related quitters and stayers.

Our preferred measure of the gains from a job-related quit is available for the periods 1966-67, 1967-69, and 1969-71. In each of these subperiods, both wage-quitters and nonpecuniary quitters experienced a significantly greater increase in satisfaction than the control group of stayers did. The differences are, in all instances, significant at the 1 percent level. Our less preferred index of change in satisfaction is available for 1966-69, 1969-71, and, for job switchers only, for 1966-67. The hypothesis that movers gain is also supported, albeit as we expect, with lower statistical significance, using this measure. For the periods 1966-69 and 1969-71 both job-related quitter groups achieved larger gains in satisfaction than stayers. The differences for 1966-69 are significant at the 1 percent significance level; for the period 1969-71 the gain for wage quitters is statistically insignificant. For the period 1966-67 both job-related quitter groups register improvements in satisfaction. A comparable figure is unavailable for stayers; however, in all other periods for which data are available, stayers registered a decline in satisfaction according to this measure.

Why Do Quitters Gain? Table 8 provides evidence that higher wages are neither the exclusive goal nor the inevitable consequence of jobrelated quits. No single subperiod has a statistically significant difference between the wage gains of nonpecuniary quitters and those of stayers. For three of the four subperiods, the average gain in wages was slightly higher for nonpecuniary quitters than for stayers. However, in each subperiod, a significant fraction of nonpecuniary quitters took nominal wage cuts: 32.8 percent in $1966-67 ; 16.5$ percent in $1966-69 ; 16.3$ percent in 1967-69; and 30.6 percent in 1969-71. In contrast, the far less numerous wage-quitters did indeed achieve wage gains; this group had significantly higher wage gains than stayers in every subperiod. These results are in close accord with the predictions of our multiple-job model. In the baseline simulations of that model with a 5 percent unemployment rate, 8.5 percent of E-E quits entailed wage cuts; 18.7 percent occurred at the 
same wage; and 72.8 percent involved wage increases. Moreover, jobrelated quits occurred more frequently among individuals receiving below-average wages and nonpecuniary rewards.

Exogenous Quitters and Job Losers. Our theoretical model and empirical work focus primarily on the causes and consequences of jobrelated quits. Table 8 , however, provides information as well on the characteristics of individuals who quit their jobs for exogenous reasons or who experienced involuntary job loss. These findings are worthy of brief discussion.

Exogenous quitters include all individuals employed in both the base and terminal interviews who left their base-year job because of family or personal reasons, location, moving, health, retirement, and "other." These exogenous quitters appear remarkably similar in their characteristics to the group of nonpecuniary quitters although the differences between them and the stayers are considerably less pronounced. Exogenous quitters report insignificantly lower base-year nonpecuniary rewards but significantly lower satisfaction than stayers. In every period this group took a significant cut in pay in comparison with those who remained in the same job and, like the job-related quitters, reported themselves more satisfied on average following their moves. This finding is not surprising; consider the situation of individuals who cite health as their reason for quitting (a large fraction of this sample). An individual in poor health, whose work requires physical exertion, is likely to feel dissatisfied with his job. An improvement in satisfaction and, most likely, a cut in pay are the expected consequences of a switch to less physically demanding labor. Because the individual's dissatisfaction is not with his firm but rather with his occupation, the individual may report a baseyear value of $N P R$ - the specific nonpecuniary reward-close to the population average.

The statistics in table 8 concerning job losers are at first glance surprising: they suggest that job losers suffer small losses. In every period summarized in table 8 , job losers experienced lower wage growth than stayers, but the differences are not statistically significant. When questioned ex post, the job losers more frequently report being better off than the control group of stayers. And before losing their jobs, this group appears dissatisfied, reporting significantly lower nonpecuniary rewards and satisfaction than the control group of stayers. Upon reflection, these results are not surprising; they suggest that workers in jobs 
that are soon to be terminated are unhappy, either because they are aware that they are soon to be laid off or because their firm's ill fortunes affect work conditions. When workers reflect on their feelings toward their old and new jobs after they have gained employment, they consider themselves lucky to be employed in a job that is less insecure. Our findings concerning nonpecuniary rewards and job losers mirror those of Christopher Ruhm concerning wages.$^{79} \mathrm{He}$ found that job losers with one to nineteen years of tenure in the Panel Study of Income Dynamics did not lose earnings following permanent layoff.

\section{BENCHMARK ECONOMETRIC RESULTS}

Our model has emphasized the importance of nonpecuniary rewards as a significant component of job satisfaction, and therefore of a worker's propensity to quit. However, we have not yet rigorously tested the hypotheses that both pecuniary and nonpecuniary returns are relevant, and equally so, in determining both quit decisions and worker satisfaction. This section of the paper formally tests these hypotheses. The nonrejection of these hypotheses suggests that $N P R$ is a good measure of the flow of nonpecuniary rewards, corresponding to $x$ in the theoretical model.

We focus on the first five years of data from the cohort of mature men of the NLS to minimize the effects of "truncation bias" due to dropouts from the sample and due to permanent departures from the labor force because of retirement and death.

The Empirical Framework. The two preceding hypotheses can be tested with just two equations. "Separation" equations link quit behavior to the pecuniary and nonpecuniary returns to work and to the unemployment rate. "Satisfaction" equations relate worker satisfaction to pecuniary and nonpecuniary rewards.

The basic separation equation to be estimated takes the form:

$$
P\left(Q_{i t}\right)=f\left[\left(N P R_{i t}^{C}-\overline{N P R}_{i t}\right),\left(W_{i t}^{C}-\bar{W}_{i t}\right), u_{i t}\right]+\epsilon_{i t},
$$

where $P\left(Q_{i t}\right)$ is the probability that individual $i$ will quit the job he holds at time $t$ over a specified period thereafter; $N P R_{i t}^{C}$ represents the

79. See Christopher J. Ruhm, "Seniority, Experience, and Earnings" (Boston University, July 1986). 
nonpecuniary reward in the current job; $\overline{N P R}_{i t}$ is the mean nonpecuniary reward in alternative jobs for which the individual is qualified; $W_{i t}^{C}$ denotes the pecuniary reward in the current job; $\bar{W}_{i t}$ denotes the mean pecuniary reward in alternative jobs for which the individual is qualified; $u_{i t}$ is a measure of labor market slack; and $\epsilon$ denotes a white-noise disturbance. ${ }^{80}$

According to our theoretical model, individuals are always on the lookout for superior jobs and will accept any job with a higher total reward. The probability of receiving such an offer during a specified interval depends on the individual's relative position in the distribution of total rewards and the degree of slack in the labor market. Accordingly, the separation equation lets the probability of a job-related quit depend negatively on the worker's current reward from work relative to the mean reward in alternative jobs and the unemployment rate. In principle, pecuniary and nonpecuniary rewards are of equal importance to the worker's decision; we shall test this hypothesis.

The satisfaction equation takes the form

$$
S A_{i t}=g\left(W_{i t}^{C}, N P R_{i t}^{C}\right)+\eta_{i t},
$$

where $S A$ denotes the level of worker satisfaction and $\eta$ is a white-noise disturbance representing a composite of additional factors affecting the individual's level of well-being. Clearly, both pecuniary and nonpecuniary rewards should have a positive (and in our theoretical model, equal) effect on worker satisfaction.

The regressands of both the separation and the gain equations are discrete variables. Individuals either quit their jobs or do not; the NLS data on job satisfaction classify workers as liking their jobs very much or fairly well or disliking their jobs somewhat or very much. In consequence, all equations will be assumed to be linear and estimated with maximum likelihood, limited-dependent variable techniques unless otherwise noted.

Benchmark Results on Separations. Estimation of the separation equation requires measures of the current pecuniary and nonpecuniary rewards of the worker, not in levels, but as (percentage) deviations from the rewards that the worker could earn in other jobs. The variable NPR,

80. In addition to the unemployment rate, the rate of autonomous vacancy creation in the individual's labor market should also be included in equation 12. Unfortunately, we have no data on this variable. 
defined above as the amount that the worker would be willing to pay to avoid having to shift to another job of the same generic type but at a new firm, provides the required measure of the "excess" nonpecuniary reward in the current job. This measure is available for the years 1966 and 1971.

Estimation of the separation equation, equation 12, also requires a measure of the average pecuniary reward potentially available to the worker in other jobs. To provide an observable counterpart for this variable, we initially hypothesize that average earnings are given by

$$
\bar{W}_{i t}=h\left(H K_{i t}\right)+\mu_{i t},
$$

where $H K$ denotes the human capital and other personal characteristics of individual $i$ at time $t$, and $\mu$ denotes a white-noise disturbance that affects the earnings, of individual $i .^{81}$

Substitution of equation 14 into equation 12 yields an estimable equation:

$$
P\left(Q_{i t}\right)=f^{\prime}\left[N P R_{i t}, W_{i t}^{C}, H K_{i t}, u_{i t}\right]+\epsilon_{i t}^{\prime} .
$$

Table 9 reports estimations of this equation over two sample periods1966-67 and 1966-69. The sample was restricted to include only wage and salary workers who were employed in both the base year of 1966 and the terminal year of either 1967 or 1969; only those who meaningfully answered the relevant questions in the base-year and terminal surveys were included. The dependent variable is a binary variable, equal to one if the individual quit between the base- and terminal-year surveys one or more times for any job-related reason (whether the primary reason for quitting was dissatisfaction with wages or with nonpecuniary aspects of the job), ${ }^{82}$ and equal to zero if the individual remained in the same job

81. Conceivably, wages may be set as compensating differentials for specific nonpecuniary returns. Firms, noticing that individuals who receive high nonpecuniary returns are less liable to quit, could exploit this fact by lowering pecuniary rewards. In this case $N P R$ would affect wages; our theoretical assumption that wages are exogenous with respect to $N P R$ would be inappropriate. We have tested for this possibility and find that $N P R$ does not significantly affect the individual's wage rate (or the difference between the individual's current and mean alternative wage controlling for human capital and personal characteristics). We thus find no evidence of compensating differentials of this type.

82. This group includes all individuals previously defined as wage-quitters and nonpecuniary quitters, as well as any individuals with multiple quits, some of which were due to wage and some of which were due to nonpecuniary causes; these individuals could not be classified either as wage or nonpecuniary quitters for the relevant period. 
Table 9. Probit Estimates of the Benchmark Separation Equation, 1966-67 and 1966-69a

\begin{tabular}{|c|c|c|c|c|c|c|}
\hline \multirow[b]{3}{*}{ Independent variable } & \multicolumn{6}{|c|}{ Period } \\
\hline & \multicolumn{3}{|c|}{$1966-67$} & \multicolumn{3}{|c|}{$1966-69$} \\
\hline & \multicolumn{2}{|c|}{ Coefficient $^{\mathrm{b}}$} & Semielasticity & \multicolumn{2}{|c|}{ Coefficient $^{\mathrm{b}}$} & Semielasticity \\
\hline Constant & 2.39 & $(1.25)$ & & 3.95 & $(1.14)$ & \\
\hline Current wage & -0.43 & $(0.17)$ & -0.019 & -0.66 & $(0.15)$ & -0.060 \\
\hline$N P R$ & -0.39 & $(0.16)$ & -0.017 & -0.39 & $(0.14)$ & -0.035 \\
\hline Local unemployment & -0.003 & $(0.004)$ & -0.0001 & -0.002 & $(0.004)$ & -0.0002 \\
\hline Education & -0.05 & $(0.03)$ & $\ldots$ & -0.03 & $(0.03)$ & $\ldots$ \\
\hline Experience & -0.02 & $(0.02)$ & $\ldots$ & -0.04 & $(0.01)$ & $\ldots$ \\
\hline Race & -0.48 & $(0.18)$ & $\ldots$ & -0.42 & $(0.15)$ & $\ldots$ \\
\hline Health & -0.12 & $(0.46)$ & $\ldots$ & 0.10 & $(0.33)$ & $\ldots$ \\
\hline House & -0.25 & $(0.16)$ & $\ldots$ & -0.16 & $(0.13)$ & $\ldots$ \\
\hline Married & -0.12 & $(0.21)$ & $\ldots$ & 0.32 & $(0.24)$ & $\ldots$ \\
\hline City & 0.04 & $(0.16)$ & $\ldots$ & -0.05 & $(0.13)$ & $\cdots$ \\
\hline South & -0.22 & $(0.32)$ & $\ldots$ & -0.34 & $(0.28)$ & $\ldots$ \\
\hline \multicolumn{7}{|l|}{ Summary statistic } \\
\hline Number of observations & 1766 & & & 1419 & & \\
\hline McFadden's $R^{2}$ & 0.07 & & & 0.07 & & \\
\hline Fraction correct & 0.98 & & & 0.95 & & \\
\hline \multicolumn{7}{|l|}{ Hypothesis test ${ }^{\mathrm{c}}$} \\
\hline Slopes (11) & $28.32^{* *}$ & & & $43.69^{* *}$ & & \\
\hline Rewards (2) & $12.10^{* *}$ & & & $27.82^{* *}$ & & \\
\hline Equal (1) & 0.04 & & & 1.98 & & \\
\hline
\end{tabular}

Source: Authors' calculations using data from the National Longitudinal Survey of Mature Men.

a. The dependent variable is 1 if the individual quit his job one or more times during the period for a job-related reason and 0 otherwise.

b. Standard error in parentheses.

c. Slopes tests the hypothesis that all coefficients are equal to zero; Rewards tests that the wage and nonpecuniary reward $(N P R)$ are equal to zero; Equal tests that the wage and $N P R$ coefficients are identical. Degrees of freedom in parentheses.

over the specified interval. Exogenous quitters and job losers were initially excluded from the sample. In accord with the binary nature of the dependent variable, probit analysis is used for the estimation.

The log of the 1966 hourly wage is used as a measure of $W^{C} .{ }^{83}$ The local area unemployment rate in 1967 is used for $u$ although, as noted

83. The regressors in equation 12 measuring pecuniary rewards in the current and alternative jobs should reflect permanent wage income. This distinction is unimportant in our data set. Bartel and Borjas, using the mature male cohort of the NLS, have shown that a separation changes only the intercept and not the slope of the wage profile. That is to say, individuals experience a change in the level of their wage following a separation, but not in the rate of growth of their wage. See Bartel and Borjas, "Wage Growth and Job Turnover." 
above, a proper measure would also control for the exogenous vacancy creation rate in the individual's labor market; for $N P R$, the nonpecuniary reward as a fraction of the wage, the measure described in the section on the importance of nonpecuniary income is used. This measure converts qualitative responses to quantitative ones with the simple aggregation scheme as previously described. A variety of variables was used to control for differences in human capital and personal characteristics: years of education; years of labor-force experience; a race dummy (equal to unity for nonwhites); a health dummy (equal to unity if poor health limited work); a house ownership dummy (equal to unity if the individual owned his house); a marriage dummy (equal to unity if the individual was married); a city dummy (equal to unity if the individual lived in an SMSA or suburbs); and a Southern dummy (equal to unity if the individual was a resident in the East-South Central census district). Values for 1966 are used throughout.

Estimates of equation 15 for the sample periods 1966-67 and 1966-69 are given in table 9; both coefficient estimates and semi-elasticities (for continuous variables), evaluated at sample means, are reported. The semi-elasticity is the effect of a 1 percent change in the regressor on the probability that the individual quits (thus, a 1 percent increase in the wage lowers the probability of a job-related quit between 1966 and 1967 by 1.9 percent, for example, from 0.5 to 0.481 ). Standard errors of the coefficients are reported in parentheses.

A variety of diagnostic statistics are reported: "McFadden's $R^{2}$ ", is the percentage increase in the log of the likelihood function due to the inclusion of the regressors; it is worth noting that this measure is very different from the percentage of correct predictions ("Fraction Correct"), which is also reported ${ }^{84}$

Three chi-squared likelihood-ratio tests are reported. The first, "Slopes," is a test of the hypothesis that all coefficients are equal to

84. McFadden's $R^{2}$ is defined as $1-[1(\beta) / 1(\psi)]$, where $1(\psi)$ is the log of the likelihood function under the hypothesis that all the slopes are zero, and $1(\beta)$ is the log of the maximized likelihood when the coefficients are unrestricted. The "Fraction correct" measure denotes the percentage of matches between the prediction of the model and the actual outcome; a match occurs when the model indicates that the individual was expected to and actually did quit (or remained in his job). See Takeshi Amemiya, "Qualitative Response Models: A Survey,' Journal of Economic Literature, vol. 19 (December 1981), pp. 1483-1536, especially pp. 1503-05. 
zero; the degrees of freedom are reported in parentheses. The second, "Rewards," is a test of the hypothesis that the coefficients on the NPR and $W$ variables are both equal to zero. The third, "Equal," is a test of the hypothesis that the coefficients on NPR and $W$ are equal.

The nonpecuniary reward has a negative and significant impact on the probability that an individual quits his job; individuals who state that their specific nonpecuniary rewards are high evidently manifest their beliefs in subsequent actions. The pecuniary return also has a negative and significant effect on the probability that an individual will subsequently quit. Our model predicts that the coefficients on the wage and $N P R$ should be equal. The coefficients on the pecuniary return are similar to those on the nonpecuniary reward, and the hypothesis that the two are equal cannot be statistically rejected. Both reward variables are clearly relevant; the hypothesis that both coefficients are zero can be rejected easily.

The local unemployment rate has a negative but insignificant impact on the probability that an individual quits. It should be recalled that differences in local unemployment rates provide an inadequate indicator of the differences in individuals' chances of receiving job offers because the rates of exogenous vacancy creation are likely to differ across cities as well as the unemployment rates. It is therefore not surprising that this effect is not significant. In this context, it is worth recalling that the data linking quit and unemployment rates by city are consistent with these results: the relation between quits and unemployment rates is weakly negative and occasionally positive in cross section, but unambiguously and strongly negative for all cities across time.

The robustness of the results in table 9 has been extensively checked. For instance, we have used different measures of the regressand, including job losers and individuals who quit for exogenous reasons in our nonmover control group. We have also used different measures of the nonpecuniary reward, including a quantitative measure for those who gave a numeric response and dummy variables for the various categories of qualitative response. The results are insensitive to the measurement of $N P R$ : the hypothesis that the simple aggregation scheme used to construct the benchmark $N P R$ measure is consistent with the data cannot be rejected with a likelihood ratio test. ${ }^{85}$ We have also used

85. NPR is used as a measure of the difference between the nonpecuniary reward on the current job and on alternative jobs. This ignores the possibility of an occupation- 
a variety of different human capital controls, including, for instance, the squares of education and experience, and controls for nationality. None of our results is sensitive to such perturbations in technique.

In summary, nonpecuniary and pecuniary rewards are relevant, and indeed equally relevant, for quit decisions.

Benchmark Results on Satisfaction. Estimation of equation 13 requires an observable counterpart to the level of worker satisfaction, $S A$. We use the answers previously described to the NLS question "How do you feel about the job you have now? Do you like it very much, like it fairly well, dislike it somewhat, dislike it very much?" scaled from 1 (most satisfied) to 4 (most dissatisfied). We use our single quantitative measure of NPR as a measure of the nonpecuniary reward and the log of the hourly wage to measure pecuniary rewards. Because the dependent variable has four possible discrete values, an appropriate estimation technique is multinomial logit.

Multinomial logit estimates of the satisfaction equation, equation 13, for the years 1966 and 1971 are presented in table 10. These are the only two years for which data on both the level of satisfaction and the nonpecuniary reward are available. Semi-elasticities measure the change in the probability that an individual reports a particular satisfaction level instead of "like job very much" due to a 1 percent change in the regressors. For example, according to table 10, a 1 percent higher wage rate in 1966 reduces the probability that a respondent "likes his job fairly well" instead of "very much" by 0.0008 . Likelihood ratio tests (distributed as chi-squares under the null hypothesis with degrees of freedom listed in parentheses) are tabulated for four hypotheses: all of the coefficients are zero (Slopes); all of the nonpecuniary coefficients are zero $(N P R)$; all of the pecuniary coefficients are zero (Wage); and the coefficients on the pecuniary and nonpecuniary rewards are equal (Equal).

Both pecuniary and nonpecuniary factors are relevant in explaining worker satisfaction. The hypothesis that both pecuniary and nonpecuniary rewards are jointly insignificant determinants of worker satisfaction can be easily rejected; the same is true of pecuniary and nonpecuniary

specific nonpecuniary reward; there is no reason to expect such an occupation-specific reward to be correlated with $N P R$. We test for this possibility by including occupation dummies in our separation equation; the dummies are jointly insignificant and none of the results is affected. 
Table 10. Multinomial Logit Estimates of the Benchmark Satisfaction Equation, 1966 and 1971

\begin{tabular}{|c|c|c|c|c|}
\hline \multirow[b]{2}{*}{ Independent variable } & \multicolumn{2}{|c|}{1966} & \multicolumn{2}{|c|}{1971} \\
\hline & Coefficient $^{\mathrm{a}}$ & Semielasticity & Coefficient $^{\mathrm{a}}$ & Semielasticity \\
\hline & \multicolumn{4}{|c|}{$\begin{array}{c}\text { Effect on probability of responding "like fairly well" } \\
\text { rather than "like very much" }\end{array}$} \\
\hline Constant & $2.84 \quad(0.54)$ & & $4.98 \quad(0.89)$ & \\
\hline Current wage & -0.53 & -0.0008 & -0.77 & -0.0024 \\
\hline \multirow[t]{2}{*}{$N P R$} & $-0.63 \quad(0.11)$ & -0.0009 & -0.57 & -0.0018 \\
\hline & \multicolumn{4}{|c|}{$\begin{array}{c}\text { Effect on probability of responding "dislike somewhat" } \\
\text { rather than "like very much" }\end{array}$} \\
\hline Constant & $2.11 \quad(1.14)$ & & $-0.69 \quad(1.70)$ & \\
\hline Current wage & $-0.73 \quad(0.21)$ & -0.0010 & -0.12 & -0.0004 \\
\hline \multirow[t]{2}{*}{$N P R$} & $-1.05 \quad(0.26)$ & -0.0015 & $-1.01 \quad(0.27)$ & -0.0032 \\
\hline & \multicolumn{4}{|c|}{$\begin{array}{c}\text { Effect on probability of responding "dislike very much" } \\
\text { rather than "like very much" }\end{array}$} \\
\hline Constant & $2.48 \quad(1.80)$ & $\ldots$ & $-3.30 \quad(3.68)$ & $\ldots$ \\
\hline Current wage & $-0.99 \quad(0.33)$ & -0.0014 & -0.69 & -0.0022 \\
\hline$N P R$ & $-0.95 \quad(0.42)$ & -0.0014 & $-1.58 \quad(0.56)$ & -0.0050 \\
\hline \multicolumn{5}{|l|}{ Summary statistic } \\
\hline Number of observations & 1882 & & 912 & \\
\hline McFadden's $R^{2}$ & 0.03 & & 0.04 & \\
\hline Fraction correct & 0.57 & & 0.55 & \\
\hline \multicolumn{5}{|l|}{ Hypothesis test ${ }^{\mathrm{b}}$} \\
\hline Slopes $(6)$ & $87.25^{* *}$ & & $64.28^{* *}$ & \\
\hline$N P R(3)$ & $46.4^{* *}$ & & $30.62 * *$ & \\
\hline Wage (3) & $43.00^{* *}$ & & $30.22^{* *}$ & \\
\hline Equal (3) & 1.4 & & $11.08^{* *}$ & \\
\hline
\end{tabular}

Source: Authors' calculations using data from the National Longitudinal Survey of Mature Men. See text for description of variables and test statistics.

a. Standard error in parentheses.

b. For definition of Slopes and Equal tests, see table 9, note c. NPR test determines whether all of the nonpecuniary coefficients are zero. Wage tests that all of the pecuniary coefficients are zero. Degrees of freedom in parentheses.

rewards individually. The coefficients on pecuniary and nonpecuniary rewards are strikingly similar; equality of the effects cannot be rejected for 1966. The hypothesis of equality can, however, be rejected in 1971 because the nonpecuniary rewards have larger effects on worker satisfaction than do the pecuniary effects. These results are insensitive to our use of the aggregate measure of $N P R .{ }^{86}$

86. We have also used deviations of the actual wage from the mean wage in estimating this equation with identical results. Inclusion of occupation dummies in the satisfaction equation does not affect any substantive conclusion of our analysis. However, the occupation dummies are jointly significant in the satisfaction equation, suggesting that there are some occupation-specific components to nonpecuniary rewards. 
In summary, the benchmark results suggest unambiguously that specific nonpecuniary rewards are highly relevant in determining both worker satisfaction and quit probabilities.

While the benchmark results on both separations and satisfaction support the theoretical model, several problems potentially affect the results. Appendix B focuses on a variety of such issues: most importantly, individual-specific intercepts ("fixed effects"); cross-equation correlations between the disturbances in the separation and satisfaction equations; heteroskedasticity; and truncation bias. None of these considerations alters the central conclusions drawn from the benchmark results.

\section{Conclusions}

This paper has presented a simple model of the labor market with job rationing. The analysis emphasizes the role of nonpecuniary rewards to work. The model easily reproduces the most important stylized facts of the American labor market: most quits are from one job to another without an intervening spell of unemployment; quits are cyclic because vacancy chains are longer and thus job opportunities are more abundant in a high-pressure economy; most job quits do not involve large wage increases; most job quits do result in significant nonpecuniary gains; quit rates vary inversely with wage rates; workers' quit probabilities decline with job tenure; there exists an inverse relationship between vacancies and unemployment. According to the model, Okun's Law understates the benefits of running a high-pressure economy.

Empirically, we have shown that the assumptions and predictions of the model regarding the nature of turnover, the existence of rents, and the causes and consequences of quits are realistic. In this last regard, we have verified the importance of nonpecuniary returns for quits. As man does not live by bread alone, people do not quit only for wages. 
APPENDIX A

\section{Labor Turnover in a Real Business Cycle Model}

THIS APPENDIX derives the short-run and long-run implications of a twosector real business cycle model for labor market turnover and discusses why such models do not possess vacancy chains. The geometry of the model is presented in figure A-1.

There are two employment activities, denoted $A$ and $B$; there is a fixed cost of working in each sector, denoted $\mu_{A}$ and $\mu_{B}$. A given individual $i$ can produce either $\epsilon_{A}^{i}$ in sector $A$ or $\epsilon_{B}^{i}$ in sector $B$; thus, each individual can be represented by a point in figure A-1. Finally, let there be any arbitrary joint distribution of $\epsilon_{A}^{i}$ and $\epsilon_{B}^{i}$ in the population.

Each individual chooses whether to work in sector $A$ or $B$ or to remain out of the labor force. The individual's net reward from working in sector $A$ is $\epsilon_{A}^{i}-\mu_{A}$; the net reward from working in sector $B$ is $\epsilon_{B}^{i}-\mu_{B}$. Individual $i$ works in $A(B)$ if the net reward from working in sector $A(B)$ is positive and in excess of the reward from working in $B(A)$. Individuals whose productivities in both sectors are lower than the fixed costs of working choose to remain out of the labor force. Graphically, individuals with $\left(\epsilon_{A}^{i}, \epsilon_{B}^{i}\right)$ in the area labeled $A$ (to the right of the line through $\mu_{A} C D$ ) work in sector $A$; those in the area labeled $B$ (above $\mu_{B} C D$ ) work in sector $B$; those in the area labeled $O L$ (the rectangle $O \mu_{A} C \mu_{B}$ ) remain out of the labor force.

We now use our model to examine both the steady-state and shortrun implications of a permanent negative productivity shock. In our model, a negative productivity shock corresponds to an increase in the cost of working (either $\mu_{A}$ or $\mu_{B}$, or both, increase); this leads to a decrease in total employment. By way of illustration, dashed lines in figure A-1 illustrate the impact of a negative shock that affects only sector $A$, increasing $\mu_{A}$ to $\mu_{A}^{\prime}$.

In the short run, a negative productivity shock causes an immediate surge in quits in a real business cycle model for two reasons. First, individuals voluntarily leave the labor force (those in area $\mu_{A} C C^{\prime} \mu_{A}^{\prime}$ in figure A-1); second, if the shock affects sectors $A$ and $B$ unequally, quits rise as workers reallocate themselves across sectors in response to the movement in intersectoral relative returns. (In the figure, individuals in 
Figure A-1. A Two-Sector Real Business Cycle Model

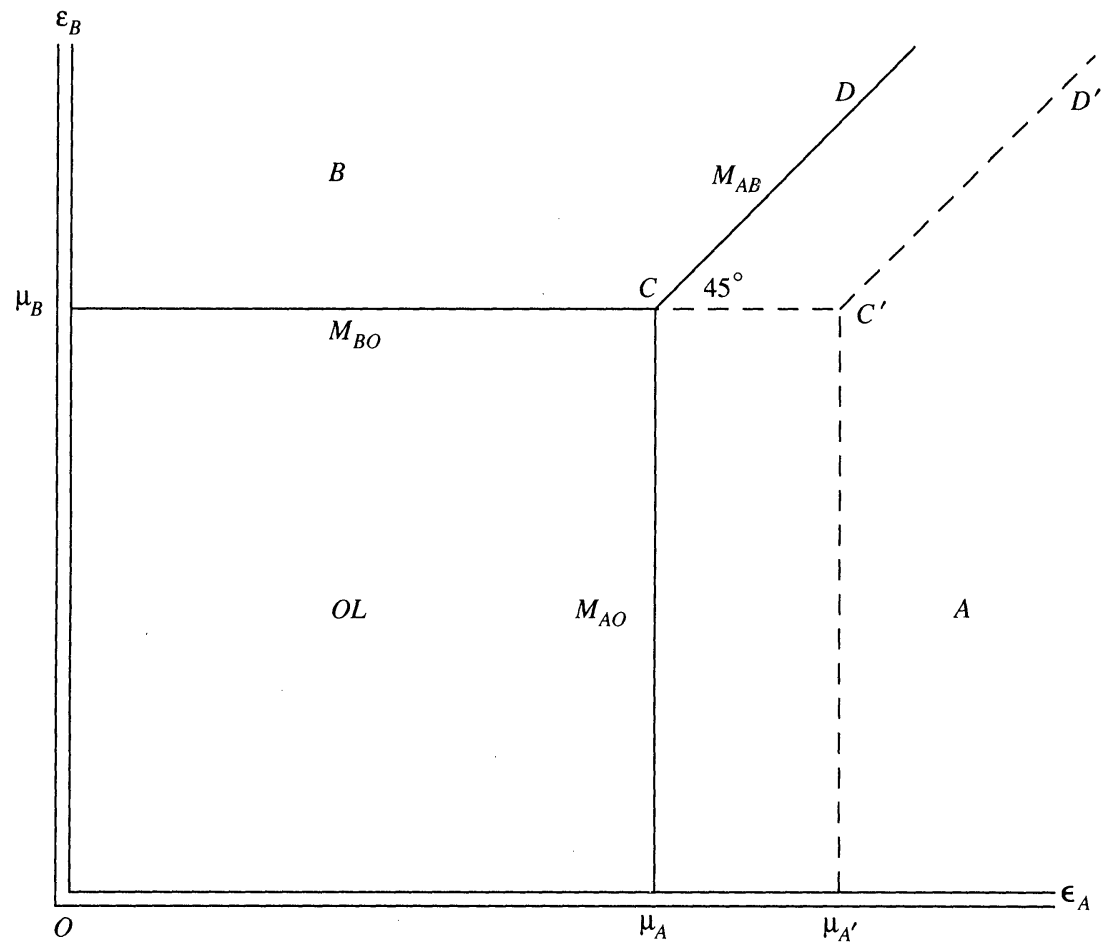

area $D C C^{\prime} D^{\prime}$ switch out of sector $A$ and into sector $B$.) This implication of the real business cycle model is counterfactual; in reality, as we have shown, an increase in the aggregate unemployment rate or a reduction in the aggregate employment rate reduces both quits and total separations. Positive productivity shocks (a decrease in $\mu_{A}$ or $\mu_{B}$ or both) similarly cause a short-run surge in $E$-E quits due to sectoral reallocations of labor; however, the first effect (E-O quits) is absent subsequent to a positive shock.

Next, consider the impact of a negative productivity shock on the steady-state quit rate after a new equilibrium allocation of labor has been attained. The shock turns out to have an ambiguous impact on the total steady-state quit rate. We assume that steady-state quits occur as a consequence of small random individual taste or productivity shocks.

In a steady state, some individuals (those on or near the line $\mu_{A} C$ ) will 
be close to the margin of indifference between working in sector $A$ or dropping out of the labor force; similarly, individuals on or near the line $\mu_{B} C$ are close to indifferent between working in sector $B$ or being out of the labor force. We denote the number of agents on these margins $M_{A O}$ and $M_{B O}$. Random changes in preferences or productivities of agents near these margins will result both in quits out of the labor force and in accessions as agents withdraw from or enter employment. We assume that quits and accessions are equal in a steady state. The number of these quits is proportional to $M_{A O}$ and $M_{B O}$.

Some individuals (those on or near the line $C D$ ) could receive almost identical rewards from work in either of the two sectors and are thus almost indifferent about the sector in which they work. Small changes in preferences or productivities of these agents result in steady-state E-E quits as agents switch sectors. We assume the number of such quits is proportional to the number of workers on the margin between the two sectors, denoted $M_{A B}$. In a steady state, switches from $A$ to $B$ and $B$ to $A$ balance.

In a steady state then, total quits as a fraction of total employment depend on $\left(M_{A O}+M_{B O}\right) /(A+B)$ and $M_{A B} /(A+B)$, where $A$ and $B$ denote total employment in sectors $A$ and $B$, respectively.

In "good" states, when the costs of working ( $\mu_{A}$ or $\mu_{B}$ or both) are low, total employment is high. $M_{A B}$ tends therefore to be correspondingly large, resulting in relatively numerous intersectoral quits. This conclusion depends critically on the underlying joint distribution of individual productivities and is unambiguously true only in the case of a neutral shock that lowers $\mu_{A}$ and $\mu_{B}$ by equal amounts. Negative productivity shocks, which raise $\mu_{A}$ or $\mu_{B}$ or both, lower total employment $(A+B)$ and also tend to reduce the size of the margin $\left(M_{A B}\right)$. The steady-state impact of a productivity shock on the rate of intersectoral quits is therefore ambiguous.

Next, consider the impact of a negative productivity shock on the steady-state rate of E-O quits; this is proportional to $\left(M_{A O}+M_{B O}\right) /$ $(A+B)$. The E-O quit rate rises if one assumes, as seems natural, that the labor supply function is convex, so that the total number of people near the margin of indifference between working and not working $\left(M_{A O}+M_{B O}\right)$ increases as employment falls. Geometrically, then, a negative productivity shock raises $M_{A O}+M_{B O}$ while lowering $A+B$. In the new steady state, the E-O quit rate thus rises unambiguously. 
The aggregate quit rate is the sum of the intersectoral (E-E) quit rate and the E-O quit rate. Since the steady-state intersectoral quit rate changes ambiguously while the E-O quit rate rises when total employment falls, the model implies an ambiguous (and quite possibly negative) correlation between the aggregate quit rate and the aggregate employment rate. In reality, as we have shown, there is a strong positive steadystate relation between employment and either the aggregate quit rate or the aggregate separation rate. The model clearly fails to rationalize this finding.

Our explanation of the procyclic behavior of quits relies on the concept of the vacancy chain. It is worthwhile to explain why there are no vacancy chains in real business cycle models.

Vacancy chains occur only in models with job rationing. Consider our one-job model. In equilibrium any two individuals with negative nonpecuniary rewards would like to trade jobs. This is clearly a Pareto inefficient situation; both agents are willing to take small wage cuts to exchange jobs. A Walrasian auctioneer would switch the workers between jobs. Flexible wages in any market-clearing model accomplish the same end. Consequently, in a market-clearing equilibrium no two equally qualified workers covet one another's jobs. In contrast, workers have no way of swapping jobs in a world with job rationing.

In a market-clearing system, when one worker retires from the labor force and an identical new entrant appears, the new entrant merely takes the place of the retiree. No other workers could gain from changing places; consequently, no vacancy chain arises. In contrast, in our model with rationing, the retirement of one incumbent creates a chance for unhappy workers to switch places since they can apply for the retiree's job and, with some probability, gain a chance to leave a job with poor rewards. An employed worker's chance of moving depends on the number of unemployed individuals relative to the number of unhappy employed workers. In a similar model with market-clearing wages, the fraction of employed workers who switch jobs each period is totally unaffected by a change in the number of retirements with equal numbers of reentries; the fraction of employed workers who would switch jobs in our one-job model, but with marketclearing wages, equals the number of individuals whose $x$ falls below zero during the period. In a steady state, this is proportional to the size of the work force. 


\section{APPENDIX B}

\section{Robustness Tests for Econometric Results}

THIS APPENDIX analyzes the sensitivity of the benchmark results presented in the section on the causes and consequences of quits to a variety of econometric issues: individual-specific intercepts ("fixed effects"); crossequation correlations between the disturbances in the separation and satisfaction equations; heteroskedasticity; and truncation bias.

\section{Correcting for the "Talent Effect" in the Separation Equation}

The most serious problem potentially affecting our estimates comes from what we will call the talent effect. ${ }^{87}$ Such an effect occurs when individuals differ in native ability, which is unobservable, and receive high wages in recognition of their talents. In this event, the human capital earnings function, equation 14 , used to predict the mean alternative wage underestimates the alternative wage of talented individuals (and overestimates the alternative wage of lemons). Native ability leads to high wages in the current and alternative jobs; the econometrician concludes that talented persons are overpaid, can expect only low wages in alternative jobs, and are, consequently, rarely expected voluntarily to quit their jobs. In reality, of course, the alternative wages of such people are quite high, and these individuals are not abnormally unlikely to quit. If this effect is important, the wage coefficient in the separation equation is biased toward zero. ${ }^{88}$

If the talent effect is important and ability is unobservable, inclusion of the wage in a separation equation leads to biased estimates. We have

87. See Farber, "Unionism, Labor Turnover, and Wages of Young Men."

88. Formally, the econometric problem is that there is an individual-specific intercept in the separation equation (unobserved ability that determines earnings capacity in alternative jobs) and this intercept is correlated with the current wage. The consequence is biased coefficient estimates. This problem adversely affects many of the papers in the literature including, for example, Bartel and Borjas, "Middle-Age Job Mobility," and Gottschalk and Maloney, "Involuntary Terminations, Unemployment, and Job Matching." 
devised two solutions to this problem. The first involves the use of instrumental variables; the second employs a panel approach to eliminate individual-specific fixed effects.

\section{Instrumental Variables}

One way of purging the bias from the talent effect is by discarding the individual-specific component of the current wage. The current wage in the quit equation, equation 12 , can be replaced with a predicted wage based on observable characteristics, including features of the job such as occupation or industry, while the alternative wage is still estimated as a function of human capital and personal characteristics. Krueger and Summers have provided persuasive evidence of industry- and occupation-specific wage differentials for persons with identical characteristics. ${ }^{89}$ Thus, occupation and industry affiliation provides systematic information concerning an individual's current wage relative to the wage in possible alternative jobs. This approach has the disadvantage of discarding information contained in the current wage.

To implement this approach we estimate an augmented version of the human capital equation, equation 14, which includes industry and occupation dummies in addition to human capital and personal characteristics:

$$
W_{i t}=h^{\prime}\left(H K_{i t}, I_{i t}, O_{i t}\right)+\mu_{i t}^{\prime},
$$

where $I$ denotes the individual's (one-digit) industry and $O$ denotes his occupation (divided into 12 categories). The fitted values of the regressand are used in place of $W_{i t}^{C}$. To estimate $\bar{W}_{i t}$, the mean alternative wage, we generate the fitted values from this equation with industry and occupation dummies set equal to zero.

This procedure assumes that individuals are mobile across industries and occupations. The mean wage earned by individuals with given characteristics is assumed to be the average wage earned by such individuals across all occupations and industries. The actual wage is assumed to embody an industry and occupation differential. Fixed

89. See Krueger and Summers, "Efficiency Wages and the Inter-Industry Wage Structure." 
effects, due to unobservable differences in talent, bias both our estimates of $W_{i t}^{C}$ and $\bar{W}_{i t}$, but the bias for both is the same, and, consequently, the difference between the two $\left(W_{i t}^{C}-\bar{W}_{i t}\right)$ is unbiased. This approach substitutes the wage premium attributable to the individual's industry and occupation into the separation equation, equation 12 , as an observable measure of $\left(W_{i t}^{C}-\bar{W}_{i t}\right)$.

The list of $H K$ regressors included in the estimation uses the rich set of variables available in the NLS. It includes: education and its square, experience and its square, expected years of labor remaining in the work force, size of local labor market, spouse's wage, number of dependents, father's education, and controls for marital status, working spouse, poor health, homeownership, race, army experience, nationality, birthplace of father, birthplace of mother, occupation of father, health of wife, residence in SMSA, and region.

Estimates of equation 12 for the sample periods 1966-67 and 1966-69 using this methodology are presented in table B-1. The results are consistent with the benchmark results; the difference between the current and alternative pecuniary reward has a negative effect on the probability that the individual quits his job, although, for the period 1966-67, the coefficient is not significant at the 5 percent level. The nonpecuniary reward. NPR, has a significant negative effect on the quit probability in both time periods. The test for equality of the nonpecuniary and pecuniary effects does not reject the hypothesis that the effects are equal in either period. The equations fit approximately as well as the benchmark equations, and the semi-elasticities are similar. It is interesting to note that the unemployment rate has a significantly negative effect on quits for the longer sample.

To test for robustness, the difference $W_{i t}-W_{i t}$ was computed in several alternative ways. Our first method generated the mean alternative wage from the augmented human capital equation, equation B.1, by setting only the industry but not the occupational effects in that equation equal to zero. This method is more appropriate if individuals are mobile across industries but not occupations, in which case the measure of their wage premium should take into account their industry, but not their occupational wage differential. Second, we estimated two separate wage equations rather than one to generate $W_{i t}^{C}$ and $\bar{W}_{i t}$. To generate $\bar{W}_{i t}^{C}$, we estimated a wage equation that includes human capital variables as well as industry and occupation dummies. To generate $\bar{W}_{i t}$, we estimated a 
Table B-1. Estimates of the Separation Equation Accounting for Fixed Effects

Probit estimates of equation 12 using an estimated wage differential from equation 16

Period

\begin{tabular}{|c|c|c|c|c|c|c|}
\hline & & & & \multirow{2}{*}{\multicolumn{3}{|c|}{$1966-69$}} \\
\hline \multirow[b]{2}{*}{ Independent variable } & \multicolumn{3}{|c|}{$1966-67$} & & & \\
\hline & \multicolumn{2}{|c|}{ Coefficient $^{\mathrm{a}}$} & Semielasticity & \multicolumn{2}{|c|}{ Coefficient $^{\mathrm{a}}$} & \multirow{2}{*}{$\frac{\text { Semielasticity }}{\ldots}$} \\
\hline Constant & -1.61 & $(0.19)$ & $\ldots$ & -0.95 & $(0.18)$ & \\
\hline \multicolumn{7}{|l|}{ Estimated wage } \\
\hline differential & -0.50 & $(0.31)$ & -0.0260 & -0.87 & $(0.26)$ & -0.0860 \\
\hline$N P R$ & -0.38 & $(0.16)$ & -0.0197 & -0.39 & $(0.13)$ & -0.3860 \\
\hline Local unemployment & -0.004 & $(0.004)$ & -0.0002 & -0.010 & $(0.004)$ & -0.0010 \\
\hline \multicolumn{7}{|l|}{ Summary statistic } \\
\hline Number of observations & 1746 & & & 1412 & & \\
\hline McFadden's $R^{2}$ & 0.02 & & & 0.04 & & \\
\hline Fraction correct & 0.98 & & & 0.94 & & \\
\hline \multicolumn{7}{|l|}{ Hypothesis test ${ }^{\mathrm{b}}$} \\
\hline Slopes (3) & $9.21 *$ & & & $26.61^{*}$ & & \\
\hline Equal (1) & 0.14 & & & 2.76 & & \\
\hline
\end{tabular}

Panel logit estimates of equation B.3, sample periods, 1966-69 and 1969-71

Independent variable

Coefficient $^{\mathrm{a}}$

\begin{tabular}{lrr}
\hline Satisfaction & 0.72 & $(0.31)$ \\
Local unemployment & -0.03 & $(0.02)$ \\
Summary statistic & & \\
Number of observations & 1306 \\
McFadden's $R^{2}$ & 0.06 \\
Slopes (2) & $7.44^{* c}$
\end{tabular}

Source: Authors' calculations using data from the National Longitudinal Survey of Mature Men. See text for description of variables and test statistics.

a. Standard error in parentheses.

b. For definition of Slopes and Equal tests, see table 9, note c. Degrees of freedom in parentheses.

c. One asterisk indicates significance at the 5 percent level. Two asterisks indicate 1 percent level.

wage equation including only human capital variables. The estimate of $W_{i t}^{C}-\bar{W}_{i t}$ was created by differencing the fitted values from these two separate equations. This method generates different estimates of the industry and occupational wage differentials if the industry and occupational dummies and the $H K$ variables are correlated. Third, we have used nine combinations of the industry and occupation differentials estimated by Krueger and Summers to compute $W_{i t}^{C}-\bar{W}_{i t}$. We use Krueger and Summers's baseline estimates of the industry and occupational differences based on the 1974 Current Population Survey as well as their variants that control for differences in benefits and working 
conditions across industries. None of these perturbations greatly affects our results. ${ }^{90}$

The substitution of an estimate for $W_{i t}^{C}$ into equation 12 in place of its actual value reflects a conscious decision to discard information. The cost of this decision can be gauged by use of the Newey specification test. ${ }^{91}$ Unfortunately, the test sometimes indicates a significant loss of information from using our proxies for $W_{i t}^{C}-\bar{W}_{i t}$ with the significance of the specification tests depending on the particular proxy.

\section{USE OF PANEL DATA}

A second technique to correct for the talent effect uses the availability of data on separations for a cross section of individuals over more than one period, to, in effect, estimate the first difference of the separation equation, equation 12. We use Chamberlain's multinomial logit estimator to account for the panel nature of our limited-dependent variable equations. ${ }^{92}$

An estimable equation is derived by taking the first difference of the separation equation, equation 12. Assuming that the mean alternative wage remains unchanged for an individual and that the probability of quitting depends only on the sum of the nonpecuniary and excess pecuniary rewards yields

$$
\begin{aligned}
P\left(Q_{i t}\right)-P\left(Q_{i t-1}\right)= & f^{\prime \prime}\left(N P R_{i t}-N P R_{i t-1}\right. \\
& \left.+W_{i t}^{C}-W_{i t-1}^{C}, u_{i t}-u_{i t-1}\right)+\epsilon_{i t}-\epsilon_{i t-1} .
\end{aligned}
$$

Unfortunately, the nonpecuniary reward variable, $N P R$, is available only in 1966 and 1971. However, satisfaction $(S A)$ variables are available from each survey and can be used to control for the level of nonpecuniary rewards. ${ }^{93}$ Under the empirically appropriate assumption that satisfac-

90. Ibid. The robustness of our results using Krueger and Summers's industry differentials taking account of fringe benefits is reassuring since the NLS wage variables include no information on fringe benefits that could be used to construct a comprehensive measure of pecuniary rewards. Further, Krueger and Summers also control for union membership (the NLS does not provide information on this variable in the relevant years) and various interactions between human capital variables.

91. See Whitney K. Newey, "Maximum Likelihood Specification Testing and Conditional Moment Tests," Econometrica, vol. 53 (September 1985), pp. 1047-70.

92. See Gary Chamberlain, "Analysis of Covariance with Qualitative Data," Review of Economic Studies, vol. 47 (January 1980), pp. 225-38.

93. Use of this variable is subject to the caveat discussed above: reported satisfaction 
tion $(S A)$ depends on the sum of the wage and nonpecuniary reward, one obtains

$$
\begin{aligned}
P\left(Q_{i t}\right)-P\left(Q_{i t-1}\right)= & f^{\prime \prime \prime}\left(S A_{i t}-S A_{i t-1}, \eta_{i t}-\eta_{i t-1}, u_{i t}-u_{i t-1}\right) \\
& +\epsilon_{i t}-\epsilon_{i t-1},
\end{aligned}
$$

where $\eta_{i t}$ is the disturbance in the satisfaction equation, equation 13. Note that the individual-specific fixed effects have been swept out of the error term.

Estimates of equation B.3 are presented in the bottom panel of table B-1. Since the most satisfied workers gave the lowest possible answers to $S A$, the sign on $S A$ is expected to be positive; increases in $S A$, the level of worker dissatisfaction, should lead to increased quit rates. The results are consistent with the model: an increase in satisfaction lowers the probability that a worker will subsequently quit. ${ }^{94}$

\section{"Garbarino's Law" and the Satisfaction Equation}

According to the wisdom of Joseph Garbarino, "the most important decision that individuals make, early in their lives, is whether or not to be happy." Natural differences in satisfaction, whose existence is implied by Garbarino's Law, potentially bias our estimates of the wage and nonpecuniary coefficients in the satisfaction equation, equation 13 .

The most direct way to handle this problem of individual-specific fixed effects is to first difference the satisfaction equation:

in any base period overestimates the satisfaction, prior to their moves, of those job switchers who received negative nonpecuniary shocks during the period in question.

94. Once $S A$ is included in this equation, there should be no further role for either pecuniary or nonpecuniary returns. In fact, when the log of the wage rate is added to this equation, the hypothesis that it is insignificant can be rejected at the 0.05 (but not the 0.01 ) significance level. There are three possible explanations for this finding. First, for reasons discussed earlier, the change in the level of satisfaction understates the gains achieved by a possibly substantial fraction of movers who suffered negative nonpecuniary shocks subsequent to the base-period measurement of their satisfaction. Second, the discrete nature of the $S A$ variable necessarily implies that adding a continuously measured subcomponent of the level of satisfaction to the discretely observed level of satisfaction will result in an increase in explanatory power. Finally, since the available satisfaction index is an imperfect gauge of true satisfaction, it should be expected that both the satisfaction index and the wage-both of which are correlated with true satisfactionhave explanatory power for quits. 


$$
\begin{aligned}
S A_{i t}-S A_{i t-1}= & g\left(N P R_{i t}-N P R_{i t-1}, W_{i t}^{C}-W_{i t-1}^{C}\right) \\
& +\eta_{i t}-\eta_{i t-1} .
\end{aligned}
$$

Our preferred measure of the change in satisfaction, based on a terminalyear question concerning the change in the worker's attitude toward his job, is available for use as the dependent variable. However, data on NPR are unavailable for most subperiods. If the movement in NPR is a white-noise process that discretely changes as a consequence of a job separation, as in our model, one can instead estimate

$$
S A_{i t}-S A_{i t-1}=g^{\prime}\left(W_{i t}^{C}-W_{i t-1}^{C}, \text { Groups }\right)+\eta_{i t}-\eta_{i t-1},
$$

where Groups denotes a set of dummies indicating whether and why the individual in question separated from his base-period job during the interval in question. We use four dummies to isolate the consequences of: quits for pecuniary reasons, quits for nonpecuniary motives, quits for exogenous reasons, and involuntary job losses. A significant coefficient on the dummy variable would indicate that members of the group experienced gains in nonpecuniary rewards as a consequence of their moves.

Multinomial logit estimates of equation B.5 are presented in the top panel of table B-2 for the 1966-67 sample period (results for other sample periods have been computed and are quite comparable). The regressand measuring the change in satisfaction is the answer to the question in the 1967 survey: "Would you say you like your present job more, less, or about the same as (the job you held) last year?'; we present the results as deviations from the answer "more."

The estimates indicate that wage gains lead to greater worker satisfaction (but at relatively weak levels of statistical significance). The group dummies also have intuitive effects on satisfaction. In particular, job-related quitters, either pecuniary or nonpecuniary, have higher probabilities of attaining an improvement in worker satisfaction; these effects are statistically significant. Interestingly, the effects are quite comparable for individuals who quit for pecuniary and nonpecuniary reasons. The effect is smaller for individuals who quit for exogenous reasons, as seems reasonable, and smaller still, although positive, for individuals who lost their jobs. The hypothesis that the group dummies are jointly irrelevant in the equation can be easily rejected. ${ }^{95}$

95. These results are insensitive to the inclusion of dummies controlling for changes in occupation, although the dummies are statistically significant. 
Table B-2. Estimates of the Impact of Wage Changes and Job Switches on Worker Satisfaction

\section{Multinomial logit estimates of equation B.5, 1966-67}

Independent variable

Coefficient $^{\mathrm{a}}$

Effect on probability of responding "unchanged" satisfaction rather than "more satisfied"

\section{Constant}

Change in (log) wage

Wage-quitter dummy

Nonpecuniary-quitter dummy

Exogenous-quitter dummy

Job-loser dummy

$\begin{array}{rr}1.89 & (0.07) \\ -0.18 & (0.23) \\ -2.75 & (0.84) \\ -2.71 & (0.39) \\ -2.28 & (0.38) \\ -1.55 & (0.28)\end{array}$

Effect on probability of responding "lower" satisfaction rather than "more satisfied"

Constant

$-0.90 \quad(0.13)$

$-0.75 \quad(0.34)$

$-15.28 \quad(1632)$

$-1.17 \quad(0.63)$

$-0.36 \quad(0.52)$

$0.67 \quad(0.34)$

Job-loser dummy

Number of observations $\quad 1882$

Summary statistic

McFadden's $R^{2} \quad 0.06$

Fraction correct $\quad 0.80$

Slopes $(10)^{\mathrm{b}} \quad 156.51^{* *}$

Groups $(8)^{\mathrm{b}} \quad 151.00^{* *}$

Panel binomial logit estimates of equation B.5, 1966-67, 1967-69, and 1969-71

Independent variable

Coefficient $^{\text {a }}$

Effect on probability that individual likes terminal-year job more than base-year job

$\begin{array}{lll}\text { Change in (log) wage } & 0.23 & (0.12) \\ \text { Wage-quitter dummy } & 2.17 & (0.49) \\ \text { Nonpecuniary-quitter dummy } & 2.31 & (0.31) \\ \text { Exogenous-quitter dummy } & 1.90 & (0.34) \\ \text { Job-loser dummy } & 0.99 & (0.22)\end{array}$

Summary statistic

Number of observations 2097

McFadden's $R^{2} \quad 0.09$

Slopes $(5)^{\mathrm{b}} \quad 145.15^{* *}$

Groups (4) $141.66^{\mathrm{b} *}$

Source: Authors' calculations using data from the National Longitudinal Survey of Mature Men. See text for description of variables and test statistics.

a. Standard error in parentheses.

b. For definition of Slopes test, see table 9 , note c. Groups tests the hypothesis that all of the groups coefficients average to zero. Degrees of freedom in parentheses. 
The estimates in table B-2 do not exploit the variation across both time and individuals available in the NLS. To make full use of the available information in the data set, we have also estimated the change in equation B.5 using Chamberlain's multinomial logit panel estimator. The estimates are presented in the bottom panel of table B-2. For the purposes of the estimation, we have grouped the three possible answers to the question (like current job: more/same/less) into a simple binary variable: one if the individual liked his current job better than the job at the last survey date, and zero otherwise.

The results indicate that wage growth between the previous and the current survey date raises the probability that an individual will consider himself better off at marginal levels of statistical significance. However, a job-related quit strongly raises the probability that an individual will gain worker satisfaction; the effects are quite comparable for quits motivated by pecuniary and nonpecuniary considerations, and the hypothesis that the effect is identical for the two subgroups of job-related quitters cannot be rejected (the chi-square statistic is 0.06 , and has a single degree of freedom under the null hypothesis of equal coefficients). Both exogenous and involuntary quits also raise the probability that the worker will gain satisfaction. The effect of an exogenous quit on satisfaction is comparable to that of a job-related quit. The impact of a job loss on satisfaction, however, is lower than that of a quit at the 1 percent level of significance.

\section{CROSS-EQUATION CONSIDERATIONS}

It is natural to expect the disturbances in equations 12,13 , and B.5 to be correlated. There are two reasons why.

First, the error in equation 12, the separation equation, may be correlated with the disturbance of equation 13 , the satisfaction equation. This could happen if individuals with average measured rewards, both pecuniary and nonpecuniary, become dissatisfied with the character of their jobs (for example, the kind of work may become too stressful or physically demanding), rather than the working conditions at their firms. Occupation-related dissatisfaction is not measured in NPR, since this variable is the individual's surplus from working in the current, rather than an alternative, firm in the same line of work. An individual who 
becomes dissatisfied in his line of work is likely to be more unhappy than equation 13 predicts, and also more likely to quit for a job-related reason than equation 12 predicts. ${ }^{96}$

Alternatively, the error in the separation equation may be correlated with the disturbance of the change-in-satisfaction equation, equation B.5. This would occur if an opportunity offering an extremely high nonpecuniary benefit at another firm becomes available to the individual, but is unobservable by the econometrician. Good breaks lead both to unexpected quits and to unexpected gains in total satisfaction. In both of these cases, estimating the two equations (that is, equation 12 and either equation 13 or equation B.5) jointly leads to more efficient estimates.

We estimated the satisfaction and separation equations jointly with a bivariate probit estimator. This estimator takes into account the potentially nontrivial correlation between the disturbances to the separation and satisfaction equations; it is the limited-dependent variable estimator comparable to Zellner's SURE (GLS) technique in the linear case (as in the linear case, use of the single equation technique leads to inefficient but not inconsistent estimates). The bivariate probit results on equations 12 and 13 indicate that the residuals of the separation and satisfaction equation tend to be negatively correlated; individuals who unexpectedly quit are somewhat more likely to be dissatisfied people. However, the correlation is small (usually statistically insignificant) and somewhat sensitive to the sample chosen.

We also estimated the separation equation, equation 12 , and the change-in-satisfaction equation, equation B.5, jointly with bivariate probit. The estimates indicate that the disturbances of the two equations are highly positively correlated; individuals who unexpectedly separate are also likely to have unexpectedly high gains in satisfaction, even after controlling for the growth of wages. Thus the "hidden opportunity" scenario seems to be of empirical relevance. However, none of our previous conclusions is affected by these results; for example, the

96. Although individuals who mention health as the primary reason for quitting are not classified as job-related quitters, it seems quite likely that some individuals who quit because their work is too physically demanding would report as a reason for quitting: dislike type of work or conditions of work or found better job. They would thus be classified as job-related quits in our analysis. 
hypothesis that the coefficients on the nonpecuniary and pecuniary rewards are equal still cannot be rejected. ${ }^{97}$

\section{HETEROSKEDASTICITY AND TRUNCATION BIAS}

The NLS does not randomly sample mature males; rather, blacks are consciously oversampled, potentially leading to heteroskedasticity. (In limited dependent variable models, heteroskedasticity leads to biased estimates.) Further, attrition rates from the sample are not equal for all individuals; individuals who separate from their jobs and, for example, change residence drop out of the sample with higher probability than random individuals. This is known as the truncated regression problem. These issues merit consideration.

The truncated regression problem does not seem to be serious in this context. By 1971, 850 of the original 5,020 sample were nonrespondents. Of these, a maximum of 7 percent could have been nonrespondents for separation-related reasons (and some of these were probably retirees who had moved and were therefore untraceable); most nonrespondents either had died or refused to be interviewed. Naturally, these problems are of even less relevance for the earlier surveys.

To check for heteroskedasticity, we used the sample weights provided by the NLS as weights for equation estimates. These are of remarkably little relevance; for example, none of the point estimates of the 1966-67 separation equation analogous to that reported in the top panel of table B-1 changes by as much as a tenth of its standard error.

97. We have also estimated equation B.5 with a two-stage probit technique, substituting fitted values derived from separation equations like equation 12, for the actual group dummy variables that appear as regressors in equation B.5. Although precision is poor (the covariance matrix must be constructed by the method described in L. F. Lee, G. S. Maddala, and R. P. Frost, "Asymptotic Covariance Matrices of Two-Stage Probit and Two-Stage Tobit Methods for Simultaneous Equations Models with Selectivity," Econometrica, vol. 48, pp. 491-503), the point estimates are consistent with the more straightforward estimation of equation B.5. 


\section{Comments and Discussion}

Laurence Ball: The paper by George Akerlof, Andrew Rose, and Janet Yellen is a valuable contribution to the literature on labor turnover. Perhaps its best feature is that in several ways it rectifies the unbalanced focus of previous work. First, most previous papers emphasize transitions between employment and unemployment, while Akerlof, Rose, and Yellen document the importance of job changes without an unemployment spell. Second, while previous work assumes that workers search for higher wages, the current paper shows that nonpecuniary aspects of jobs are important. Finally, previous work emphasizes the costs of turnover, while the current paper points out the gains from workers' ability to move to better jobs. All of these innovations can potentially change the ways that we think about turnover.

In my remaining comments, I will first discuss the authors' basic explanation for procyclical employment-to-employment quits and then turn to their findings concerning nonpecuniary aspects of jobs.

The theoretical model in the first part of the paper is a useful framework for discussing labor turnover. The central result is an equation for the steady-state rate of employment-to-employment quits. Slightly simplified, this equation is:

$$
Q_{E E}=\alpha\left(\frac{1-u}{u}\right)(\beta N) .
$$

$Q_{E E}$ is the flow of quits, $\alpha$ is the proportion of workers looking for new jobs, $u$ is the unemployment rate, $\beta$ is the rate at which workers are exogenously separated from jobs, and $N$ is the labor force. $\beta N$ is the flow of exogenous job openings, and as the authors explain, the variable $\alpha[(1-u) / u]$ is the length of a vacancy chain-the total number of job 
switches resulting from each exogenous opening. Given this setup, it is easy to see the result that a decrease in steady-state unemployment leads to greater turnover. The intuition is that low unemployment implies long vacancy chains. An exogenous job opening is likely to be filled by an employed worker, who creates a new opening by leaving his old job; this opening is likely to be filled by another employed worker, and so on until the chain is finally ended when one of the rare unemployed workers is hired.

I have several comments about this model. First, the authors perform simulations to show that the model produces a negative effect of unemployment on quits. But the size of the effect is much smaller in the simulations than in the empirical results discussed later in the paper. While a typical simulation produces an elasticity of quits with respect to unemployment of -0.2 , the empirical estimates imply an elasticity of -1.3-so the model explains less than one-sixth of the effect in the data. The quit equation suggests two possible sources of this understatement. First, the authors assume that the flow of exogenous openings, $\beta N$, is constant, while in fact it probably decreases with increasing unemployment-with high unemployment, workers hold onto their current jobs. Second, in the simulations $\alpha$, the proportion of workers who want to move is strongly increasing in $u$, and this largely offsets the negative effect of $u$ on $(1-u) / u$. Again, in actual economies high unemployment may make workers less likely to leave current jobs for less certain prospects. In future work, the authors might modify the behavior of $\alpha$ and $\beta N$ to make the model's quantitative predictions more accurate.

My second point about the model is a caution about interpreting the results. The authors' references to "procyclical" quits are misleading because the results mainly concern the steady-state rather than cyclical relation between quits and unemployment. The few non-steady-state results show a strong cyclical relation. But this probably arises mainly from the creation of new jobs-and hence new vacancy chains-in upturns, not from the changes in the lengths of chains that the authors emphasize. Also, it does not make sense to recalculate Okun's Law, which is a cyclical relationship, by adding a steady-state effect.

One important issue concerning the model is its welfare and policy implications. The authors make some tantalizing remarks about a "serious market failure" that arises because, given their assumption of job rationing, unhappy workers are unable to change jobs by bidding down 
wages. And the authors claim that reductions in unemployment have "positive externalities." These suggestions imply a role for government intervention in the labor market. Since the authors do not develop their ideas about welfare, I thought about them. It does appear that the model contains externalities. In particular, it appears that inefficiencies arise because each individual ignores the effects of his behavior on the aggregate quit rate, which influences the prospects of all workers. Behavior that raises $Q_{E E}$, and hence allows more workers to switch jobs, has positive externalities and should be encouraged. Thus, the equation for $Q_{E E}$ suggests positive externalities from behavior that raises $\alpha$ or $\beta$ or that reduces $u$.

Are these results sensible? Reducing $u$ means creating a new job, and it makes sense that a firm deciding whether to do so ignores the benefits to workers of the resulting vacancy chain. So the model provides a new reason that the equilibrium unemployment rate exceeds what a social planner would choose. It also seems plausible that there are positive externalities from an increase in $\alpha$-that is, from a greater willingness of workers to take new jobs. When the president of a corporation decides whether to move, he ignores the benefits from the resulting vacancy chain - the promotion of the vice president to president, the replacement of the vice president with the assistant vice president, and so on. On the other hand, the finding that there are positive externalities from a higher $\beta$-more exogenous separations-seems suspicious. The problem is that the model assumes that the unemployment rate is exogenous, and thus fails to capture the undesirable rise in unemployment that would result from a higher separation rate in actual economies.

In asserting that job rationing leads to market failure involving mobility, the authors raise an important issue that goes beyond their specific model. Lucas and Prescott's 1974 paper shows that, with competitive labor markets, there is no clear reason for individuals' mobility decisions-for example, choices about whether to switch industries or geographic regions-to produce inefficiency. ${ }^{1}$ Is this result altered if the assumption of competitive labor markets is replaced with some kind of rationing? Perhaps Akerlof, Rose, and Yellen are right that inefficiencies arise because wages no longer provide the right signals

1. Robert E. Lucas, Jr., and Edward C. Prescott, "Equilibrium Search and Unemployment," Journal of Economic Theory, vol. 7 (February 1974), pp. 188-209. 
about when to move. Working out this idea would be very useful for evaluating public policies that affect mobility, such as unemployment insurance and trade adjustment assistance.

My remaining comments concern the authors' evidence on the importance for quit decisions of nonpecuniary aspects of jobs. The results are striking in two ways. First, nonpecuniary factors appear to be much more important than I would have guessed. Of the National Longitudinal Sample of older men, 73 percent say that "liking work is more important than wages." Second, most workers are quite satisfied with their jobs56 percent say they like their jobs "very much," and fewer than 10 percent dislike their jobs "somewhat" or "very much." The stereotype that most workers find their jobs boring but keep them to pay the mortgage is not supported. Finally, in line with these findings, positive nonwage aspects of jobs create tremendous disincentives for workers to quit. Forty-three percent of the sample say that they would not switch to a similar job in the same geographical area for any wage. And many more would demand a raise of 50 percent or more.

These results are so strong that it is difficult to accept them fully. Is economists' emphasis on pecuniary rewards so misplaced? Would most workers earning $\$ 20$ an hour on the General Motors assembly line refuse a $\$ 30$ an hour job next door at Ford?

There are several reasons to believe that the importance of nonpecuniary rewards is overstated. First, survey results may be unreliable when some answers sound better than others-people may understate the degree to which they are money grubbers and overstate their love for challenging and useful work. Second, even if people are honest, some of the questions cited by the authors do not seem to be fair tests of the importance of pecuniary and nonpecuniary variables. For example, when people are asked whether they like their jobs and what they like or dislike, they may ignore wages and focus on the jobs themselves, even if wages have more important effects on their behavior.

The authors test the reliability of their main measure of nonpecuniary benefits-the raise that workers would demand to switch jobs-by estimating its effect on actual quits and comparing this to the effect of wages. Their results are somewhat convincing, but their claim that the effect of nonpecuniary variables is as large as that of pecuniary variables is an overstatement. When they control for the important "talent effect" problem in table A-1, the point estimate for the effect of the wage is more 
than twice as large as the estimate for the nonpecuniary variable for the 1966-69 sample. And when the authors modify their procedure by assuming that only industry wage differentials, not occupational differentials, are uncorrelated with talent, the wage coefficient is more than twice as large for both time periods. (These results were reported to me by the authors.)

Finally, and perhaps most important, even if we accept the result that workers require large wage increases to quit, the interpretation is unclear. The authors cite the result as evidence that workers greatly value feelings of appreciation, good management, and amiable coworkers on the current job. But an alternative is that workers are reluctant to switch jobs because they would lose security. Recall that the workers in question are men in their fifties. Many have long tenures with their employers and are confident that they can continue working at a predictable wage, pay the college tuition, and retire on a good pension. If they take a new job, it might not work out, and they may eventually earn lower wages or even become unemployed, which could be disastrous. So they do not switch unless tempted by a very large raise.

In the survey by Clifford Jurgensen cited by the authors in an earlier draft, job security is listed as the most important characteristic of jobs, ahead of both pay and the factors like coworkers stressed by Akerlof, Rose, and Yellen. ${ }^{2}$ And security should be interpreted as a pecuniary variable-concern for security means fear of losing future income. In other words, the fact that workers turn down jobs that offer higher current earnings might simply mean that they fear lower earnings in the future.

In conclusion, let me emphasize that the authors' evidence is impressive despite its problems. While I do not think that nonpecuniary variables are as important as they do, I think these variables are considerably more important than I did before I read the paper.

Robert E. Hall: One of the most interesting new developments in economics is thick-market theory. Peter Diamond and others have shown that a market may have more than one equilibrium. It is advantageous for a market to be thick. High rates of output and trade lower the costs

2. Clifford E. Jurgensen, “Job Preferences (What Makes a Job Good or Bad), 'Journal of Applied Psychology, vol. 63 (June 1978), pp. 267-76. 
of each seller. In Diamond's famous parable, the inhabitants of a tropical island harvest coconuts and then trade them with each other. In the thick-market equilibrium, it pays to climb far up the palm because many other people are doing the same thing, and it is likely that the coconut can be traded quickly so consumption can occur. In the thin-market equilibrium, only the easiest coconuts are harvested. Few people are trading coconuts, and it does not pay to climb far up the tree. Multiplicity of equilibriums is the expected situation when there are technical external complementarities, as in Diamond's model.

Applications of thick-market theory come to mind easily. There is a remarkably thick market for cameras in midtown Manhattan, where the cost of buying a camera is much lower than elsewhere and where the cost of selling cameras is much lower because of the high density of customers. Thick-market forces operate over time as well. For example, the selling of certain kinds of consumer goods is concentrated in the sixweek Christmas shopping season. During that time, thick-market benefits accrue to buyers and sellers.

Akerlof, Rose, and Yellen, in this interesting and challenging paper, apply a version of thick-market theory to the labor market. They concentrate on thick-market benefits to workers. The central point is that a thick labor market, where jobs are easy to find and unemployment is low, results in improved matches of jobs and workers. A thick market makes it possible for a worker to achieve the optimal combination of earnings and nonpecuniary job characteristics. In a high-unemployment, thin labor market, the same worker would not want to quit a job that was a poor match because the cost of finding a new job is high.

The choice between a thin and a thick market exists only in a market with multiple equilibriums. Akerlof, Rose, and Yellen assume a setup with a continuum of equilibriums. Firms do not adjust wages to provide the optimal flow of jobseekers. Instead, they simply ration jobs. The authors assume that the job-finding rate for workers is proportional to the ratio of the number of jobs to the number of unemployed. Then it is easy to see that the labor market can be in equilibrium at any unemployment rate. By contrast, in a natural rate model (as in Appendix A of the paper), the thickness of the market is determined uniquely by its equilibrium conditions. The questions considered in the paper are meaningless if there is only a single unemployment rate possible in the model. With a determinate equilibrium, we would have to investigate 
how changing one of the determinants-say, the job-matching efforts of the public employment service-affected the equilibrium. The costs of the change in the determinants would have to be reckoned against the benefits of the improved equilibrium. With indeterminancy, there is no cost side.

The authors refer repeatedly to something they call the "vacancy chain." The explanation given for a vacancy chain-that the sequence of job changes is longer when there are fewer unemployed ready to move into a vacancy-is defective because it does not recognize stochastic equilibrium. As long as the unemployment rate is not changing over time, the chain does not end when someone moves from unemployment to employment: that move has to be counterbalanced by another move from employment to unemployment, which keeps the chain going. However, although the idea of a vacancy chain is incorrect, the point is right that thick markets have higher job-matching flows. The model assumes that the flow of workers into jobs occurs at a rate high enough to offset an exogenous flow from employment to out of the labor force and from employment to unemployment. The flow into employment comes only from job-finding by the unemployed. When the labor market is thick and unemployment is low, the weekly job-finding rate is high. By assumption, the job-finding rate for workers who are badly matched and who want to move to another job is the same as the rate for the unemployed. Hence they share in the benefit of the thick market. Although this conclusion follows purely from the assumption of equal job-finding rates, that assumption seems perfectly reasonable. The "vacancy chain" is not a new insight, but just a confusing way to express the idea that employed jobseekers benefit from a thick labor market.

The authors look only at the jobseeker's side of the labor market. Lower unemployment, higher vacancies, and faster job-finding are obviously benefits to the jobseeker. The paper does not go into the interesting companion issue, namely the benefits and costs to the employer. The authors rig their model so that there are no benefits or costs, but surely in reality employers care about the selection of workers available in the market and the time needed to fill vacant jobs. Although the traditional view has been that workers gain and employers suffer when unemployment falls, this view should not be taken for granted. Employers are not deserting the drum-tight labor markets of the Northeast, even though unemployment is now close to zero. In a true thick 
market, as expressed in Diamond's model, for example, there is a net benefit in a thick market to those on both sides. The thick camera market in Manhattan is one where it is cheaper for customers to shop and cheaper for merchants to sell. An interesting question raised by the Akerlof-Rose-Yellen paper is whether a tight, low-unemployment labor market is a thick market in the same way. And if a particular labor market, such as the Northeast, is truly a thick market, can the national economy achieve the benefits of a thick labor market by expanding the overall economy with monetary and fiscal policy?

The authors' main purpose in the paper is to describe thick market benefits accruing to workers. They focus in particular on workers who quit one job after finding a better one. In some cases, the benefit shows up in GNP-the new job pays a higher wage and the worker is correspondingly more productive. Economists have long emphasized this type of benefit. The authors emphasize the type of benefit that escapes measurement in GNP. Workers frequently change jobs without wage improvement, but obtain a benefit in the form of higher job satisfaction. Okun's Law, which looks only at GNP, understates thick-market benefits to the extent that improvements in job satisfaction are widespread in a tightening labor market. However, even the skeptic about nonpecuniary job characteristics should be interested in this paper. Standard jobmatching benefits that are recorded in GNP are also in the domain of the authors' view of the labor market.

The paper devotes excessive attention to the side issue of rationing in the labor market. Rationing is a side issue because thick-market effects are important in models where employers use wage adjustments optimally as part of their recruitment strategies. It goes without saying that the labor market is not a perfect auction market. The essential contribution of Diamond's work and related research is to drop an auction market view and replace it with one where individuals face realistic problems and use all of the instruments at their disposal to solve those problems. Akerlof, Rose, and Yellen's view that employers never think about the possibility of wage adjustments is retrograde in comparison to current research, not to mention common sense. All of the empirical findings they cite in favor of rationing really amount to support for some kind of middle ground between the extremes of the auction market on one hand and strict wage rigidity on the other. The authors diminish the force of their message by dogmatic insistence on the second polar view. 
Much of the paper is devoted to evidence on the importance of nonpecuniary job characteristics. I find the overall framework for this material puzzling. When workers care about different types of work, they will have preference orderings about work similar to their orderings over different goods for consumption. Reducing these orderings to a single monetary equivalent is not something we would ever do in standard demand theory, and I see no reason why we should try to do it for labor supply theory. On the other hand, the paper does give some validation to the idea of a monetary equivalent by showing that the monetary equivalent has about the same coefficient as earnings in the satisfaction equation.

The single most persuasive piece of evidence on the importance of nonpecuniary job characteristics, in my view, is the finding that wage reductions are common in voluntary job changes. Note that this finding does not rely on any form of reported job satisfaction. Even the hardheaded economist who rejects all survey questions that appear sociological or psychological has to respect this piece of evidence.

The Akerlof-Rose-Yellen paper is an important milestone in the development of thick-market theory, in my view. All future discussions of thick-market benefits in the labor market will have to include consideration of the nonpecuniary benefits documented in the paper. But the paper would be even more of a milestone if it were a little less dogmatic on wage rigidity and rationing. As thick-market theory develops, I doubt that the extreme view of wage determination adopted here will prove viable.

\section{General Discussion}

There was considerable discussion of labor market rationing, both its role in the theoretical model of Akerlof, Rose, and Yellen and its empirical importance. Akerlof argued that a thick-market model such as Diamond's relies fundamentally on a lack of information, whereas the authors' own model assumes perfect information, but labor market rationing prevents unhappy workers from changing places. The emphasis on job rationing also explains why the unemployment rate is treated as exogenous, actually parameterizing the degree of job rationing. Alan Blinder found the assumption of rationed labor markets realistic and argued that Robert 
Hall had gone too far in his characterization of the other extreme of perfect competition. If there are heterogeneous agents under perfect competition, only individuals on the margin will be indifferent to a transaction; all the others will receive rents. Thomas Juster agreed that rationing is an important feature of labor markets, citing the automobile industry as an important example. He noted that the high wage paid by General Motors may be rational because it increases the productivity of its workers, but saw no evidence in that market of productivity matching. William Nordhaus observed that the market for college admissions is nonclearing and analogous to the authors' view of the labor market. Tuition is set at too low a level for the market to clear: many students would like to attend at that price but are not admitted. Presumably, like firms, colleges want to be able to choose students from a larger pool of applicants than would be forthcoming at a higher tuition level.

Juster pointed out some measurement problems in the NLS data used by Akerlof, Rose, and Yellen to determine the nonpecuniary rewards of working. First, he mentioned the problem of determining how individuals who actually receive zero nonpecuniary rewards would answer the question, "How do you feel about the job you have now?" Under certain survey environments, such individuals might reply, "I like it fairly much," but under alternative environments they might answer, "I dislike it somewhat." A second problem arises when individuals are asked to compare their current and previous jobs. Respondents may tend to justify their own decision to change jobs by answering that they get more nonpecuniary benefits from their new job. A third problem comes with interpreting responses to hypothetical questions such as, "What would the wage or salary have to be for you to be willing to change jobs?", According to Juster, economists are justifiably suspicious of interpreting answers to these hypothetical questions as indicators of the behavior of individuals faced with the actual alternatives.

Juster suggested benchmarking responses based on actual behavior whenever possible. Though this is not possible for the NLS data, he reported on his own results from another data set that asked individuals, on a scale of 1 to 10 , how much satisfaction they derived from engaging in each of 25 different activities such as housework, market work (employment), child care, and watching television. The benchmarking comes from being able to compare the satisfaction respondents claim to get from employment to the satisfaction they get from watching tele- 
vision. Juster's results are strikingly consistent with Akerlof, Rose, and Yellen's results from the NLS. The average nonpecuniary benefits from employment actually exceed those of leisure activities such as watching television. But Juster warned that the results do not prove that respondents work too little since the marginal nonpecuniary benefit of an hour of work may be far less than the average. In fact, low marginal nonpecuniary benefits of work, when evaluated at 40 hours a week, are consistent with the evidence that observed labor supply is quite inelastic. Unfortunately, the data set contains very few respondents who move to new jobs, so it would be difficult to study the effect of changing jobs on the nonpecuniary benefits of work.

The results of the Akerlof, Rose, and Yellen model are driven by fluctuations over time in individuals' nonpecuniary benefits of work. Juster argued that the empirical evidence of these fluctuations could be reinterpreted as evidence of respondents randomly saying at one time, "I love my job" and at another time, "I sort of like it," noting that his own benchmarked measures of nonpecuniary benefits are quite stable through time. Nordhaus agreed that fluctuations in nonpecuniary rewards are unlikely to be important. He observed that, in practice, nonpecuniary rewards are closely tied to pecuniary rewards. For example, workers who receive smaller pay increases than their co-workers will generally have a low opinion of their work place. Therefore, it may be that nonpecuniary rewards are as sticky as real wages over the business cycle. Juster tried to determine the relationship between nonpecuniary benefits of work and wages. He found that high nonpecuniary benefits are not associated with high wages but rather with social aspects of the work, although low nonpecuniary benefits are associated with low wages. Juster suspects that low wages indicate to a worker that his work is not being valued and thus reduce the job's nonpecuniary benefits.

Alan Blinder suggested that the authors incorporate a fixed cost of changing jobs into their model. The fixed cost could represent the costs of moving, decisionmaking costs, and the costs associated with uncertainty about the nonpecuniary benefits of a new job. This addition to the model could explain why many individuals say they would require an implausibly large premium to change jobs. Furthermore, the fixed cost of changing a job can be viewed as an investment in future job happiness. With this amendment, the interest rate might begin to have important 
effects in the model, with a high interest rate reducing quits. Thomas Juster objected to the assumption that every quit creates a vacancy. In particular, for service jobs there may be a nonlinear relationship between quits and vacancies because a small number of quits may not cause a firm to hire replacements immediately. Andrew Rose doubted whether the nonlinearity would matter in the aggregate since employment is fixed by assumption.

Wayne Vroman argued that the estimate of a benefit replacement ratio of 0.6 used in the simulations is too high. Feldstein's estimate of 0.55 applies to periods when unemployed individuals are receiving unemployment benefits. Actually, benefits begin a week after the start of an unemployment spell and are often exhausted before the termination of a spell. Furthermore, in many states, workers who have not worked long enough between unemployment spells do not qualify for any unemployment insurance. Vroman believed a more reasonable estimate of the benefit replacement ratio is 0.4 to 0.45 . He went on to note that 1966-69 is an unusual period of a high-pressure economy, so the parameter estimates of the separation equations (table 9) may not be representative. He recommended that the authors estimate the separation equation over periods with higher unemployment to determine whether the motivations for separations are the same.

Matthew Shapiro suggested that because there is much more crosssectional variation in nonpecuniary benefits of jobs than in wages, it is not surprising that nonpecuniary factors have more explanatory power than wages in determining the choice of employment. He went on to stress the potential benefit of employment-to-employment quits for improving productivity. He noted, however, that these nonpecuniary benefits arising from changes in employment and unemployment are likely to be small relative to other costs and benefits. Moreover, he cautioned against nonsystematic additions to the output side of Okun's Law. For example, if these benefits of job dynamics are counted as welfare gains, forgone leisure of employed workers should be counted as a cost. 